\title{
Farmers' perception of opportunities for farm development
}

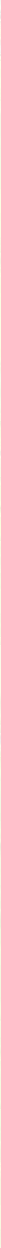

Ron Methorst 


\section{Propositions}

1. Introducing the notion of internal and external factors in strategic decision-making in farm development suggests a binary division that is non-existent.

(this thesis)

2. Economic drivers used in strategic decision-making in farm development are subordinate to farmers' views and preferences.

(this thesis)

3. The rise in narcissistic personality traits in business management students as found by Westerman (2012, Journal of Management Education 36(1) 5-32), increases the need to study designs for systemic intervention strategies.

4. The focus on ecological risks of CMO techniques in the public debate overshoots the risks of accumulation of economic and political power in just a few companies.

5. Student-teacher interaction is taken more seriously when it is approached as a play.

6. Securing and facilitating independent investigative journalism is more supportive to democracy than demanding referenda.

Propositions belonging to the thesis, entitled

'Farmers' perception of opportunities of farm development'.

Ron Methorst

Wageningen, 18 November 2016 
Farmers' perception

of opportunities for

farm development

Ron Methorst 


\section{Thesis committee}

\section{Promotor}

Prof. Dr ].S.C. Wiskerke

Professor of Rural Sociology

Wageningen University \& Research

\section{Co-promotors}

\section{Dr D. Roep}

Assistant professor, Rural Sociology Group

Wageningen University \& Research

Dr].A.A.M. Verstegen

Senior researcher entrepreneurship \& innovation, Wageningen Economic Research Wageningen University \& Research

\section{Other members}

Prof. Dr R.B.M. Huirne, Wageningen University \& Research

Dr I. Darnhofer, University of Natural Resources and Life Sciences, Vienna, Austria

Dr L.A. Sutherland, James Hutton Institute, Aberdeen, Scotland

Prof. Dr E. Mathijs, University of Leuven, Leuven, Belgium

This research was conducted under the auspices of the Wageningen Graduate School of Social Sciences (WASS) 


\title{
Farmers' perception of opportunities for farm development
}

\author{
Ron Methorst
}

Thesis

submitted in fulfilment of the requirements for the degree of doctor at Wageningen University

by the authority of the Rector Magnificus

Prof. Dr A.P.J. Mol,

in the presence of the

Thesis Committee appointed by the Academic Board

to be defended in public

on Friday 18 November 2016

at 4 p.m. in the Aula. 


\section{Ron Methorst}

Farmers' perception of opportunities for farm development, 196 pages.

PhD thesis, Wageningen University, Wageningen, NL (2016) With references, with summaries in English and Dutch

ISBN: 978-94-6257-943-9

DOI: $10.18174 / 391066$ 
This thesis is dedicated to all entrepreneurial and pioneering people aiming to reconnect farming and society 


\section{Table of contents}

1 Introduction: farm development in relation to its context $\quad 9$

$\begin{array}{lll}1.1 & \text { Problem definition } & 17\end{array}$

$\begin{array}{lll}1.2 & \text { Research objective and questions } & 18\end{array}$

$\begin{array}{lll}1.3 & \text { Thesis structure } & 19\end{array}$

2 Theory, analytical framework and methodology 21

$2.1 \quad$ Opportunity identification 23

$2.2 \quad$ Strategic decision-making 25

$2.3 \quad$ Three-fold embedding 27

$2.4 \quad$ The analytical framework 29

$2.5 \quad$ Research methodology 32

2.5.1 The socio-material context of Kampereiland case study 33

$\begin{array}{ll}2.5 .2 & \text { Research phases } \\ \end{array}$

2.6 Ethical remarks: consent and confidentiality 47

3 Differences in farmers' perception of opportunities for farm 49 development

3.1 Introduction 52

3.2 Theoretical background 55

3.3 The case study 58

3.4 Methodology 59

$\begin{array}{lll}3.5 & \text { Results } & 61\end{array}$

$\begin{array}{lll}3.6 & \text { Discussion } & 65\end{array}$

$\begin{array}{lll}3.7 & \text { Conclusions and outlook } & 69\end{array}$

$4 \quad$ Drivers for differences in farmers' perception of 73 opportunities for farm development

$\begin{array}{lll}4.1 & \text { Introduction }\end{array}$

4.2 Theoretical background of pRfM and the drivers 77

$\begin{array}{lll}4.3 & \text { Methodology } & 79\end{array}$

4.4 Results 84

4.5 Discussion, conclusions and outlook 87 
$5 \quad$ Three-fold embedding of farm development 91

$\begin{array}{ll}5.1 & \text { Introduction } \\ 5.2 & 94\end{array}$

$\begin{array}{lll}5.2 & \text { Theoretical background } & 95\end{array}$

5.3 Methodology 98

$\begin{array}{lll}5.4 & \text { Results } & 101\end{array}$

5.4.1 Ideal-typical characteristics of the clusters 101

5.4.2 Three-fold Embedding of Milk Max 103

5.4.3 Three-fold Embedding of Milk Balance 105

5.4.4 Three-fold Embedding of Milk Plus 107

5.5 Discussion and conclusions 110

$\begin{array}{lll}6 & \text { Discussion and conclusion } & 115\end{array}$

6.1 Findings 117

6.2 Reflection on methodology and generalizabilty 122

6.3 Contribution to Sociology of Entrepreneurship 130

6.4 Implications for further research 132

6.5 Implications for practice 134

$\begin{array}{ll}\text { References } & 137\end{array}$

$\begin{array}{ll}\text { Appendices } & 145\end{array}$

$\begin{array}{ll}\text { The questionnaire } & 147\end{array}$

$\begin{array}{ll}\text { Summary } & 169\end{array}$

Samenvatting 177

Acknowledgements / Dankwoord 185

$\begin{array}{ll}\text { About the author } & 189\end{array}$

$\begin{array}{ll}\text { Curriculum Vitae } & 189\end{array}$

Completed Training and Supervising Plan 191 


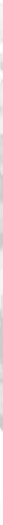
bet rom 
7

\section{Introduction: farm development in relation to its context}





\section{Introduction: farm development in relation to its context}

Farm development is part of, reacts on and shapes the context in which the farm operates. This interaction is the overarching topic of interest that started this thesis. Farm development affects the context of the farm and developments in the context affect farm development, the farm and its context co-evolve. On the level of the individual farm strategic decisions need to be made. As observed in practice, farmers differ in their perception of the room for manoeuvre for farm development within the context in which the farm operates. This observation has prompted this thesis in which the focus is primarily on the family farm, an 'icon of the Western countryside' (Woods 2014, 31). Diversity or heterogeneity is one of the main features of farming and farm development, as many studies have shown in the past 25 years (Ploeg 1994; Pender et al. 2004; Beyene et al. 2006; Oostindie 2015; Ploeg and Ventura 2014). Earlier as well as more recent research on farming styles has shown that an explanation of the heterogeneity in farm development cannot be reduced to the impact of 'external' structural forces, such as 'markets', 'technology' or 'nature', on farming, even when these are mediated into farming practices and decision-making by capable farmers (Ploeg 1994, 2003; Ploeg and Ventura 2014). This means that the personal characteristics of the farmer(s) and the farm family are important in explaining heterogeneity in strategic decision-making on family farms.

In family farms the process of strategic decision-making is very much influenced by the family situation (Gasson et al. 1988). A well described recent overview of literature on this part is provided in a study on factors influencing strategic decisions on development of dairy production (Hansson and Ferguson 2011) and in a study on the influence of the farm family on motives for diversifying the farm business (Hansson et al. 2013). In the research on farmers' perception the focus is on what Hansson and Ferguson $(2011,111)$ call the 'decision-maker specific factors'. In a family farm situation there is no straight forward link to one person making the decisions, the farm family engages in micro level network discussions that affect the outcome of the decisionmaking process (Gasson et al. 1988; Hansson 2007). This thesis will refer to 'the farmer' as decision-maker to make clear that the focus is on the decision-maker specific factors while acknowledging that 'the farmer' does not refer to one person but to the complex interaction in the farm family regarding decision-making.

On farm level decisions are made on both the everyday operational farming and on the strategy for farm development. The decision-making process is therefore of interest when aiming to understand differences in the perception of the room 
for manoeuvre for farm development. This interest is in both the process of making strategic decisions and in how this is affected by the relation of the farm with its context. In the process of making strategic decisions, farmers aim to secure a family farm income and to secure the continuity of the farm business. In the reiterative and continuing process of strategic decision-making, farmers aim to anticipate and balance the effect of developments within the context of the farm, with the needs and aims of the family farm. In this process the farmer relates in an implicit or explicit manner towards the dynamic and complex context, under which the farm operates. The farmers' decisions lead to (changes in) farm practices and these farm practices are embedded into the context in which the farm operates. Embedding of the farming practices, in turn, affects the context of the farm. When the farm affects the context, it is likely to also affect the opportunities for further farm development and future strategic decisions. This means that farm development is not isolated from, but closely related to, and affected by, the context, under which the farm operates.

The context of the farm consists of both social- and material components. Social components can be further differentiated into economic, cultural and political processes that structure the social context of an individual farm. Material components in the context of the farm are factors that are formed by natural or bio-physical processes and shape the dead and living matter that characterise an individual farm. Social and natural processes are not isolated from each other, the interaction and coevolution of social and natural processes create a seamless interwoven socio-material context (Roep 2000). It is within this complex and dynamic context that farmers must operate their business, and within which they need to assess the opportunities for farm development, and make strategic decisions. In the process of making strategic decisions, the farmer can encounter three contextual developments with strong impacts: 1) an income squeeze in farm business; 2) changes in the socio-material context of the farm due to shifting societal demands and expectations for farms and rural areas; and 3) new opportunities that enable diversification of farm development strategies. These three developments will be further explained in the following paragraph.

The first development is the economic challenge created by a decrease in margins that result from a 'cost price squeeze'; an increase in the cost of the resources and decrease in the price of the farm products (Ploeg 2000). The predominant strategy of dairy farms in the Netherlands in reaction to this economic challenge is enlargement of scale and specialisation of production (Schans and Keuper 2013); a development that is anticipated to strengthen further with the abolishment of the European Union (EU) milk quota system in 2015 (Meulen et al. 2012). The change in EU 
dairy market policies has increased price volatility creating a need for farmers to find ways to deal with this development. The second development concerns the changes in the socio-material context that affect farming. In farm development, the farm both reacts on and enacts the context, whilst adapting to changes and perceived threats and opportunities (Bieleman 1987; Darnhofer et al. 2010; Feola et al. 2015). In the second half of the $20^{\text {th }}$ century, changes in the socio-material context in trade, technology and logistics enabled farm production to bypass the limitation of locally available resources. This led to a dramatic increase in production levels via specialisation, intensification and scale enlargement of farms (Ploeg and Roep 2003). This process of modernisation was actively stimulated by the Dutch government, showing an example of how the different aspects of the socio-material context interact (Lowe et al. 1993; Ploeg 2003; Wals et al. 2012; Grin 2012). The success of this modernisation of agricultural production also created an antithesis, as developments in farm practices had a negative impact on environmental quality, landscape values and biodiversity (Knickel 1990; RIVM 2002; Marsden 2003; Yakovleva and Flynn 2004; Wiskerke and Roep 2007; Primdahl and Kristensen 2011; Wästfelt et al. 2012). The relation of the farm with its socio-material context changed, as a result of agricultural modernisation, because it loosened the connection between product, production and location. This process was described as the dis-connecting, dis-embedding and dis-entwining of food production (Wiskerke 2009). Another development in the socio-material context of the farm is the changing societal demand of rural areas that easily raises tensions with the predominant scale enlargement strategy in farming (Wästfelt et al. 2012), especially in regions with high natural-or cultural-historical value, or in regions that are close to urban areas. In many places, farmers are expected to develop into 'rural entrepreneurs', incorporating environmental and countryside management into their farm practices. This change requires farmers to assume multiple new roles whilst shifting some of the effort and resources away from the task of food production (Atterton and Ward 2007). The shift of efforts and resources required to fulfil these new functions is another reason for tensions in the decision-making process on farm development (Wästfelt et al. 2012). Understanding the process behind this tension on the level of the individual farm is important, as the tensions affect decision-making in farm development. Each individual farm makes strategic decisions, and due to the increase in average farm size, the effect of a decision of one individual farmer on the socio-material context is more apparent (Primdahl and Swaffield 2010). The third development is the diversification of farms, as a result of inclusion of new services and functions of rural areas in farm strategies, referred to as 'multifunctional agriculture' 
(Roep 2000; OECD 2006; Horlings 2010). Examples include energy production and new value chains with products and services that build upon the characteristics of the farm and the rural context as added value (Potter and Tilzey 2005; Oostindie 2015). The development of diversification increases the number of possibilities for farm development, and, thus, the heterogeneity in farm development. Heterogeneity in farm development did not, however, start with diversification in farming. Literature on heterogeneity in farming has shown the existence of different 'farming styles', in which farm practices are organised in distinctive ways, based on the different approaches of the production factors, labour and capital on the farm (Ploeg and Long 1994; Ploeg 2003). 'Each style can be seen as a distinctive way of equilibrating the many balances that link farming, the farming family and the outside world' (Ploeg and Ventura 2014, 23).

These three developments meet in the field of interest for this thesis: the process of strategic decision-making of the farmer, who operates in, and is part of, a socio-material context that affects, and is affected by, the farm practices. A farmer, in the role of entrepreneur, aims to secure farm income by selecting a strategy for farm development in an iterative process of deliberating about the aims and needs of the family farm in relation to the opportunities for farm development that are perceived as viable. In the decision-making on farm strategies, the family farm is inherently intertwined with pre-existing socio-material structures; the farmer does not, and cannot make strategic decisions, as if it operates on a 'blank canvas'. The socio-material structures both enable and restrict farm development, the structures offer limitations and opportunities (Giddens 1984). In other words, there is 'room for manoeuvre' to act within the socio-material context. Operating in this room for manoeuvre, farmers are knowledgeable and interpretive actors, whose actions are guided by, but not determined by, social structures. In making decisions, the farmer influences and, thus, enacts the socio-material structures. This means that the actions and decisions of farmers affect the room for manoeuvre for farm development

In entrepreneurship research, the topic of strategic decision-making in the context of small business is part of a growing body of research. The importance of studying entrepreneurship in relation to its context is described by Watson $(2013,407)$ : 'To act entrepreneurially is to innovate, to deal with social and economic circumstances, with those very circumstances constraining as well as enabling the shaping of entrepreneurial actions and their outcomes'. Another important author in this respect is Welter (2011), who has illustrated how a contextualised view of entrepreneurship contributes to a further understanding of the phenomenon of entrepreneurship. The relation of the actor with its context is a key research field for Sociology, the fields of Entrepreneurship Research and 
Sociology are, therefore, increasingly acknowledged as being of interest for each other (Watson 2013; Devereaux Jennings et al. 2013). The combination of the views developed in Entrepreneurship Research and the views developed in Sociology, offer an avenue for this thesis for a study into the process of strategic decision-making of the farmer in relation with the socio-material context of the farm. The perspective of a Sociology of Entrepreneurship in the agricultural domain is in line with the call to connect the research fields of Entrepreneurship Research, Agricultural Economics and Rural Sociology (Alsos et al. 2011, 11), or, as they state: 'we believe that the Entrepreneurship Research domain has a very specific contribution to make to the understanding of the current changes that are taking place within agriculture and rural areas'. The following paragraph will look deeper into the two fields that are of particular interest for this thesis: 1) strategic decision-making in farm development; and 2) embedding of farming in its socio-material context.

To study strategic decision-making in the context of family farming, this thesis draws upon literature in small business studies. Family farms share important characteristics with small businesses, as the family farm is an independent business, managed by its owner or part owners and has a small market share (Culkin and Smith 2000). Like small business owners, farmers of family farms operate a complex combination of tasks and responsibilities, as they need to combine the entrepreneurial, managerial and technical role as a craftsman (Chandler and Jansen 1992) and farmers learn personally from the experience of running the farm (Atherton 2003). The farmer, as owner-manager of a small business, is the actual decision-maker, when it comes to selecting a development strategy (Jocumsen 2004; Hang and Wang 2012; Culkin and Smith 2000; Pietola and Lansink 2001). Strategy is defined in this thesis as: "a choice out of available routes and means in order to realise a goal" (Encyclo 2012). The socio-material context highly affects strategic decision-making in farm development, leading to heterogeneity in farmers' decisions on farm development strategy. To understand this heterogeneity, it is important to understand the differences in farmers' perceptions of opportunities (Korsgaard et al. 2015). The study of differences in perceptions of opportunities is, however, complicated, as the context of the farm affects the perception of opportunities (Sutcliffe and Zaheer 1998; Yanes-Estévez et al. 2010). This raises the question whether or not it would be possible to identify differences in farmers' perception of opportunities in a case study of family farmers that operate their farms in a socio-material context that is comparable for all farmers in the case study. Being able to identify differences in farmers' perceptions while operating in a comparable context enables to study the differences in farmers' perceptions by placing it in relation to other aspects of the family farm. 
The second field of interest is the embedding of the farm in the socio-material context, in which it operates. The embedding in the context is an important aspect in the identification of opportunities (Portes and Sensenbrenner 1993; McKeever et al. 2015) and is, therefore, likely to also be important for the perception of opportunities. Farm development strategies cannot be explained solely by economic drivers, social embeddedness is also an important factor in farm development (Feola et al. 2015). The concept of Embeddedness is a prominent theoretical and analytical tool to study the relation between an actor or a business and the context in which it operates (Akgún etal 2010; Roep and Wiskerke 2012a; Ferguson and Hansson 2015). Embeddedness finds its roots in study of the social dimension of economic activity (Granovetter 1985; Dequech 2003). The context, in which an actor is embedded, is broad, ranging from territorial to cultural and from social to ecological. In the context of the study of agri-food networks, embeddedness is often studied through focus on the territorial context of food production (Sonnino 2007). This approach creates a binary view, in which embedding of food production is seen as 'the re-placement' of food and food production in its local context, in response to the 'dis-embedding' forces of conventional food networks (Coodman and Goodman 2009, 208). The binary focus on one aspect of embeddedness creates the risk of losing the interaction between the different fields of embeddedness. An avenue for a more complex approach of embeddedness is found in the work of Hess. Hess reconnects embeddedness to its original meaning: 'the social relationships between both economic and non-economic actors', and brings it back to the simple question of: 'who is embedded in what' $(2004,176)$. Hess introduced three dimensions of embeddedness: 1) societal embeddedness, which signifies the importance of where an actor comes from, considering the societal (i.e., cultural, political, etc.) background; 2) network embeddedness, which describes the network of actors a person or organisation is involved in; and 3) territorial embeddedness, which considers the extent to which an actor is 'anchored' in particular territories or places (Hess 2004, 177). The combination of the three dimensions creates a three-dimensional embeddedness perspective and offers a symmetrical, non-binary approach to study differences in the embedding of farms. For use in this thesis, the term 'embedding' is preferred over 'embeddedness': the embedding of a farm in the socio-material context is an active and evolving process, and not a static state of being. This avenue of three-fold embedding raises the question of how strategic decision-making in farm development is related to the embedding of the farm in the socio-material context.

The combination of the questions related to these two fields creates the core focus of this thesis: the identification of differences in farmers' perception of 
opportunities and the study whether these differences relate to differences in the embedding of the farm in the socio-material context. The following paragraph presents the problem definition that is the basis for this thesis.

\subsection{Problem definition}

The situation of the family farm is influenced by the socio-material context of the farm, and the farm influences its socio-material context. Due to changes in societal demands, farmers are increasingly expected to align their primary production process with the protection of vulnerable community assets (landscape, biodiversity, and environmental quality). The question of how these changes affect family farm development creates a need to better understand the heterogeneity of farm development in relation to a changing socio-material context. The socio-material context offers room for manoeuvre for farmers in the identification and implementation of opportunities for farm development. This room for manoeuvre is, however, subjective by definition. Hence, it is imperative to further develop a view that includes the subjective nature of entrepreneurship in relation to the identification of opportunities, as part of the strategic decision-making process (Kor et al. 2007; Short et al. 2010). Another requirement is to contextualise entrepreneurship in the context of the everyday-and real-life situations of business owners (Bjerke 2007, 31; Johannisson 2011; Watson 2013) More knowledge is required on how family farms are embedded in their socio-material context, and if differences in the embedding of the farm in the socio-material context relate to differences in the farmers' perception of opportunities for farm development. A better understanding of farmers' perception of opportunities can contribute to bridging the gap between the 'farmer-as-entrepreneur' discourse, with a dominant focus on production, and the rural discourse that values the vulnerable characteristics of rural areas (Anderson 2013). As farmers are important stakeholders in regional development (Lauwere et al. 2006), it is important to better understand the strategic decision-making process in farm development and, therefore, to better understand the differences in farmers' perception of opportunities. A better understanding of the embedding of the family farm in the socio-material context is required to support the development of economically healthy farms that are well-adapted to changes in the socio-material context. Farms that are able to incorporate the changes in societal demands in their farm development strategy contribute to sustainable land use, which is a key challenge for rural areas (Woods 2012). 
This means that there is a need to advance the understanding of the Sociology of Entrepreneurship in the context of farm development, as it offers an avenue to a better understanding of strategic decision-making as a process that is related to the embedding of the farm in its socio-material context. The Sociology of Entrepreneurship approach enables the study of differences in farmers' perception of opportunities for farm development and exploration of how these differences are related to the embedding of their farm in the socio-material context.

\subsection{Research objective and questions}

Following the problem definition, the research objective for this thesis is formulated as:

to increase the understanding of differences in family farmers' perception of opportunities for farm development, to understand what drives the differences in farmers' perception of opportunities for farm development and to understand how differences in family dairy farm practices differ in the embedding of the family farm in the sociomaterial context of the farm.

The research for this thesis is based in a case study of family dairy farmers operating in a highly comparable socio-material context of the farms in the case study area, to be further described in chapter 2. This highly comparable context allows for a combination of quantitative and qualitative methods to answer the following three research questions:

1. What are the differences in farmers' perception of opportunities for farm development whilst operating in a highly comparable context?

2. What are the most important drivers for differences in farmers' perception of opportunities for farm development?

3. What are the differences in the embedding of the farm practices that are linked to differences in farmers' perception of opportunities for farm development? 


\subsection{Thesis structure}

This thesis consists of six chapters. This introduction chapter described the background of the research, the problem definition and the research questions. In chapter two the theoretical background is presented which is the basis for the analytical framework followed by the methodologies used for this thesis. Chapters three to five describe the empirical studies which were conducted to answer the three subsequent research questions. Chapter six presents the main findings of the three empirical studies to be discussed in the light of the problem definition followed by a reflection on the methodology used for the research in this thesis. Chapter six closes with the implications of this study for further research and for practice. 


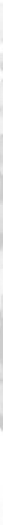
bet rom 


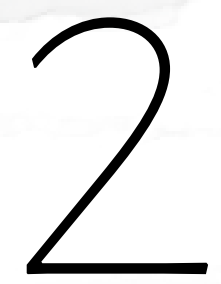

Theory, analytical framework and methodology 



\section{Theory, analytical framework and methodology}

As described in chapter one, farm development is heavily influenced by the sociomaterial context, yet farmers do have a room for manoeuvre for farm development: 'the structures - both on-and off-farm, both material and social - constrain choices. But their influence is mediated by farmer's beliefs, and the potentials farmers perceive in a dynamically changing context' (Darnhofer et al. 2016, 116). This thesis has two main focus points: 1) to understand the differences in farmers' perception of opportunities as part of the process of decision-making on farm development; and 2) the embedding of the family farm in the socio-material context of the farm. The perception of opportunities is important in the early phase of the strategic decision-making process of the farmer. In this thesis the early phase in the strategic decision-making process is defined as the phase when a business owner is triggered, either by developments in the business itself or in the context of the business, to a conscious need that a strategic decision needs to be made.

For strategic decision-making it is important that all relevant opportunities are included in the process of making decisions. The first focus point of this thesis connects to two fields in literature: 1) opportunity identification; and 2) strategic decision-making. The second focus point connects to the field of embeddedness and more specifically to the third field of interest: 3 ) embedding of the farm practices. The literature is viewed in the light of the analytical concept that is designed for this thesis: the perceived Room for Manoeuvre (pRfM). Paragraphs 2.1, 2.2 and 2.3 present the literature in the three fields that are relevant for this thesis followed by the analytical framework that is presented in paragraph 2.4. Paragraph 2.5 describes the research methodology and paragraph 2.6 provides information on the ethical side of the research methodology.

\subsection{Opportunity identification}

Opportunity identification is central to entrepreneurship research (Shane and Venkataraman 2000; Ardichvili et al. 2003; Short et al. 2010). McMullen and Shepherd (2006, 132) define entrepreneurship as: 'To be an entrepreneur, therefore, is to act on the possibility that one has identified an opportunity worth pursuing'. Entrepreneurship is a vital element of the continuous development of an ongoing business (Johannisson and Dahlstrand 2009; Watson 2013). The challenge for strategic entrepreneurship is to both exploit existing opportunities and to identify new opportunities (Ireland et 
al. 2001). This thesis uses the following definition of opportunities: 'an opportunity is an idea or dream that is discovered or created by an entrepreneurial entity and that is revealed through analysis over time to be potentially lucrative' (Short et al. 2010). In line with Kor et al. (2007), an opportunity is not necessarily seen as a completely new innovation to the economy. Being new to the specific business is sufficient to call a development option an opportunity.

In literature on opportunity identification, two important views are debated: the 'how' and the 'why' of opportunity identification (Gartner et al. 2003; Short et al. 2010). Looking at the question 'why', differences in motivation are important. A 'pull' motivation is driven by the entrepreneurs wishes whereas a 'push' motivation is driven by changing circumstances (Amit and Muller 1995). In the situation of a push motivation, the opportunity that is identified is not necessarily a preferred development by the business owner. Regarding the question 'how' opportunities are identified, two perspectives can be described: opportunity 'discovery' or opportunity 'enactment' (Gartner et al. 2003). The discovery perspective takes opportunities as 'there' to discover for those with enough 'entrepreneurial alertness' (Gaglio and Katz 2001). An opportunity is so to say waiting to be found and to be exploited. In the enactment perspective, opportunities are the result of the sense-making activities of individuals (Gartner et al. 2003). The entrepreneur uses his experiences and recognises a given situation as an opportunity for him to develop the business. Renko et al. (2012) argue to use 'opportunity perception' to bridge the gap between the discovery view and the enactment view. The perception of an opportunity is subjective and idiosyncratic to each entrepreneur and the market conditions constrain the success of a strategy based on a perceived opportunity. The subjective approach to entrepreneurship is supported as well by Kor et al. (2007) as they emphasise the need for a subjectivist theory of entrepreneurship. In the analytical concept pRfM the subjective opportunity enactment perspective is the starting point.

The enactment perspective creates a link between opportunity identification and the approach of the farmer who enacts and thus influences the socio-material structures and thereby influences the room for manoeuvre for farm development. The opportunity enactment perspective views the farmer as agent in interaction with the structures in the socio-material context. Opportunities and entrepreneurs cannot be understood independently (Sarason et al. 2006; Sarason et al. 2010). Entrepreneurial ventures are described as 'recursive processes that evolve as the entrepreneur interfaces with the sources of opportunity and engages in the venturing process' (Sarason et al. $2006,288)$. This view is shared in this thesis. Opportunity enactment puts the focus on 
the subjective and idiosyncratic perception of the business owner. Reality is not about 'seeing' but about 'sense-making' (Weick (1995) in Gartner et al. 2003) and different actors perceive different realities due to the differences in the way information is framed (Long 2001). The pRfM of a business owner is his personal 'perceived room for manoeuvre'. Another business owner in a comparable situation may or may not 'see' the same opportunities as viable. In the enactment of business development, a small business owner influences and is influenced by the context in which the businesses operate (Atherton 2003). The subjective perception of opportunities in the context of farm development is supported by the different ways of enactment of farms, or farming styles, that were found in relation to the context of labour requirements and product markets (Ploeg et al. 2009).

In literature on (rural) entrepreneurship, opportunity identification is an important concept as entrepreneurship and entrepreneurial skills receive growing attention (Shane and Venkataraman 2000; Bergevoet 2005; McElwee 2006; Wolf et al. 2007). Edward-Jones $(2006,783)$ reviewed literature on farmer decision-making in relation to the adoption of new technologies: 'As a result of this work it is clear that farmers' decisions are influenced by a range of factors which may be grouped under six headings: sociodemographics of the farmer, psychological makeup of the farmer, the characteristics of the farm household, structure of the farm business, the wider social environment and the characteristics of the innovation to be adopted.' This finding is related to the adoption of a clearly defined new technology or policy. This thesis does not focus on adoption of a clearly defined innovation, but on farmers' perception of their opportunities. The factors named by Edward-Jones are, however, a useful starting point for the analytical framework of this thesis.

\subsection{Strategic decision-making}

This thesis studies the farmer in the role of entrepreneur in the continuous attention that is needed for strategic decision-making: assessing the development opportunities, making an implicit or an explicit decision for a development strategy and evaluating the effects of the choices made. For 'strategy' this thesis uses the following definition: 'A choice out of available routes and means in order to realise a goal' (Encyclo 2012). This means that continuation of current activities is seen as an opportunity as well, as continuation can be a viable route to realise the goal of the business owner. The field of strategic decision-making (SDM) has been studied extensively in the context 
of small business. SDM in small business differs from SDM in large business: SDM in small business is informal, intuitive, and less rational and small business owners aim for other goals besides profit maximisation (Liberman-Yaconi et al. 2010). Family farms share important characteristics with small businesses as the farmer needs to fulfil different roles in the business in a complex combination of tasks and responsibilities combining the entrepreneurial, managerial and technical role as craftsman (Chandler and Jansen 1992). Farmers personally learn from the experience of running the farm, as do small business owners (Atherton 2003). For this thesis we can therefore draw on literature on strategic decision-making in small business.

A number of recent studies describe models to represent the SDM process in small businesses (Jocumsen 2004; Liberman-Yaconi et al. 2010; Hang and Wang 2012). The models begin with a trigger causing the need for a strategic decision and end when a strategic decision is made. This end points is then in turn the start for the continuous development of the business involving new SDM processes. All models imply an interaction between the different steps and depict the process as iterative. The iterative nature underlines that SDM in small businesses is not a clear-cut procedure following a prescribed route in a number of steps. The circular-iterative character of SDM is most evident in the model of Liberman-Yaconi et al (2010). This model depicts three overlapping circles of activities: 1) informing; 2) option generating; and 3) deliberating. The activities lead in a circular-iterative way to a decision followed by the implementation of the decision. In all three models the starting point is where the need for a decision is triggered. However, although the SDM models may start at this point, the owner-manager does not start on a blank page without a history: the experiences, the personal limitations in views and biases will affect the SDM (Simon and Houghton 2002). The personal experience of the small business owner is the starting point for this continuing cycle as it affects the business owners' perception of the opportunities.

The analysis of the opportunities for business development is influenced by the business owner's perception. The perception is found to be more important than a formal analysis (Parnell et al. 2000; García-Pérez et al. 2014). The perception of opportunities is influenced by dominant paradigms, lock-in effects and path dependencies (Vanloqueren and Baret 2009; Lamine et al. 2012; Cowan and Gunby 1996). How well a business owner is able to perform this analysis is described by the analytical concept'strategic awareness capability' (Hannon and Atherton 1998). Strategic awareness capability is defined as 'the process of continuously improving how one identifies and conceptualises one's own world, recognises events in this world, interprets these events and makes decisions on taking appropriate action to achieve positive business outcome' (Hannon and Atherton 
1998 , 112). According to this definition, strategic awareness capability is a competence in which a business owner performs according to the capability of the business owner. Competences of business owners can be measured (Lans et al. 2011), yet do not provide insight in the business owner's perception of the opportunities for the development of the firm. A step further to providing this insight is the 'evoked set of opportunities' that is defined as: 'the full set of possibilities perceived as opportunities by a decision maker' (Krueger et al. 2009, 122). The indication to a 'full set' does not necessarily link to the 'complete set' of opportunities. A complete set of opportunities based on an objective expert analysis is only theoretically possible due to the subjective nature of opportunities. The evoked set of opportunities is limited to the opportunities that the business owner is actively aware of, or the opportunities that the business owner, when presented to him, can reasonably assess as to whether it would fit in his evoked set of opportunities (Krueger et al. 2009, 122).

\subsection{Three-fold embedding}

Embedding is introduced in literature as the analytical concept of Embeddedness to study the social dimension of economic activity. Granovetter (1985) is widely acknowledged for revitalizing the concept in economic sociology as the incorporation of social relations into economic action (Dequech 2003). In literature Embeddedness appears to be used from different perspectives. Jack and Anderson (2002) focus specifically on the meaning of an individual's ties to the local social structure leaving out the other aspects of Embeddedness. In literature on food networks, Embeddedness is used to theorise the development of alternative food networks (Morgan et al. 2006; Akgún et al. 2010; Roep and Wiskerke 2012b). Embeddedness is then used to study the social dimension and the ecological and cultural relationships of a food system in the territorial context of food production (Sonnino 2007). Embeddedness of food production is then seen as 'the re-placement' of food and food production in its local context in response to the 'dis-embedding' forces of conventional food networks (Coodman and Goodman 2009, 208). However, this approach introduces the risk of a binary division between 'good' local-embedded and 'bad' global dis-embedded food systems (Sonnino 2007). Embedded then easily becomes normative as it is seen as a 'unique, distinguishing, almost magical' attribute of alternative food strategies (Hinrichs 2000, 297) and can lead to dichotomy thinking (Morgan et al. 2006, 166). To avoid using a normative and binary approach, embeddedness can best be viewed as the 
activity of embedding, a dynamic process that can vary and is object of management choices (Sonnino 2007; Moragues-Faus and Sonnino 2012). The dynamic process approach places the emphasis on the agency of an actor in making choices which means that for the analytical purpose of this thesis the term 'embedding' is preferred over 'embeddedness': the embedding of a farm in the socio-material context is an active and evolving process, and not a static state of being. Embedding has as well often been approached as a one-dimensional concept, an approach that did not always fit with the perceptions of firm managers on their embeddedness (Ferguson and Hansson 2015). Ferguson and Hansson (2015) conclude that there is a need for a more complex approach to studying embedding in relation to entrepreneurial development. An author who offers an avenue for a more complex approach is Hess. In a review on the different uses of embeddedness in literature, Hess $(2004,176)$ states that a reconnection to the original meaning is needed: 'the social relationships between both economic and non-economic actors', or: 'who is embedded in what'. This view focuses on embedding as an active positioning resulting in an extent of embeddedness between two ends of a scale as opposed to a binary approach. In placing the emphasis on the extent of the embeddedness, a binary approach is avoided as an actor is always embedded.

Hess extracts threegeneral dimensions to beused in thestudy of embeddedness: 1) societal embeddedness signifies the importance of where an actor comes from, considering the societal (i.e., cultural, political, etc.) background; 2) network embeddedness describes the network of actors a person or organization is involved in; and 3) territorial embeddedness considers the extent to which an actor is 'anchored' in particular territories or places (Hess 2004, 177). These three dimensions are used in this thesis to study the embeddedness of the practices of different patterns of farm development as the 'Three-fold Embedding'. The dimensions of Three-fold Embedding need to be carefully re-conceptualised in the context of family dairy farming to ensure a clear and meaningful understanding of each dimension. The societal embedding is re-conceptualised as socio-cultural relations of the farmer, asking how farmers view themselves as a farmer, what 'culture' of farming does the farmer 'belong' to, what is the identity in values, norms and opinions. The network embedding is re-conceptualised as the value chain relations, asking which value chain the farm is a part of or linked to, or which networks or spheres of influence affect farm development. The territorial embedding is re-conceptualised as the resource relations of the farm, asking about the origin of the resources for farm production. For measuring the extent of embedding each of the dimensions needs to be operationalised which will be explained in the methodology section. 


\subsection{The analytical framework}

In the analytical framework (Figure 2.1), the three main analytical concepts are used: Opportunity Identification, Strategic Decision-Making and Three-fold Embedding.

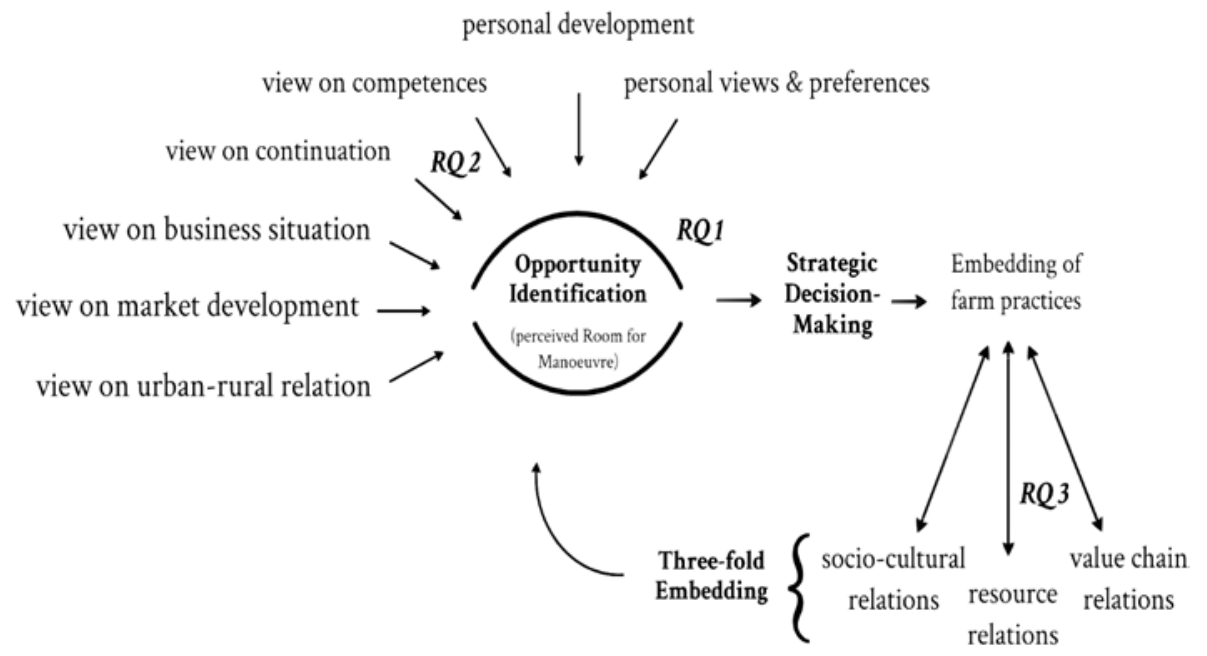

Figure 2.1 Analytical framework of farm development: Opportunity Identification, Strategic Decision-Making and Three-fold Embedding (including positioning of the research questions).

These analytical concepts are placed in relation to each other; the internal loop represents the reiterative nature of this process, as part of a continuous cycle of farm development in relation to, and in interaction with, the socio-material context. The results of the process are, therefore, also linked to a moment in time, as circumstances or perceptions of the circumstances change. An analysis of the situation, thus, represents a 'photograph' of the situation at that moment in time. In the analytical framework, the analytical concept perceived Room for Manoeuvre (pRfM) is placed next to Opportunity Identification. The analytical concept pRfM was designed for this thesis, and is defined as: 'the opportunities perceived as viable by the farmerin order to obtain a (substantial part of) farm income'. The pRfM can, thus, be seen as the result of opportunity identification. The name: 'perceived Room for Manoeuvre' was chosen, as it connects closely to the words used in the real life world of the farmer, who deliberates about the questions: 'what are my opportunities? what is my room for manoeuvre?'. The pRfM is an operationalisation of the concept: 'evoked set ofopportunities', which is defined as: 'the full set of possibilities perceived as (entrepreneurial) opportunities by a decision maker' (Krueger et 
al. 2009, 122). The subjective nature of the perception of opportunities is incorporated within the name, ' $P R F M$ '. The $p R f M$ is directly connected to the person of the farmer, while the 'evoked set ofopportunities' may indicate a more objective approach: the farmer and the set of opportunities. The pRfM is related to the strategic awareness capability, defined as: 'the process of continuously improving how one identifies and conceptualises one's own world, recognises events in this world, interprets these events and makes decisions for appropriate action to achieve positive business outcome' (Hannon and Atherton 1998, 112). A farmer with a higher strategic awareness capability is likely to have more opportunities included within the pRfM.

In Strategic Decision-Making, the farmer assesses (a selection of) the opportunities that are part of the pRfM. The pRfM may include opportunities that are not preferred by the farmer, even though the option is in itself perceived as viable. The concept of 'strategy' is in this study defined as: 'a choice out of available routes and means in order to realise a goal' (Encyclo 2012). This means that continuation of current activities is one of the opportunities, as it is a way to realise the goal: obtaining benefits for the farm (Hansen et al. 2011, 14). In the context of a farm as a running business, entrepreneurial opportunities also include the adaptation of ideas and opportunities already in practice on other farms. The strategic decisions of the farmer lead to farm practices, the characteristics of the farm as a result of the decisions of the farmer. These characteristics are shaped in the process of Three-fold Embedding for the three dimensions: socio-cultural relations, resources relations and value chain relations. The two-headed arrow in the analytical framework between farm practices and the three dimensions of Three-fold Embedding depicts the reciprocal nature of the relation. It is not a cause and effect relationship, the socio-material context affects farm practices and farm practices affect the socio-material context.

The design of the analytical framework was based on a combination of a literature study and an exploratory study in family dairy farming that is part of the research for this thesis. The combination of literature and the exploratory study enables connection between Entrepreneurship Research and real-life context: a connection that is deemed important (Bjerke 2007, 31; Watson 2013; Johannisson 2011). In the framework, the pRfM is placed at the centre in the 'eye' of the farmer, 'looking' at the opportunities for farm development to support farm income. As a result of the often implicit assessment (i.e. opportunity identification), a set of opportunities is perceived by the farmer as viable, this is the set of opportunities that is within the perceived Room for Manoeuvre. 
In Figure 2.1, two sets of relations can be seen with regard to the pRfM. The first set of relations regards placement of the 'eye' in relation to a range of seven drivers that are expected to influence the pRfM (top left of Figure 2.1). All these drivers are based on the farmer's view of these drivers. The second set of relations regards placement of the 'eye' in relation to Strategic Decision-Making, which results in specific farm practices. These farm practices are then connected to the three dimensions of threefold embeddedness (bottom right of Figure 2.1). For the relation of farm practices with Three-fold Embedding, a double-headed arrow is used, signifying the reciprocal effect. In the analytical framework, the three research questions are placed using the indicators: RQ 1; RQ 2; and RQ 3. RQ1 aims to explore the differences between farmers in their pRfM, whilst operating in a highly comparable context. RQ 2 aims to enhance understanding of whether there are specific drivers that are important in creating differences between farmers in their PRFM or not. RQ 3 aims to increase understanding of the differences within the Three-fold Embedding of the farm practices, which are linked to differences in farmers' perception of opportunities.

The seven drivers of pRfM (top left of the framework) cover a range from personal to business aspects, as the model is based on real-life context. The farmer's perceptions of these seven drivers influence the individual's subjective view on the situation of their own farm; this in turn influences his SDM process. The pRFM is not static; pRfM evolves with changes in the situation of the business and the owner-manager. The seven drivers for the pRfM are: 1) personal views and preferences; 2) personal development; 3) view on (entrepreneurial) competences; 4) view on continuation of the farm; 5) view on (farm) business situation; 6) view on market development; and 7) view on urban-rural relations. The first driver is the personal view and preference: how owner-managers view themselves and their preferences (Farmar-Bowers and Lane 2009); their personal motivations (Alsos et al. 2003; Vik and McElwee 2011); and self-conceptualisation (Burton and Wilson 2006). The second driver is personal development, consisting of: education level (Jongeneel et al. 2008; Carter 1998); experience (Hansson and Ferguson 2011); and networks of the owner-manager (Granovetter 1973; Clark 2009; Thornton et al. 2011; Ferguson and Hansson 2015). The third driver is the view on entrepreneurial competences relating to the business strategy (Bergevoet 2005; Bergevoet et al. 2004; Lans et al. 2011). The fourth driver is the view on continuation of the firm. In familyowned businesses, the influence of the family is important for the owner's view on continuation (Gasson et al. 1988). The fifth driver is the view on the current business situation, based on material resources (Shucksmith and Herrmann 2002), and pathdependency, as a result of choices made earlier (Clark 2009). The sixth driver is the 
view on market development, that is, if and how the market is expected to change (Shucksmith and Herrmann 2002; Hansson and Ferguson 2011). The seventh (and last) driver is the view on urban-rural relations. The change in societal views over the last few decades on the urban-rural relation and the role of agriculture has created a market for diversification strategies (Atterton and Ward 2007), especially in peri-urban situations (Zasada 2011).

The Three-fold Embedding of the different farm practices that are linked to differences in the pRFM of the farmer, is studied using a re-conceptualisation of the three general dimensions of embeddedness named by Hess: 1) societal embeddedness, which signifies the importance of where an actor comes from, considering the societal (i.e., cultural, political, etc.) background; 2) network embeddedness, which describes the network of actors a person or organisation is involved in; and 3) territorial embeddedness, which considers the extent, to which an actor is 'anchored' in particular territories or places (Hess 2004, 177). The dimensions are carefully re-conceptualised in the specific context of dairy farming to ensure a clear and meaningful understanding of each dimension. The societal embeddedness is re-conceptualised as socio-cultural relations of the farmer; exploring how farmers view themselves as farmers, which 'culture' of farming does the farmer 'belong' to, what is the identity in values, norms and opinions. The network embeddedness is re-conceptualised as the value chain relations, exploring which value chain the farm is a part of or linked to, or which networks or spheres of influence affect farm development. The territorial embeddedness is re-conceptualised as the resource relations of the farm, exploring the origin of the resources for farm production.

\subsection{Research methodology}

The aim to study differences between farmers using quantitative methods presents a challenge in how to deal with the differences in the socio-material context of farms. Two options for handling this challenge are: 1) either include a high number of farmers to leverage the differences in context; or 2) use a case study with a highly comparable context of the farms in the case study area. The second option, a case study with farmers operating in a highly comparable socio-material context, will mean a limitation in the number of farmers in the research population. A limitation in the number of respondents might lead to limitations for a quantitative analysis due to the number of cases and due to the absence of variance in the population. Case studies provide rich data and are accepted as an effective tool for research on small and medium enterprise (Chetty 1996) and as an appropriate approach for theory 
building (Eisenhardt and Graebner 2007). To be able to use both qualitative and quantitative methods, the challenge is to find a case study with the following three characteristics: 1) a population operating in a highly comparable context; 2) that is large enough to allow the use of statistical methods; and 3) with variance between the respondents in the case study even though they operate in a highly comparable socio-material context. The case study of Kampereiland provides this combination of a highly comparable socio-material context of the farms in the case study area and enough potential variance between farmers as the population size is 102 farmers. The case study of Kampereiland offers a situation where there is potential tension between territorial and societal developments. The predominant sectorial developments in dairy farming of scale enlargement and intensification of production meets limitation due to the natural values of the case study area. The uniqueness of the case study is the highly comparable socio-material context in which all dairy farmers operate: the same type of farming (dairy), the same biophysical circumstances (soil type, climate), the same economic context (all in the dairy market and all are tenant farmers), in the same socio-cultural setting (shared history and cultural background). This highly comparable socio-material setting allows to study differences in farmers' perception of opportunities for farm development. Paragraph 2.5.1 presents a detailed description of the socio-material context of the Kampereiland case study.

\subsubsection{The socio-material context of Kampereiland case study}

Kampereiland ('the island of Kampen') is a river delta where the river I]ssel meets the lake I]sselmeer, which was created when the former sea was closed by a dam in 1932. The town of Kampen owns the islands in the river delta since 1363. Using land reclamation techniques the amount of land was expended to around 4,000 ha of agricultural land and 800 ha water, roads and nature areas. The main activity is dairy farming (102 of the total 108 farms). The isolation aspect of being an island is no longer a physical reality due to bridges and two new polders in the former sea. The history as an island has, however, influenced the culture and identity of Kampereiland, even though the town of Kampen was less than $10 \mathrm{~km}$ away. The 600 people have good social connections with an active community centre, a church, a primary school, a quarterly journal and various social and leisure groups. A yearly harvest festival is organised around the museum farm and attracts thousands of visitors. Kampereiland became part of a National Landscape (2005) due to its characteristic Dutch river delta landscape influenced by centuries of farming and the former coastal areas were designated as Natura 2000 nature reserves (2011). In Figure 2.2 the location of Kampereiland is presented and in Figure 2.3 a map is presented of the individual farms on Kampereiland. 


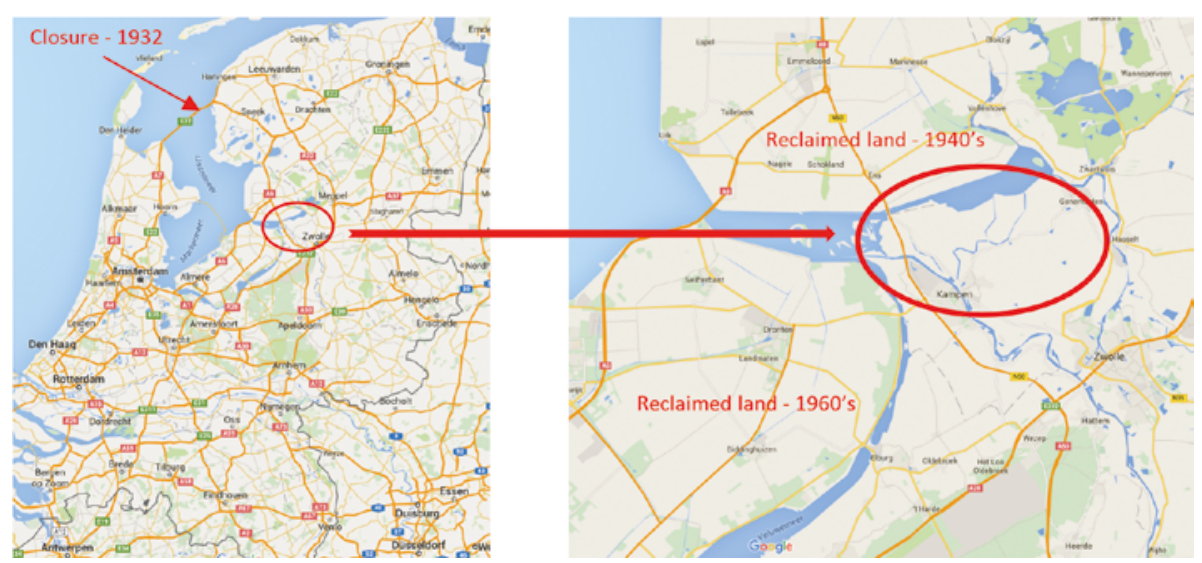

Figure 2.2 Location of Kampereiland in the Netherlands (Coogle Maps)

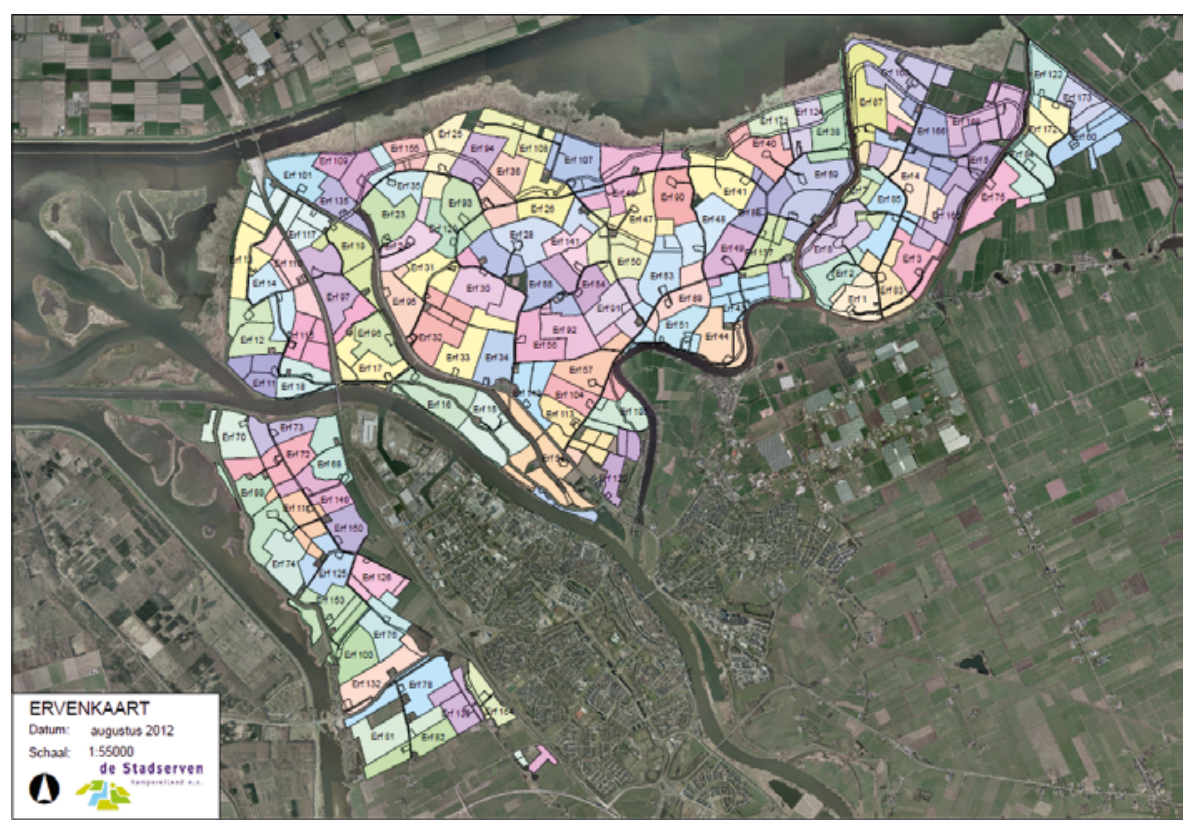

Figure 2.3 Map of the farms on Kampereiland in 2012 (De Stadserven, lessor of Kampereiland)

All farms are tenant farms with the town of Kampen as the lessor. The lessor's policy is to take care of the 'heritage of our fathers' using four guiding principles: 1) retain property of Kampereiland; 2 ) obtain a reasonable financial return; 3) take care of nature and landscape values; and 4) conduct a loyal tenancy policy. After an increase 
to 170 farms in the 1950 s when around 60 new farms were built, the number of active farms decreased to 108 in the year 2012 (of which 102 dairy farms). A farm has on average around 45 ha in use including land owned or rented outside of Kampereiland. The tenancy situation affects the land market in Kampereiland as there is no free land market. To buy land the farmer needs to go to neighbouring areas $(5+\mathrm{km})$. The economy of the farms in Kampereiland strongly relies on dairy farming, though farm income is often supplemented by an off-farm job by the farmer or a family member. Dairy farms in Kampereiland were until the 1980's known for their larger than average size and high economic return, however, the development of farm income in Kampereiland became worrisome in the last decade (Duitman 2005; Methorst 2013). The milk produced is delivered to (inter)nationally operating dairy organisations, mostly cooperatives. About two-thirds of the production of the Dutch dairy industry is exported, with the EU as the main market (ZuivelNL 2016). Dairy farmers on Kampereiland are part of the Dutch dairy sector which is characterised as having 'a high degree of specialisation, horizontal concentration, vertical integration and growing internationalisation and export' (ZuivelNL 2016, 3).

Kampereiland is characterised by specialised dairy farming and there are no options of developing intensive farming like pig or poultry farming, the policy of the lessor is not to allow the development of intensive animal farming production such as pigs or poultry farms. In the Netherlands there are several regions where (most of) the farms are specialised dairy farms and there are regions where a combination of different sectors in animal husbandry is more common. Especially in the region with more sandy soils dairy farming is often combined with pig or poultry farming. There are no organic dairy farms in Kampereiland at the time of the survey (2013) whereas for the Netherlands in total this was 366 organic dairy farms out of 18.665 or 1.9\% (CBS 2016). In Kampereiland around 10\% of the farmers are engaged in onfarm diversification via care, child care, direct sales, recreation or education (based on the exploratory phase of the research for this thesis). For the total of all farms in the Netherlands this is around 19\% with 12.800 out of 67.481 farms (Agriholland 2016). A direct comparison is difficult as data on diversification are complex to compare given the different definitions of diversification used in practice. The data do suggest that the case study area is not a forerunner in the Netherlands when it comes to developing diversification of farms. When looking at the gender perspective, the Kampereiland case study appears to be similar to the general situation in the Netherlands. A very common situation is a combined management of the farm where the management is shared between the farmer and the partner of the farmer often combined with one 
or more persons of the next generation (potential successors). Traditionally the man is most active in the farm in the Netherlands. The role of the woman can vary from a complete partnership in farm management by taking part in both daily and strategic decisions to a more traditional role, mostly caring for the calves and the bookkeeping. When doing the survey, there were no farms with a female farmer as the official owner but there were multiple farms where the wife or the daughter was actively involved in both operational and strategic decision making. There is no indication that this is very different from other regions in the Netherlands.

The policies and legislation concerning the two Natura 2000 areas and the National Landscape affect the development potential of dairy farming in Kampereiland. To support the sustainable development of Kampereiland, the lessor developed a programme aiming to support long term economic viability of the farmers while strengthening the nature and landscape values. Dairy farming in Kampereiland is as well affected by national and supranational legislation on environment, animal health and animal welfare. Since 1984 the dairy farmers in the European Union (EU) were limited in the amount of milk that could be produced. The abolishment of the EU milk quota system in 2015 is expected to lead (and indeed has led) to scale enlargement and specialisation of production in Dutch dairy farming (Meulen et al. 2012). The change in Common Agricultural Policy has increased price volatility of the primary products of the farm while accessibility of capital for investment decreased due to the financial crisis. These developments combined increase the economic challenge for dairy farmers in the development of their farm.

The uniqueness of the case study is the highly comparable context which allows to study differences between individual farmers but concomitantly might affect the results and in doing so limit the general validity. The Kampereiland case study is in many aspects a 'normal' area with specialised dairy farmers, it is an 'ordinary' Dutch dairy farm region. Two aspects are specific for the case study: 1) all farmers are tenant farmers; and 2) there is no free land market in the direct surroundings of the farms as the lessor owns all the land. This situation does affect farm development opportunities for the farmers in the case study, which means that the generalisation of the findings in this study needs careful attention. However, this study does not aim to analyse the effect of a specific change in the context on the development of dairy farms. The aim is to understand the differences in farmers' perception of the opportunities for which a case study is selected in which the dairy farmers operate in a context that is comparable for all farmers in the case study. The different clusters of farmers in this study were acknowledged by the stakeholders as valid as well for dairy farming in general. This 
underlines that the Kampereiland case study offers a good context for the research described in this thesis. For the broader generalisation of the results of this study the specific conditions of dairy farming in the case study do need to be addressed which will be done in paragraph 6.2, the reflection on the methodology.

\subsubsection{Research phases}

The focus on one specific case study allowed for an empirical study in three phases: 1) exploratory research; 2) quantitative research; and 3) qualitative research. The combination of methods used allows as well the triangulation of findings (Sarason et al. 2006)

\section{Phase 1: Exploratory research}

The aim for this phase was to gain information from both theory and practice to provide a good understanding of the setting in which the dairy farmers in Kampereiland operate their farms. The case study provide a high level of access to information as all farmers are tenant farmers from the same lessor and both the lessor and the Tenant Farmers Union co-operated in this research by providing access to information and support in contacting the farmers. Various studies were done in the past for the purpose of policy development which presents extensive information about the development of Kampereiland. This includes a socio-graphic doctorate thesis in 1953 (Hendriks 1953). This documentation combined with the personal conversations and the interviews allowed for an 'everyday ethnography' (Watson 2013) supporting a grounded understanding of the developments in the case study area. The combination of a literature study with a thorough research on the context of the case study, allows for a grounded understanding of the thoughts and decisions of farmers of farm development. In March 2012, 17 in-depth and semi-structured interviews were conducted with farmers. The farmers were selected at random from the list of 108 farmers provided by the lessor. Later detailed information showed that 6 of the 108 farmers were no longer active as dairy farmers, leading to a population size of 102. All but one farmer who was contacted agreed to be interviewed. The interviews followed an interview guide of three leading questions: 1) the history of the farm and its development; 2) the plans for farm development; and 3) the regional development programme Weidse Waarden'. In the spring and summer of 2012 a total of 6 in-depth and semi-structured interviews were conducted with stakeholders of

1 The program Weidse Waarden is a regional development program initiated by De Stadserven, the lessor of Kampereiland and funded by De Stadserven and the province of Overijssel as part of a program to support the prospects and viability of farming in National Landscape I]sseldelta 
dairy farm development in Kampereiland. The persons interviewed were: the director of De Stadserven (the lessor), the lessors steward for the farmers, the lessors program coordinator for the regional development program Weidse Waarden, the independent advisor acting as project manager for the program Weidse Waarden, a board member of the organisation for agriculture and nature conservation and a project leader from the Water Board leading (projects on the ecological value of waterways). All interviews were recorded and transcribed for analysis.

The analytical framework was developed in 2012 using the information in the exploratory phase. The survey was developed in the period September 2012 to January 2013. The main analytical concept of pRfM was defined as: 'the opportunities perceived as viable in order to obtain a (substantial part of) farm income.' The concept pRfM was operationalised by listing 15 opportunities of farm development that are known as routes for farm development in Dutch dairy farming in general and in the case study area in particular. The opportunities for farm development are grouped as follows (opportunities may be combined on the same farm):

Dairy production system

Diversification-people oriented

Diversification-not people oriented

End to dairy production

Other intensive, extensive, certified organic care, recreation, farm shop, dairy processing

energy, nature, other company, off-

farm job

income from other source joint farming, relocating the farm, other option

A $16^{\text {th }}$, blank, option was included to allow farmers to introduce opportunities not yet named. This blank option did, however, not lead to new opportunities outside of the 15 opportunities listed. Respondents were asked to indicate on a Likert scale from 1 to 5 for each opportunity their perception on the viability of the opportunity in their situation, the so-called first-person opportunity (McMullen and Shepherd 2006). The respondents were asked as well to indicate which opportunities were in current practice on their farm, which opportunities they were planning to start on their farm and which option they would prefer provided a situation without limitations.

For each of the drivers of the analytical framework a set of questions was developed by operationalising the drivers in the context of the case study. For each questions the respondents were asked to what extent they agreed with the statement 
in the question on a 5-point Likert scale ('certainly not agree' to 'certainly agree'). The questions were carefully phrased to make the question and answer independent from the specific situation of the family farm. The questions were as well designed in such a way that a farmer should be able to respond without needing extra information from other sources but his own mind. In the creation of the questionnaire expertise was used from experienced sociologists, an expert in questionnaire development and from an independent advisor active in Kampereiland. The questionnaire was tested by two dairy farmers situated close to Kampereiland. The total questionnaire is included as Appendix and consists of 95 questions or around 40 to 60 minutes to complete. Careful attention was paid to the design of the questionnaire in order to give it an attractive appeal and to make sure the respondents would not be faced with inconsistencies in the questions. The questionnaire was both printed and available on internet leaving the choice to the farmer which one to use. Each farmer received a personalised printed version of the questionnaire including an individual code and password to be used for the internet version of the questionnaire. Next to the printed version by mail, all farmers received as well a personalised e-mail with a direct link to the internet version of the questionnaire.

The questionnaire was sent in February 2013 via regular mail and e-mail to all 102 farmers (census) leading to 85 responses and 79 completed questionnaires (78\%). 60 respondents reacted in the first 10 days and after a reminder via e-mail and phone another 25 farmers responded. The group of non-respondents were assessed by local experts on their characteristics. The experts concluded that the farmers in the group non-respondents were not markedly different from the respondents. The high response rate is a critical success for this research as it allows for a quantitative analysis of the data. A high level of participation was imminent for the success of the research as the total number of farmers in the case study area was limited to 102. The high response rate is the result of a combination of factors. The exploratory phase created the basis for a questionnaire in which the farmers recognised the reality of their life as dairy farmers. The professional experience of the researcher in farm advisory combined with the connection of the researcher with CAH Vilentum as University of Applied Sciences supported the response rate of the farmers. The connection to CAH Vilentum created trust as many farmers had either studied themselves or knew someone who studies or studied at CAH Vilentum. The context of a PhD research linked to Wageningen University and CAH Vilentum created the trustworthiness needed to guarantee the independence of the research. The survey was sent to all dairy farms in the case study. A dairy farm may be owned and managed by a single farmer or by a number of persons 
including a combination with two generations. In the covering letter of the survey it was stated that the survey was meant for the person most responsible for the strategy of the farm in its development.

The survey was sent to the addresses of the 102 farmers. Many farms are managed by more than one person, mostly by multiple members of the family possibly including different generations. To guide the answering of the questions by the person most involved in decision-making the following remark was made in the introduction part of the survey: 'The survey is meant for the person most involved in decision-making on the development of the farm'. In the survey a question was included whether the person answering the survey was going to stop being a farmer within a period of ten to fifteen years from that point and whether the farm was expected to continue once the person answering the survey stopped. In this way it was possible to include the age effect of the farmer in the study. The total number of respondents was too small to focus on a further partitioning in age groups. Obviously there was no control whether the answers given would represent the combined opinion of all persons involved in farm or only the opinion of the person answering the questions. A strategy to include all opinions would have been to send a survey for each individual member of the active farm management. This strategy would however increase the amount of time for a respondent to complete the survey. This was expected to highly decrease the willingness to complete the survey and therefore it was chosen not to send multiple surveys to one farm address. Especially as there would have been no control whether indeed all persons involved would have completed the survey. A check on the quality of the overall answers was possible by looking at the overall consistency and coherency of the results of the analyses. As the results showed a high consistency and a high coherency there are no doubts about the validity of the answers given in the survey.

\section{Phase 2: Quantitative analysis}

To answer research question one, a statistical, quantitative analysis was performed on the data of the first question in the survey (Spring 2013). In this question the farmers were asked to rate on a 5-point Likert scale the perceived viability, for themselves on their farm, of 15 opportunities to generate a substantial part of farm income. Using a Principal Component Analysis (Varimax with Kaizer Normalisation) three dimensions were found in which the farmers differentiated. To establish the number of factors to be retained we used Eigen values and the suggestions of the scree plot in combination with an analysis on the theoretical sound and reliable interpretation of the factors. To facilitate interpretation of the factors, the factor solution was rotated. Using these three dimensions a two-stage cluster analysis was conducted leading to four clusters of 
farmers. The first stage clustering procedure is hierarchical to determine an appropriate number of segments. A steep increase in the agglomeration coefficient indicates the merging of clusters that are too different, which therefore indicates an appropriate number of clusters. Several solutions were explored to find a parsimonious solution. The second stage clustering procedure is non-hierarchical to further minimise the heterogeneity within clusters. Cluster centres of the first stage were used as starting values in the second stage. Non-hierarchical procedures often result in clusters of more equal size than hierarchical procedures. The characteristics of the four clusters were determined using information from three sources: 1) the average score of each pattern for the 15 opportunities in farm development; 2) the average production characteristics for each pattern; and 3) interviews with stakeholders of dairy farming on the characteristics of the farms (these interviews will be further described in the section on Phase 3). The average production characteristics were based on question 82 in the survey in which the farmers were asked to indicate for 1985, 2005 and 2012 the number of ha of land, the number of cows and the milk production per cow. The answers are estimates from the farmer and therefore not based on actual statistics. As the aim of this question is to long term development of the farm this level of accuracy is sufficient. The clusters proved to be coherent, consistent and meaningful to farmers and stakeholders of dairy farm development (see chapter 3). The three dimensions of the pRfM that lead to the four clusters of opportunities perceived as viable for farm development reflect a possible development and not necessarily actual farm development. In other words, it is a measure of opportunities perceived as viable. Opportunities perceived as viable are not necessarily put into practice (Zwan et al. 2012).

The seven drivers of pRfM were operationalised in the context of the case study using a set of questions for each driver in the questionnaire with a 5-point Likert scale ('certainly not agree' to 'certainly agree'). The questions were carefully phrased to make the question and answer independent from the specific situation of the family farm. The results were analysed using Principal Component Analysis (PCA). PCA allows sets of questions to be determined which are related and can be combined in one measure. To establish the number of factors to be retained we used Eigen values and the suggestions of the scree plot in combination with an analysis on the theoretical sound and reliable interpretation of the factors. To facilitate interpretation of the factors, the factor solution was rotated. The resulting set of measures combined with individual questions are presented in Table 4.3 (chapter 4). For each measure the number of questions is included, the variance accounted for, and the reliability of the measure using Cronbach Alpha value (Field 2009). The reliability of the two measures 
for networks (driver 2, personal development) was low, likely due to the comparable socio-cultural situation leading to small differences between farmers. This means it is not possible to differentiate for networks between respondents in a highly reliable manner (Cronbach Alpha values of .48 and .33). However, as these measures are the best estimate available and the analytical framework aims to represent the real life context, they were included in the analysis. The PCA on the questions on competences showed the level of being goal-oriented as the primary measure and analysing, networking and pursuing as secondary meaning these three will be correlated. This correlation means it is hard to determine the individual effect of each of the three measures. However, as the measures are based on literature (Lans et al. 2011) and the statistics are good (Cronbach Alpha values of .83, .71, .82), the measures for the three competences were therefore used in the analysis.

For research question two, what are the drivers behind differences between farmers in their pRfM, the three dimensions were related to the underlying variables of the seven drivers, in total 22 variables. Using multiple regression analysis the contribution of each of the 22 explanatory variables (the independent variables) was determined as part of the total model. Three multiple regression analyses were performed with as dependent variables the three dimensions of pRfM: 'diversifying', 'ending' and 'maximising' of production (Methorst et al. 2016). The 22 explanatory variables represented the 7 drivers of the analytical framework. Stepwise regression was used to determine the explanatory value of each of the 7 drivers in the total model. In this analysis the explanatory variables of a specific driver are both included and excluded in the regression model to establish the change in F-value as a result of adding this set of explanatory variables. The individual influence of each of the 22 explanatory variables is determined using the Beta values from the regression analysis (see for the results Table 4.1 in chapter 4). The assumptions for regression analysis were thoroughly tested and proved to allow for this methodology to be used. The test used were: (1) multicollinearity: a VIF value of 10 for an individual variable indicates a possible problem; (2) independence of the standardized residuals: the Durbin-Watson statistic needs to be between 1 and 3 and close to the value 2; (3) effect of outliers: max $5 \%$ of the cases may have a value of the standardized residual above 2 and $1 \%$ above 2.5; and (4) the effect of influential cases on the model: Cook's distance needs to be smaller than 1 and DFBeta value needs to be within the range of -1 to +1 (based on Field 2009, 214-224).

The regression analysis for the three dimensions resulted in a relative large standard error as part of the regression model. This relative large standard error 
is to be interpreted as a confirmation that there is considerable variance between the respondents. The variance is important as the farmers are operating in a highly comparable context. A small standard error would indicate a high degree of predictability of farm development due to small differences between the farmers in their answers. This in turn would indicate that farmers share their rationale which points towards a strong external influence on the farmers' views. This would indicate that all farms react in a similar way to the context in which they operate. In reverse reasoning, the combination of a relative small sample size with the relative high standard error in the regression models combined with the high coherency in the quantitative and qualitative results indicates that there is enough variance within the sample to be used for the purpose of this thesis. The farmers do operate in the same, highly comparable context, yet operate as individuals.

\section{Phase 3: Qualitative analysis}

In the third, qualitative, phase (conducted in the first months of 2014) a series of 31 semi-structured interviews was conducted for two purposes: 1) a confirmatory purpose; and 2) an exploratory purpose. The confirmatory purpose aimed to test whether the results of the statistical analysis are recognised as real existent patterns of farm development. The exploratory purpose was to obtain data to answer RQ3: the three-fold embeddedness of the farms. The interviews were conducted with 15 dairy farmers selected at random from the four clusters of farmers and 16 stakeholders from advisory, suppliers, veterinary, the lessor and farmer organisations. Table 2.1 presents information on the farmers interviewed. For reasons of privacy the data about farm size are categorised in groups for both milk production and number of ha land. Out of the 16 interviews, 9 were with both man and woman and 7 were with a man. Looking at management roles, the farmer could be either manager or co-manager. Co-manager refers to a situation where the management of the farm is shared with other persons (e.g. the partner, parents or children). The stakeholders in farm development that were interviewed were all male, except for one double interview in farm accountancy with both a male and a female person. 
Table 2.1 Characteristics of the farmers interviewed

\begin{tabular}{|c|c|c|c|c|c|c|c|}
\hline $\begin{array}{l}\text { Pattern } \\
\text { of farm } \\
\text { development }\end{array}$ & $\begin{array}{l}\text { Person } \\
\text { interviewed }\end{array}$ & $\begin{array}{l}\text { Role in farm } \\
\text { management } \\
\text { 1) }\end{array}$ & $\begin{array}{l}\text { Highest } \\
\text { education } \\
\text { level for } \\
\text { owners }^{2)}\end{array}$ & $\begin{array}{l}\text { Involvement } \\
\text { next } \\
\text { generation } \\
(>12 \text { yrs })\end{array}$ & $\begin{array}{l}\text { Age } \\
\text { group }\end{array}$ & $\begin{array}{l}\text { Farm milk } \\
\text { production } \\
\text { (kg/year) } \\
(2012) \\
\end{array}$ & $\begin{array}{c}\text { Land in } \\
\text { use (ha) } \\
\text { (2012) }\end{array}$ \\
\hline Milk Max & Man + woman & Co-manager & 2 & high & Senior & $<500.000$ & $<35$ \\
\hline Milk Max & Man & Manager & 3 & na & Middle & $<750.000$ & $<46$ \\
\hline Milk Max & Man + woman & Co-manager & 4 & high & Senior & $>750.000$ & $<46$ \\
\hline Milk Max & Man + woman & Co-manager & 3 & na & Middle & $<750.000$ & $<46$ \\
\hline Milk Max & Man & Co-manager & 3 & high & Senior & $>750.000$ & $>46$ \\
\hline Milk Balance & Man + woman & Co-manager & 2 & na & Middle & $<750.000$ & $>46$ \\
\hline Milk Balance & Man & Co-manager & 2 & high & Middle & $<500.000$ & $<46$ \\
\hline Milk Balance & Man & Co-manager & 2 & high & Middle & $<750.000$ & $<35$ \\
\hline Milk Balance & Man & Co-manager & 2 & high & Middle & $<750.000$ & $<35$ \\
\hline Milk Balance & Man & Manager & 3 & na & Middle & $>750.000$ & $<46$ \\
\hline Milk Balance & Man + woman & Co-manager & 1 & low & Senior & $<500.000$ & $<35$ \\
\hline Milk Plus & Man + woman & Co-manager & 2 & high & Middle & $<750.000$ & $>46$ \\
\hline Milk Plus & Man + woman & Co-manager & 3 & middle & Middle & $<750.000$ & $>46$ \\
\hline Milk Plus & Man + woman & Co-manager & 2 & high & Middle & $<500.000$ & $<35$ \\
\hline Milk Plus & Man & Manager & 3 & na & Young & $<750.000$ & $>46$ \\
\hline End Milk & Man + woman & Co-manager & 3 & low & Senior & $<750.000$ & $<46$ \\
\hline
\end{tabular}

1) Co-manager refers to the farm management being shared with one or more other persons

2) 1=lower level, $2=$ medium level, $3=$ bachelor level, $4=$ master level

The interviewees were first asked about the different types of dairy farms they would expect to find after which the four patterns of farm development which were found were presented. The farmers were told in which pattern their farm was placed according to the statistical analysis and were asked whether this was correct. Next the interviewees were asked whether these four patterns of farm development were in line with the expectation. In the next part of the interviews the interviewees were asked to place the determinants of the analytical framework in the order of importance for the patterns of farm development. To facilitate this process the names of the four patterns including a short description of the characteristics were printed on a small piece of paper and were placed on the table. The determinants were as well printed on a small piece of paper, a short description was added to ensure a common understanding by all the interviewees. The interviewees were then asked to place the determinants physically in the order of importance for the specific pattern. For the interviews with stakeholders the following determinants were used: (work) experience, societal developments, market 
and technology developments, network of the entrepreneur, personal preference, entrepreneurial competences, involvement of the family, technical/financial situation. For the interviews with farmers the determinant societal developments was split in two: 1) chances of societal developments; and 2) limitations of societal developments. This was done to avoid the tension on an abstract level that societal developments can offer both chances and limitation. Once the farmers had placed all determinants in the order of importance according to their view, an extra determinant was added: developments in a $25 \mathrm{~km}$ circle around the farm. The farmer was then asked to place this determinant somewhere in the list of determinants that was made by the farmer. The dairy farmers were asked to place the determinants in the order of importance for the pattern that suited their situation and for a pattern that was most opposed to their situation. As the farmers were less used to this way of working it would take too much time to do the exercise for all four patters of farm development. This resulted in a total of twelve rankings for the Milk Max pattern, seven rankings for the Milk Balance pattern, eleven rankings of Milk Plus pattern and one ranking for the End Milk pattern.

In the last phase of the interview the interviewees were asked to explain the reasoning that made the interviewee to place the determinants in the particular order. The interviewees were asked specifically why a specific determinant would not be placed higher or lower or why it is was placed on a different position for different farm development patterns. In some cases the discussion led to minor changes in the order of the determinants. The researcher participated actively in the conversation by asking questions about the reasoning, yet was careful to ensure that the actual decisions on where to place the determinants was made by the interviewee. During the interviews with farmers it was clear that handling information in this way was an unfamiliar exercise, yet all interviewees managed to place the determinants in an order that matched their view of the specific farm type. The interviewer explicitly asked the interviewees in the end of the interview whether the final order of the determinants was the view of the interviewee which was confirmed by all interviewees. In the discussion the order of importance appeared to be in three parts, a top three or four determinants, a bottom three or four determinants and a middle group. The exact ranking within each group was open for debate, especially in the middle and bottom group. Most of the interviewees, both farmers and stakeholders indicated that they enjoyed the interview and liked this approach as it offered them a perspective they would normally not use. A photo was then made of the table with all the papers placed in the order by the interviewee. The interviews were recorded and transcribed by the researcher for further analysis. 
The transcribed interviews were analysed for the characteristics of the farm practices for each of the four patterns of farm development. The quotes describing specific characteristics of the farm were selected and sorted. The sorted information was used to construct the ideal-typical set of characteristics for the farm practices of the three patterns (End Milk was excluded due to limited number of farmers combined with a large range in motives to end milking). Ideal-types are a coherent theoretical concept that is 'formed from characteristics and elements of the given phenomena but it is not meant to correspond to all of the characteristics of any one specific case' (Soliva 2007, 63). In this way a balanced view was obtained about the characteristics of the farm practices of the three patterns based on the views from both dairy farmers from different patterns and stakeholders with various backgrounds. These ideal-typical sets of characteristics of farm practices were used to determine the extent of the three-fold embeddedness of each pattern of farm development based on Hess (2004) (see chapter 5). To estimate the extent of the embedding of the farm, a scale was used that placed the nature of the relations as a 'close' set of relations on one end to a 'stretched' set of relations on the other end. The words 'close' and 'stretched' have been selected to avoid a geographical connotation and to avoid a positive or negative connotation to either end of the scale. Avoiding a geographical connotation is important as embedding has often been used in the one-sided perspective of territorial embedding. For each ideal-typical pattern of farm development the position on the three scales of embedding was the result of an informed judgment of the researcher. This informed judgment is based on the data from interviews with 15 farmers and 16 stakeholders on the characteristic farm practices for the different ideal-typical farms. This position resembles three sliders on a sound mixing panel. The sliders can be positioned on the scales and the combined positioning represents the characteristics of the family farm.

The following guidelines were developed to determine the extent of the embeddedness between close or stretched. Socio-cultural relations of the family farm: to what extent do they represent an attachment to the land in use and to the direct surroundings of the farm, both physical and social. Does the farmer 'belong' to this location (close) or could the farmer easily move to another farm in a different location (stretched). How does the farmer position himself, as caretaker of the farm and its land (close) or as manager of an economic activity (stretched). Value chain relations of the farm: how is the relation of the farm with the market outlets of its product. Are the products part of a globalised value chain where products are marketed anywhere in or outside Europe (stretched) or is it a value chain where products are marketed using a brand linked to the farm or the region (close). Is the family farm primarily connected 
to the agri-industrial oriented value chain network (stretched) or is the farm primarily connected to the agri-food oriented value chain network (close). Resources relations of the farm: where do the resources come from (mainly feed and fertilizer). Is it primarily based on the agro-ecological view to be self-proficient in producing feed (close) or is it primarily based on agri-industrial view to use all resources available to maximise farm output (stretched)

\subsection{Ethical remarks: consent and confidentiality}

In this research the empirical basis is the personal information provided by the farmers in the survey or during interviews and by stakeholders of dairy farm development in Kampereiland during interviews. For this reason it is needed to express a few ethical remarks. The Tenant Farmers Union and the lessor of Kampereiland were approached and both organisations agreed to co-operate in the research as they were highly interested in the results of the research. The results are useful in the on-going process of re-orientation on the future of dairy farming in Kampereiland and in designing appropriate policies relating to tenancy and farm development. All persons involved in acquiring data for the research were informed about the purpose of the research, what was asked from them, what type of information was needed, how the information was recorded and how it would be used. As the research deals with personal and therefore possibly confidential information, anonymity and confidentiality were guaranteed. All participants in the research have explicitly given their informed consent for the interviews and the recordings. 


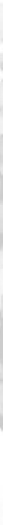
bet rom 


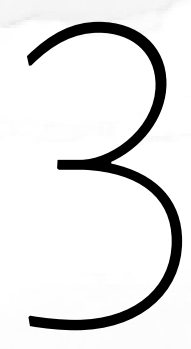

Differences in farmers' perception of opportunities for farm development 



\section{Abstract}

This paper empirically identifies differences between dairy farmers in their perception of opportunities for farm development. The analytical concept 'perceived room for manoeuvre' (pRfM) is used to measure this perception. A unique case study of 79 dairy farmers operating in a highly comparable socio-material context allows for an accurate analysis of differences between farmers. pRfM is defined as: 'the opportunities perceived as viable in order to obtain a (substantial part of) business income' Therefore differences in the pRfM will likely affect the early phase of strategic decisionmaking (SDM) and consequently explain heterogeneity in farm development. The empirical test of pRfM was done using a mix of quantitative and qualitative methods: exploratory research, a questionnaire and in-depth interviews with stakeholders in farm development. Data were analysed using principal component analysis leading to three dimensions of pRfM: perception of the opportunity (1) to diversify; (2) to end production; and (3) to maximise production. A two-stage cluster analysis revealed four coherent clusters of farmers which stakeholders confirmed to reflect meaningful differences in farm practices. This is important because once we understand the drivers behind the differences in PRFM, this insight can be used for the design and evaluation of intervention programmes on farm and rural development.

This chapter is in review for publication at NJAS - Wageningen Journal of Life Sciences as: R.G. (Ron) Methorst, D. (Dirk) Roep, F.J.H.M. (Frans) Verhees and].A.A.M. (Jos) Verstegen. Differences in farmers' perception of opportunities for farm development 


\subsection{Introduction}

This paper is an empirical study of the differences in the perception of opportunities by dairy farmers, being small business owners. Differences in perceptions of business owners are difficult to study as the perceptions are affected by the context of the businesses (Sutcliffe and Zaheer 1998; Yanes-Estévez et al. 2010). A better understanding of how business owners' perceive the opportunities is however important as it plays a role in the opportunity identification in the early phase of a strategic decision-making process (SDM). In this thesis the early phase in the SDM is defined as the phase when a business owner is triggered, either by developments in the business itself or in the context of the business, to a conscious need that a strategic decision needs to be made. In the context of small business, SDM has been modelled by a number of studies. The models start with a trigger caused by an internal or external development and up to the actual strategic decision. The personal characteristics of the business owner are known to be an important factor to explain the heterogeneity in small business (Jocumsen 2004; Liberman-Yaconi et al. 2010; Hang and Wang 2012). The small business owner's perception of opportunities is found to be more decisive for the outcome of SDM than formal analyses (Parnell et al. 2000; García-Pérez et al. 2014). The perception is influenced by dominant paradigms, lockin effects and path dependencies (Vanloqueren and Baret 2009; Lamine et al. 2012; Cowan and Cunby 1996). The opportunities for business development are by definition perceived and therefore impossible to objectify, different business owners will perceive the opportunities in a given situation in different ways. A useful concept to study the perceived opportunities for business development is the 'evoked set of opportunities' (Krueger et al. 2009, 122): 'the full set of possibilities perceived as opportunities by a decision maker'. The evoked set of opportunities is limited to the number of opportunities that are within the perceived reach of the business owner: their perceived room for manoeuvre (pRfM). The evoked set of opportunities implies that there are differences between decision-makers in their pRfM even when they operate in a comparable context. Differences in the capability to analyse the opportunities for business development are likely to affect the pRfM of business owners. This capability is described by Hannon and Atherton $(1998,112)$ as 'strategic awareness capability': 'the process of continuously improving how one identifies and conceptualises one's own world, recognises events in this world, interprets these events and makes decisions on taking appropriate action to achieve positive business outcome. The perception of the business owner is therefore important for the SDM of small businesses. In order to 
study the differences in perception between business owners it is important to be able to identify differences in the pRfM. However, no studies were found that operationalise the pRfM in an empirical way. The lack (or even absence) of these empirical studies is understandable as the contexts of businesses usually vary in many ways and this complicates a comparative analysis of perceptions of business owners (Sutcliffe and Zaheer 1998; Yanes-Estévez et al. 2010). For this paper we use a unique case study in dairy farming that does allow for an empirical analysis of differences between business owners with respect to their pRfM, as all 102 family dairy farmers operate in a highly comparable socio-material context.

Family dairy farming in the Dutch or North West European context is a specific kind of small business, yet does share important characteristics with small businesses in general as the farm is an independent business, is managed by its owner or part owners and has a small market share (Culkin and Smith 2000). The farmer needs to fulfil different roles in the business as do small business owners (Chandler and Jansen 1992) and the farmer personally learns from the experience of running the business (Atherton 2003). In the context of the case study, the farmers operate in a context with high natural and cultural-historical value and are confronted by changing societal demand on rural and farm development, a context that is the case for many farmers (Wästfelt et al. 2012). The farmer needs to find a strategy to counter the cost price squeeze that is the result from increasing costs of resources and a decrease in the price of products (Ploeg 2000). Scale enlargement and specialisation has been and still largely is the predominant strategy in Dutch dairy farm development, a strategy that negatively affects landscape and biodiversity values (Marsden 2003; Wiskerke and Roep 2007) and therefore has limited potential in the case study area. Alternative farm development strategies in the European context entail new value chains based on regional products and on the characteristics of the farm in the rural context such as farmers' markets, care and recreation (Potter and Tilzey 2005; Oostindie 2015). This means there is a range of opportunities for farm development. The farmers' perception of these opportunities will affect the SDM of the farmer as is the case for small business owners (Liberman-Yaconi et al. 2010). The perception of a business owner is as well the driver of opportunity recognition (Renko et al. 2012), recognising opportunities is important as it may increase the number of opportunities for farm development. A better understanding of the differences in the pRfM is therefore important for understanding heterogeneity in farm development and small business development in general. 
For this paper the analytical concept 'perceived Room for Manoeuvre' (pRfM) was used to empirically study differences between farmers in their perceptions of opportunities for farm development. pRfM is defined as: 'the opportunities perceived as viable in order to obtain a (substantial part of) business income. Perception is here used as a noun and in the following definition: 'the way you think about or understand someone or something' (Merriam-Webster 2015). Or in everyday words: 'perceptions are shaped by what we know, by what we think we know, and what we do not know' (Renko et al. 2012). In McMullen and Shepherd's (2006) model of entrepreneurial action, an opportunity that is part of the pRfM of a farmer is referred to as 'first-person opportunity' which is preceded by recognising an opportunity to be an opportunity that is valid in a general sense (' a third person opportunity'). The pRfM is therefore a selection out of the range of general opportunities in the early phase of SDM. A better understanding of the pRfM of a farmer in the early phase of the SDM is also of practical relevance for the range of stakeholders that have an interest in farm or rural development. In rural areas large parts of the land are in use by farmers (Berkhout and van Bruchem 2006), making farm development of interest for stakeholders in regional development (de Lauwere, Verstegen et al. 2006). Policy schemes and development programmes of local governments influence business development, e.g. by supporting the diversification of small business (Liberman-Yaconi et al. 2010) or in the adaptation to changes in the environment (Feola et al. 2015). However, the final strategic decision for the development of a farm is made by the farmer in the role of owner-manager who has a rather autonomous position in decision-making (Culkin and Smith 2000; Pietola and Lansink 2001; Jocumsen 2004; Hang and Wang 2012). This means that in order to be effective, policies and programmes need to connect to the world of the decision maker (Pietola and Lansink 2001) meaning it is important to understand how the farmer perceives the opportunities for farm development that together with the preferences of the farmer result in the selection of a strategy. This paper contributes to this understanding in an empirical study on the differences between farmers in their pRfM and is an answer to the call to study entrepreneurship in the context of the everyday and real life situations of business owners (Bjerke 2007, 31; Johannisson 2011; Watson 2013). This paper answer as well to the call to integrate research on strategic management with research on entrepreneurship (Kor et al. 2007; Short et al. 2010) and the view that the domain of entrepreneurship research can contribute to the understanding of the changes in agriculture and rural areas (Alsos et al. 2011, 11). 


\section{Research questions}

This paper aims to explore if the analytical concept pRfM can be used to study the differences between business owners in their SDM. pRFM is introduced and empirically tested for validity in the context of family dairy farming operating in a challenging yet highly comparable socio-material context. If the analytical concept pRfM allows to identify farmers based on the differences in their pRfM, it will open the path for further study on how differences in the pRfM are related to other characteristics of the farm and the farmer. This paper analyses the following research questions:

1. Can the analytical concept pRfM be measured?

2. Can the analytical concept pRfM differentiate between farmers in a meaningful way?

3. How does pRfM relate to strategic decision-making and consequently to the development of the farm over time?

4. How does pRfM relate to the personal preference of the farmer for farm development?

A positive answer to Questions 1 and 2 provides a basis for the further study of pRfM. Question 3 tests the validity of the pRfM using a time perspective. How is the relation of pRfM at the moment of study to farm development in the past? A consistency between pRfM and farm development in the past indicates that pRfM is (relative) stable over a longer period of time. Question 4 tests the validity of the analytical concept pRfM in relation to the personal preference of the farmer given a situation without limitations. When pRfM and personal preference mostly overlap, pRfM apparently does not deviate from mere personal preference.

\subsection{Theoretical background}

First the context of small businesses will be defined followed by the connection of pRfM with recent theory on SDM in small businesses. The analytical concept pRfM is closely related to the identification of opportunities which is an important topic in entrepreneurship research. There is no single definition of small businesses available in literature. For this paper the definition of the Bolton Committee (a committee on the role of small businesses in the UK economy) will be used: 'a small firm is an independent business, managed by its owner or part owners and having a small 
market share' (Culkin and Smith 2000). Family dairy farms meet this definition. Due to the low number of employees in family dairy farms, they could even be classified as micro-firms (Liberman-Yaconi et al. 2010). In a literature review Liberman-Yaconi et al (2010) describe that owner-managers of small businesses typically cannot delegate (parts of) the SDM to other people in the firm. Owner-managers usually do not have specialised expertise in all aspects related to SDM and need to combine SDM with their managerial tasks. The context in which entrepreneurs operate has been highlighted as very important (Shane 2008; Watson 2013). This context is not just the start-up business owner who is looking for opportunities to develop a new venture. Entrepreneurship is also a vital element of the continuous development of an ongoing business (Johannisson and Dahlstrand 2009; Watson 2013).

\section{pRfM and the SDM process}

'Strategy' is defined in this study as "a choice out of available routes and means in order to realise a goal" (Encyclo 2012). In this view continuation of current activities is an opportunity as well, as it can be a route to realise the goal of the business owner. A number of recent studies describe models to represent SDM in small businesses (Jocumsen 2004; Liberman-Yaconi et al. 2010; Hang and Wang 2012). The starting point of these models is a trigger that creates the need for a strategic decision and the end point is the moment when a strategic decision is made. All models imply an interaction between the different steps and depict the process as iterative. This interaction underlines that SDM in small businesses is not a clear-cut procedure following a set number of steps. The circular-iterative character of SDM is most evident in the model of Liberman-Yaconi et al (2010), as it depicts three overlapping circles of activities: (1) informing; (2) option generating; and (3) deliberating. The activities lead in a circular-iterative way to a decision followed by the implementation of the decision and an evaluation of the results. This iterative process is recognised as well in the context of agriculture (Huirne 2003). In all three models the starting point is where the need for a decision is triggered. Although the SDM may start at this point, the ownermanager does not start without a history: his experiences, limitations in his views and his biases will affect the SDM (Simon and Houghton 2002). The owner-manager will from time to time assess the situation of his firm and the viability of opportunities for the development of his firm. This pRfM acts as a preliminary filter for the selection of opportunities for a formal assessment in an SDM process.

As stated in the introduction, the pRfM operationalises the 'evoked set of opportunities' of a small business owner, the set of opportunities perceived as 
viable opportunities for business development. The name pRfM for the analytical concept underlines the connection to the everyday language of entrepreneurs when deliberating on their range of opportunities, their 'Room for Manoeuvre'. Using words that connect to the context of everyday life facilitates a common understanding between researchers and business owners (Gartner et al. 2003). A viable opportunity is not necessarily put in practice, e.g. due to limited resources or a mutual exclusion of opportunities. Another reason is the gap between thinking about and actively realising an opportunity. This gap can be large (Zwan et al. 2012).

\section{Opportunity identification}

The challenge for strategic entrepreneurship is to both exploit existing opportunities and to identify new opportunities (Ireland et al. 2001). Opportunity identification has a central place in entrepreneurship research (Shane and Venkataraman 2000; Ardichvili et al. 2003; Short et al. 2010). For this paper we build on the following definition: 'an opportunity is an idea or dream that is discovered or created by an entrepreneurial entity and that is revealed through analysis over time to be potentially lucrative' (Short et al. 2010). Two important views exists concerning: 'why' and 'how' are opportunities identified (Gartneretal. 2003; Shortetal. 2010). Looking at the question'why', differences in motivation are important. A 'pull' motivation is driven by the entrepreneurs wishes and a 'push' motivation is driven by changing circumstances (Amit and Muller 1995). A push motivation means that the opportunity identified is not necessarily a preferred development by the business owner. Regarding the question 'how' opportunities are identified, two perspectives can be described: 'discovery' or 'enactment' (Gartner et al. 2003). The discovery perspective takes opportunities as 'there' to discover for those with enough 'entrepreneurial alertness' (Gaglio and Katz 2001). An opportunity is so to say waiting to be found. In the enactment perspective opportunities are an outcome of the sense-making activities of individuals (Gartner et al. 2003). The entrepreneur uses his experiences and recognises a given situation as an opportunity for him to develop the business. Renko et al (2012) argue to use 'opportunity perception' to bridge the gap between the discovery view and the enactment view. The perception of opportunity is subjective and idiosyncratic to each entrepreneur. Different actors perceive different realities, e.g. because of different prior experiences or because of the way information is framed (Long 2001). Reality is not about 'seeing' but about 'sense making' (Weick (1995) in Gartner et al. 2003). The pRfM of a business owner is his personal 'perceived room for manoeuvre'. Another business owner in a comparable situation may or may not 'see' the same opportunities as viable. The development of small businesses is 
'enacted'; it influences and is influenced by the environment in which the businesses operate (Atherton 2003). The subjective approach to entrepreneurship is supported as well by Kor et al (2007) who state that an opportunity is not necessarily a completely new innovation to the economy. Being new to the specific business is sufficient to call a development option an opportunity.

\subsection{The case study}

The case study area is Kampereiland (the Netherlands), an area of 4,200 hectares of cultivated land owned by the town of Kampen. The land is rented by 102 family dairy farms, the average farm needs to strengthen farm income (Methorst 2013). The highly comparable socio-material context of the farms in the case study area allows for an accurate investigation of differences in perceptions between farmers. Farmers operate in challenging circumstances due to structural changes that increase the importance of SDM and entrepreneurship (Clark 2009; Hansson et al. 2010; Verreynne 2006; Bergevoet and Woerkum 2006). The end of the EU production limitation has brought to an end the highly regulated and protected economic system (Potter and Tilzey 2005; McElwee 2006). An increase in price volatility is expected while production costs are rising due to legislation on environmental impact and animal welfare (Meulen et al. 2012; Samson etal. 2016). The predominantstrategy in Dutch dairy farming is increasing the production capacity via scale enlargement and intensification of production (Schans and Keuper 2013), a strategy in line with the focus of policies and markets on the production of large quantities of uniform products (Ploeg 2003; Benvenuti 1989). Diversifying their activities is another strategy for farm owners (Atterton and Ward 2007; Ploeg et al. 2009). The owner of Kampereiland aims to develop opportunities for diversification of dairy farms, as scale enlargement and intensification endanger the natural and landscape values of Kampereiland. The ability to recognise opportunities has not been developed for a long time as the need for a critical assessment of the economic situation of the farm was low (McElwee and Bosworth 2010). Moreover, farm development in the past had created a path dependency causing reluctance to cross the boundaries of agriculture and choose a diversification strategy (Wilson 2008). In general farmers are more focused on improving current conditions rather than exploring new ideas (Haugen and Vik 2008; McElwee 2006; Morgan et al. 2010; Vesala and Vesala 2010). 


\subsection{Methodology}

\section{Approach}

In this paper we follow Kor et al (2007) and Renko et al (2012) taking the subjective opportunity enactment perspective as the starting point for the pRfM. Research on farm development in relation to the context of labour requirements and product markets has revealed different ways of enactment which result in different ways of organising the farm (Ploeg et al. 2009). The pRfM is tested in a context of family dairy farming which creates an opportunity to focus as well on the why and how of opportunity identification in this context. The research consists of three phases: 1) exploratory qualitative research; 2) quantitative research; and 3) confirmatory in-depth interviews with farmers and stakeholders.

In Phase 1, a combination of literature study and exploratory ethnographic research is used to operationalise the set of opportunities for dairy farm development that are considered to be opportunities in general, the so-called third-party opportunities (McMullen and Shepherd 2006). Phase 2 entails a survey collecting data by sending a questionnaire to respondents in the case study area. Using the results of the exploratory research in Phase 1, the pRfM is operationalised in the questionnaire as the opportunities perceived by the farmer as viable in order to obtain (part of) his income. In the context of a farm as a running business, opportunities include the adaptation of ideas and opportunities already in practice on other farms. The list of 15 opportunities can be divided in 5 groups: 1) Opportunities related to the primary production process of milk; 2) Opportunities related to diversification involving direct contact with people; 3) Opportunities related to diversification - not in direct contact with people; 4) Opportunities involving ending dairy production; and 5) Other opportunities for farm development. A $16^{\text {th }}$, blank, opportunity is added to provide a possibility for respondents to add an opportunity which was not included in the list. The details of the 15 opportunities can be found in Table 3.1. To ensure the quality of the questionnaire external expertise in the context of the case study and in the design of questionnaires is used and the questionnaire is tested on dairy farmers. In Phase 3 , interviews with survey respondents and stakeholders of dairy farm development are conducted to check the results of the statistical analysis for validity and meaningfulness from a practical perspective. 


\section{Data}

The questionnaire was sent in February 2013 via regular mail and e-mail to all 102 farmers (census) leading to 79 completed questionnaires (78\%). The group of non-respondents were assessed by local experts as not markedly different in their characteristics from the respondents. Respondents were asked to indicate on a 5-point Likert scale their perception of the viability of each opportunity in their situation, the so-called first-person opportunity (McMullen and Shepherd 2006). Data on production characteristics were asked for the years 1985 and 2012 and the farmers were asked to indicate their preferred opportunity provided a situation without limitations.

\section{Data analysis}

Data from the questionnaire were analysed using principal component analysis (Varimax with Kaizer Normalisation) and two-stage cluster analysis. To establish the number of factors to be retained the Eigen values and the suggestions of the scree plot will be used in combination with an analysis on the theoretical sound and reliable interpretation of the factors. To facilitate interpretation of the factors, the factor solution was rotated. The second step was a two-stage clustering procedure. The first stage clustering procedure is hierarchical to determine an appropriate number of segments. A steep increase in the agglomeration coefficient indicates the merging of clusters that are too different, which therefore indicates an appropriate number of clusters. Several solutions were explored to find a parsimonious solution. The second stage clustering procedure is non-hierarchical to further minimise the heterogeneity within clusters. Cluster centres of the first stage are used as starting values in the second stage. Non-hierarchical procedures often result in clusters of more equal size than hierarchical procedures. To analyse the relation between the preferred opportunities (given a situation without limitations) and the clusters of pRfM, each of the 15 opportunities that could be selected as personal preference was placed in a group based on the resemblance of the opportunity with the characteristics of the four clusters. A fifth group called 'other' was needed consisting of five opportunities that did not exclusively fit in the characteristics of the four clusters: off-farm job, energy production, dairy and nature, relocation of the farm and joint farming. A cross table was made to relate the five groups based on personal preference with the four clusters based on the pRfM (Table 3.3). The validity and meaningfulness of the findings in practice was tested by presenting the findings to 15 respondents (selected at random) and 16 stakeholders of dairy farm (Phase 3 of the research). The leading question was whether the clusters found were recognised and whether the interviewee missed specific (sub)groups of farmers in the results. 


\subsection{Results}

In this section, the four research questions as stated in the introductory section will be answered.

\section{1) Can the analytical concept pRfM be measured?}

Using principal component analysis three factors were found to explain $50.3 \%$ of the variation (rotation in 5 iterations). The scree plot shows a clear heel at the fourth factor (with an Eigen value of 1.02). Combined with the test for a theoretical sound interpretation three factors were determined to form the three dimensions of the pRfM. The three dimensions are interpreted using the oblique rotation leading to the following three dimensions: 1) diversifying dairy; 2) ending dairy; and 3) maximising dairy. Each of the farmers has a score for these three dimensions meaning it is possible to measure the pRfM of a farmer.

\section{2) Can the analytical concept pRfM differentiate in a meaningful way between business owners in their pRfM?}

Using the three dimensions of the pRfM four clusters were found. The clusters were examined on the coherency using the mean values for the 5-point Likert scales for the 15 opportunities presented in the questionnaire (Table 3.1). The combination of opportunities with a high mean score were used to describe the characteristics of the clusters. The resulting characteristics of the clusters are as follows:

\section{1: $\quad$ Maximising production $(\mathrm{n}=29)$}

Focus on maximising production per ha using imports of feed next to own feed production. Joint farming is seen as 'maybe possible'. Energy production may add to farm income.

\section{2: $\quad$ Optimising resources $(\mathrm{n}=21)$}

Focus on milk production using on-farm produced feed with limited inputs of (concentrated) feed. The use of the farm as production unit is optimised. Off-farm job and energy production are seen as possible opportunities.

\section{3: $\quad$ Diversifying production $(n=21)$}

Focus on milk production possibly combined with on-farm diversification. The use of the place where the farm is located is optimised. Dairy farming is based primarily on own produced feed, comparable to Cluster 2. 


\section{4: $\quad$ Ending production $(\mathrm{n}=8)$}

Focus on ending dairy farming in the near future, income from other activities (possibly retirement). Currently optimising on-farm resources, possibly an off-farm job or another company.

The question on meaningfulness is answered using interviews with stakeholders (Phase 3 of the research). The clusters found were presented to 15 farmers and 16 stakeholders of dairy farm development in Kampereiland. All interviewees recognised the four clusters as existent in the context of Kampereiland and in Dutch dairy farming in general. They found the clusters to be in line with their own views on the existing differences between farmers. For most interviewees the number of farmers with a positive perception of diversification (21 farmers in Cluster 3 ) exceeded their expectations.

These results show that the analytical concept pRfM allows a differentiation of business owners. The characteristics of the clusters found are meaningful for both farmers and stakeholders in dairy farm development in the region. The next part describes the relation of pRfM with the long-term strategic development of the business.

Table 3.1 Average score on the perceived viability of the presented opportunities for farm development for the four clusters of dairy farmers. Scale 1-5 ('1-certainly no' to '5-certainly yes')

\begin{tabular}{|c|c|c|c|c|}
\hline \multirow[b]{3}{*}{ Opportunities for farm development ${ }^{1)}$} & 1 & 2 & 3 & 4 \\
\hline & $\begin{array}{l}\text { Maximising } \\
\text { production }\end{array}$ & $\begin{array}{l}\text { Optimising } \\
\text { resources }\end{array}$ & $\begin{array}{l}\text { Diversifying } \\
\text { production }\end{array}$ & $\begin{array}{l}\text { End } \\
\text { production }\end{array}$ \\
\hline & $n=29$ & $\mathrm{n}=21$ & $n=21$ & $\mathrm{n}=8$ \\
\hline Intensive dairy, high milk yield/ha and per cow & 4.2 & 2.4 & 2.5 & 1.8 \\
\hline Joint farming with 1 or more other dairy farms & 3.3 & 1.8 & 2.7 & 2.6 \\
\hline Relocating outside Kampereiland & 2.6 & 1.6 & 2.2 & 3.1 \\
\hline Land-based dairy, mostly own feed & 2.3 & 4.2 & 4.2 & 3.5 \\
\hline Organic dairy & 1.3 & 1.7 & 2.5 & 1.6 \\
\hline Dairy plus another company & 1.9 & 1.5 & 2.9 & 3.0 \\
\hline Dairy plus income from nature conservation & 2.5 & 2.8 & 3.5 & 2.4 \\
\hline $\begin{array}{l}\text { Average }{ }^{2)} \text { of } 4 \text { opportunities: Dairy plus } \\
\text {-processing own milk, -on-farm costumers, } \\
\text {-care, -recreation }\end{array}$ & 1.5 & 1.3 & 2.9 & 1.4 \\
\hline $\begin{array}{l}\text { Average }{ }^{3)} \text { of } 2 \text { opportunities: End dairy plus } \\
\text {-other company, -other income source }\end{array}$ & 1.4 & 1.4 & 1.9 & 3.4 \\
\hline
\end{tabular}




\section{3) How does pRfM relate to the development of the business over time?}

Table 3.2 presents the average production characteristics in $\mathrm{kg}$ of milk per cow, per ha and per farm for the four clusters for the years 1985 and 2012. The percentage of growth in this period is included in Table 3.2. Cluster 1, maximising production, shows the highest numbers for all three parameters, both in absolute numbers and in growth rate. Milk production per ha is nearly $18,000 \mathrm{~kg}$ in 2012 , clearly showing a focus on maximisation of production using imported feeds. According to local experts a level of $14,000 \mathrm{~kg}$ of milk per ha is considered to be self-sufficient for roughage. Total milk production is by far the highest and doubled between 1985 and 2012

Table 3.2 Production characteristics for the four clusters 1985-2012 (x1000 kg)

\begin{tabular}{|c|c|c|c|c|c|c|c|c|c|}
\hline \multirow[b]{2}{*}{ Cluster') } & \multicolumn{3}{|c|}{ milk / cow } & \multicolumn{3}{|c|}{ milk/ha } & \multicolumn{3}{|c|}{ milk/farm } \\
\hline & '85 & $' 12$ & delta \% & ‘85 & $' 12$ & delta \% & '85 & $' 12$ & delta $\%$ \\
\hline 1 & 6.7 & 9.0 & 34 & 14.3 & 17.9 & 25 & 437 & 893 & 104 \\
\hline 2 & 6.8 & 8.3 & 22 & 12.4 & 14.1 & 14 & 346 & 543 & 57 \\
\hline 3 & 6.7 & 7.5 & 12 & 12.2 & 11.9 & -2 & 366 & 622 & 70 \\
\hline 4 & 6.7 & 7.2 & 7 & 12.2 & 10.7 & -12 & 334 & 410 & 23 \\
\hline
\end{tabular}

1) 1-maximising production, 2 -optimising resources, 3 -diversifying production, 4 -end production

The focus on maximising production for Cluster 1 farmers in their PRFM is linked to their strategy over the past 25 years. For the other three clusters the data show a great similarity in the business for the year 1985 while there are clear differences between the clusters in 2012. Starting with 4 farms, ending production, a stable and limited growth for all three characteristics appears. The limited growth in total milk production and number of ha is the result of a policy of the lessor to redistribute milk quota and land among other tenant farms when farms ended their production. The decrease in milk production per ha for Cluster 4 farms shows they have not actively pursued to increase farm production. The focus on ending production for Cluster 4 farms in their PRFM is consistent with long-term farm development.

Both Cluster 2 farms, optimising resources, and farms in Cluster 3, diversifying production, have increased total milk production between 1985 and 2012 with respectively $57 \%$ and $70 \%$. The clusters show a different development looking at production per ha and per cow. Cluster 2 farms, optimising resources, increased the production per cow and per ha to $14,000 \mathrm{~kg}$ per ha and 8,300 kg per cow which fits the strategy of optimisation of available assets. This strategy differentiates Cluster 2 farms from the focus on maximising production of Cluster 1 farms. These data show that the focus of Cluster 2 farms in their pRfM, optimising resources, is consistent with long-term development. 
Cluster 3 farms, diversifying production, combine an increase in total milk production with a decrease in production per cow and per ha. This points to a production strategy with lower production levels per unit, which decreases the pressure on the production units for maximum production. A decreased pressure on maximisation of production per unit increases the flexibility of the business owner to spend time and energy on other activities. The combination of less focus on production per unit and more attention for other activities for Cluster 3 farms is recognised by interviewees. For Cluster 3 farms we can conclude as well that their focus on diversifying production in their pRfM is consistent with the long-term development of their farms.

We can conclude that the coherent and meaningful clusters of farmers, which were found based on their pRfM, were not only clusters at the moment when the questionnaire was answered. There is a clear link with the general development of the farms over a longer period of time.

\section{4) How does pRfM relate to the personal preference of the business owner?}

Table 3.3 presents the cross table with the five groups according to preferred farm strategy and the four business strategies deemed viable. For each group the highest Pearson Chi square value of the opportunities with the specific group is presented. For Croups 1 to 4 these values are all below the value of 0.05 . This is not the case for the fifth group, which can be explained by the fact that the five strategies in this group can be combined with all four business strategies found.

The most preferred way of farming is 'maximising production' with 35 out of 79 farmers. Ending production is the least preferred ( 3 farmers) followed by diversifying production (6 farmers) and optimising resources (17 farmers). The diagonal of Croup 1-Cluster 1 to Croup 4-Cluster 4 represents those 35 farmers whose preferred strategy is the same as the strategy perceived as viable. For 25 farmers, however, there is a discrepancy between the preferred strategy and the strategy perceived as viable. 17 farmers would prefer maximising production as strategy, 7 farmers would prefer optimising resources and 1 farmer would prefer diversifying production. The pRfM measures the strategies that are perceived as viable and this measure is different from measuring the preferred strategy. 
Table 3.3 Farm type preferred by the farmers within the four clusters of dairy farmers according to perceived Room for Manoeuvre

\begin{tabular}{|c|c|c|c|c|c|c|c|}
\hline & & & Cluster & 1 & 2 & 3 & 4 \\
\hline & m strategy preferred & $\begin{array}{l}\text { Pearson } \\
\text { Chi Square }\end{array}$ & Total & $\begin{array}{l}\text { Maximising } \\
\text { production }\end{array}$ & $\begin{array}{l}\text { Optimising } \\
\text { resources }\end{array}$ & $\begin{array}{l}\text { Diversifying } \\
\text { production }\end{array}$ & $\begin{array}{l}\text { End } \\
\text { production }\end{array}$ \\
\hline 1 & $\begin{array}{l}\text { Maximising } \\
\text { production }\end{array}$ & 0.05 & 35 & 18 & 9 & 7 & 1 \\
\hline 2 & $\begin{array}{l}\text { Optimising } \\
\text { resources }\end{array}$ & 0.00 & 17 & 1 & 10 & 5 & 1 \\
\hline 3 & $\begin{array}{l}\text { Diversifying } \\
\text { production }\end{array}$ & 0.01 & 6 & 1 & 0 & 5 & 0 \\
\hline 4 & End production & 0.01 & 3 & 0 & 0 & 1 & 2 \\
\hline 5 & $\begin{array}{l}\text { Other opportunities } \\
\text { chosen }^{2)}\end{array}$ & 3) & 18 & $9^{1)}$ & $2^{1)}$ & 3 & 4 \\
\hline & Total & & 79 & 29 & 21 & 21 & 8 \\
\hline
\end{tabular}

1) including 1 missing value ${ }^{2)}$ opportunities which can be combined with all four clusters ${ }^{3)} 0.25 / 0.22 / 0.32 / 0.93 / 0.42$

\subsection{Discussion}

The analytical conceptpRfMallows to differentiate between family dairy farmers in their perception of the viability of opportunities for farm development. Using the analytical concept meaningful, coherent and consistent clusters were found that reflect different patterns of farm development. This section will discuss the usefulness of the analytical concept to study strategic decision-making in small businesses. The first question is on possible limitations of the methodology used followed by the question about the validity of the results outside the context of the case study. The central question is how the findings of this study affect the theoretical understanding of SDM. Additionally the results are discussed in relation to the question how and why opportunities are identified in the context of family dairy farming. The results offer the chance to discuss opportunity identification in the specific context of family dairy farming.

\section{Survey data collection}

The exceptional high response rate of $80 \%$ is likely to be related to the ethnographic study of the case study area in the first phase of the research. This allowed for the design of the questionnaire to use the wording that connects to the every-day reality of the farmers. Using local experts it was possible to analyse the $20 \%$ non-respondents resulting in the conclusion that the non-respondents were not markedly different from the respondents. Two minor issues can be raised regarding the questionnaire: 1) does the person who answers the questionnaire represent the actual decision maker? 
and 2) are the answers on viability of opportunities influenced by presenting a list of opportunities? Regarding the first question, family dairy farms predominantly have shared management with one or more family members. Different persons active in management may differ in their perceptions on viability of opportunities for farm development, especially when management is shared between different generations. The covering letter for the questionnaire specifically noted that the questions were meant for the person most involved in SDM. However this cannot be guaranteed. Nevertheless, the overall consistency of the results supports the validity of the answers given. The second question is whether presenting a list of opportunities may have affected the answers given. To ensure that the list represents 'the total playing field' of dairy farm development the questions were based on the explorative, ethnographic study of the context of dairy farming in Kampereiland in Phase 1. The questionnaire was discussed and tested with both experts and farmers. The blank option presented to the farmers did not bring forward opportunities outside the list of opportunities presented.

\section{Generalizability in a broader context}

The first question is whether the results can be generalized for family dairy farmers outside Kampereiland. In interviews with both dairy farmers and stakeholders of dairy farming, the results were deemed to be plausible in general for family dairy farming. The next question is on the generalizability for small businesses in general. In small businesses a very broad range of different sectors can be found, each with very different characteristics. Dairy farming as small business is characterised by working with natural resources, living animals and a capital intensive infrastructure which gives them a high resource dependency (Bjerke 2007, 75). The capital intensive infrastructure leads to a strong connectedness of dairy farms with the production location, it is not easy to move the business to another location. Dairy farming is therefore a specific type of small business and the results need to be interpreted with these characteristics in mind. However, there is no clear reason why the influence of the owner-manager's perception of opportunities for SDM would be different in a different sector. Testing the analytical concept pRfM in a different context of small businesses would be interesting. It would require an operationalisation that is fitting to the specific context of those small business owners.

\section{The analytical concept pRfM}

The central question of this paper is whether the analytical concept pRfM allows to study the role of the individual business owner's perception of opportunities for SDM. Overall, the results in Table 3.1 and the interviews with respondents and stakeholders show that the pRfM allows for a meaningful, coherent and consistent way of 
distinguishing between small business owners in their pRfM. All dairy farms in the case study operate in comparable environmental conditions. Therefore, the differences in pRfM are related to either differences in the farmers' perception of the context or to differences in the situation of the farm. And the latter, the differences in the situation of the farm, are related to the decisions made by (the predecessor of) the farmer while operating in comparable context. The differences between dairy farms in this study were therefore strongly related to differences between the farmers. The pRfM therefore allows a distinction to be made between business owners in their perception of the viability of opportunities. This means that the analytical concept offers a tool to identify differences between business owners in their perception of their opportunities and thus allows for a further study on the relation with other characteristics of the business and/or the business owner. More knowledge on why business owners differ in their pRFM can increase the understanding of SDM in small businesses. An interesting avenue for further research is to investigate the aspects that drive the differences found between business owners and to study how the differences in pRfM are related to the embeddedness of the business in the context in which it operates.

The theoretical contribution of the analytical concept pRfM to literature on SDM is the focus on the importance of the perception of the owner-manager of the opportunities for business development in the early phase of the decision-making process. The pRfM spans the 'room for manoeuvre' for business development as perceived by the business owner. When more opportunities are deemed viable, it leads to an increase in the pRfM. However, this is not necessarily a reason to change the business strategy. Especially not when the preferred strategy is successful in providing income. In theory there is no need for the pRfM to contain more opportunities than the one preferred. However, when the pRfM contains more than one business strategy the resilience of the business is better A business is more likely to be able to absorb changes in the market or in the business situation when it has more than one opportunity for business development (Darnhofer et al. 2010). When the pRfM contains more than one opportunity the business owner has a larger freedom in making a decision about the business strategy to follow. The pRfM is not staticand so new opportunities for a business strategy may be added to the pRFM. The combination of the preferred strategy with the pRfM may provide a theoretical approach to explain why small business owners do or do not change their business strategy.

The analytical concept pRFM is of practical use as it allows the pRfM of business owners to be measured and thus to identify different subgroups of business owners based on their pRfM. Measuring the pRfM in the early phase of designing a policy or support programme is useful for gathering information about the perspective of the business owners regarding their opportunities for business development. Measuring 
changes in the pRfM after a policy is implemented or a support programme has finished can be useful for monitoring the effects. It may take several years before the effect of changes in business strategies are seen in practice.

\section{Opportunity identification in the context of dairy farming}

The aim of this study is to test the usefulness of the analytical concept pRfM. The data can be interpreted from the viewpoint of 'how' and 'why' opportunities are identified in the context of family dairy farming. For the question how opportunities are identified, the discussion in the literature focuses on either opportunity discovery or opportunity enactment (Gartner et al. 2003). The pRfM implicitly assumes that a general opportunity for business development becomes a concrete opportunity as a result of a sense-making process. In the perspective of the pRfM, opportunities are enacted by the business owner. The validity of the pRfM in this study supports the assumption that opportunity identification in family dairy farming is a process of enactment. The assumption is further supported by the clear reasoning on the viability of the different opportunities for farm development shown by the farmers in the interviews. All opportunities presented were acknowledged as existing, yet not all opportunities were assessed as viable for their specific situation (third-party versus a first-party opportunity, McMullen and Shepherd 2006). The farmers named different aspects as important in the sense-making process, varying from economic to personal reasons. In the context of family dairy farming, opportunities are assessed in the light of the current situation and the farmer's goals. When this leads to a positive perception then an opportunity becomes a 'real' opportunity for the farm in its own situation.

The data on pRfM in relation to the preferred opportunity (Table 3.3) provide an insight into the question as to why opportunities are identified. Only six farmers preferred diversification as strategy, whereas 52 farmers preferred a full focus on dairy farming. Within these 52 farmers 35 preferred a focus on maximisation of production. In the context of Kampereiland the conditions for a full focus on maximisation of production are not optimal due to nature and landscape restrictions. The focus on maintaining dairy farming as core production is dominant. Opportunities for farm development are predominantly assessed on their contribution to obtaining an income by dairy production. This confirms other studies on the guiding factor to change the business strategy, revealing that personal motivation to look outside the dairy sector is not the most important factor (Vik and McElwee 2011). So when farmers do consider opportunities that lie outside of their personal preference, this is driven by a need to change the strategy (push) rather than a desire to change the strategy (pull). In agriculture, the shift towards diversification is seen as a shift towards 
more entrepreneurial behaviour (Grande et al. 2011), though for small businesses in general, diversification of production is found to indicate a survival strategy (Robson et al. 1993). The context of dairy farming is likely to have affected this finding due to: 1) path dependency (Wilson 2008), 2) the lack of urgency for a critical assessment due to protected markets (McElwee and Bosworth 2010) and 3) the primary focus on improving current conditions rather than exploring new ideas (Haugen and Vik 2008; McElwee 2006; Morgan et al. 2010; Vesala and Vesala 2010).

\subsection{Conclusions and outlook}

The analytical concept pRfM has proven to be useful for distinguishing business owners based on their perception of the viability of business strategies. The pRfM has three dimensions in which business owners differentiate: 1) diversifying production; 2) ending production; and 3) maximising production. Using these three dimensions, four clusters of business owners were found: 1) maximising production; 2) optimising resources; 3) diversifying production; and 4) ending production. The clusters proved coherent and meaningful from the perspective of business owners and stakeholders. The clusters are as well consistent with the characteristics of the long-term development of the businesses in the cluster. The pRfM proved to be different from just measuring the business owner's preferred strategy. This conclusion leads to the question which driving factors can explain the differences found and how differences in the pRfM are related to differences in the embeddedness of the farmers in the context in which they operate. More research is needed to further develop the theoretical and explanatory potential of the analytical concept pRfM in relation to SDM. One step would be to develop the analytical concept into a tested measure and another would be to include the relation with the preferred business strategy in the framework.

Regarding the practical importance, a better understanding of drivers for differences in the pRfM is useful in the design and evaluation of policies and support programmes on small business development. Due to the connection with the location, small businesses are an integral part of the area in which they are located. This is particularly true when the businesses use capital-intensive production factors linked to a specific location such as buildings and land. In such a situation the development of the businesses affects the development of the area and vice versa. For the design of effective support programmes it is important to understand the driving factors in the decisionmaking process regarding business strategies, especially when the aim is to stimulate diversification of small business development that involves new business strategies. 


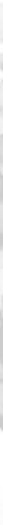
bet rom 


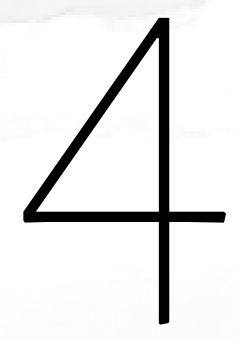

\section{Drivers for differences in farmers' perception of opportunities for farm development}





\section{Abstract}

Nature and landscape are increasingly appreciated as public goods and community assets in need of protection. Policy schemes aiming to protect vulnerable nature and landscape assets affect opportunities for farm development and thus the opportunities for farm income strategies. Farmers as small business owners need to counter an ongoing income squeeze in their strategic decision. Farmers' perception of the opportunities affects strategic decision-making. In a case study with dairy farmers operating in a highly comparable socio-material context, farmers differed in the perception leading to three main income strategies: 'maximising' or 'ending' of milk production and 'diversification of farm business' with the most dominant strategy being 'maximising'. Multiple regression analysis was used to explore the significance of seven drivers for the differences between farmers' perception of farm development opportunities. The 'personal views and preference' is the most significant explanatory driver for all three income strategies. 'View on markets' is of less significance and 'view on urban-rural relation' is not significant in explaining differences between farmers. 'Maximising' and 'diversifying' are opposites in their drivers. To increase the effectiveness of policy schemes and support programmes, personal views and preferences of farmers need to be taken into account.

This chapter is published by Local Economy as:

R.G. (Ron) Methorst, D. (Dirk) Roep, F.J.H.M. (Frans) Verhees and].A.A.M. (Jos) Verstegen Drivers for differences in dairy farmers' perceptions of farm development strategies in an area with nature and landscape as protected public goods. Local Economy 31(5) 554571, DOI: $10.1177 / 0269094216655520$ 


\subsection{Introduction}

This paper studies the drivers for differences between dairy farmers' perception of the viability of opportunities for farm development to support a substantial part of farm income. Economically healthy farms are important for the local economy yet not all farm development opportunities are positive for the development of vulnerable public goods which are seen as local community assets. Opportunities for farm development like scale enlargement and specialisation negatively affect landscape and biodiversity values (Marsden 2003; Wiskerke and Roep 2007). Developments in the sector and the market may oppose the interest of the local surroundings creating a challenge for the farmer in the selection of a strategy.

Farm development has always affected and has always been affected by the context in which it operates, both in the past and in modern times (Bieleman 1987; Feola et al. 2015). As a result of agricultural modernisation that stimulated specialisation, intensification and scale enlargement, production increased dramatically in the second half of the 20th century (Ploeg and Roep 2003). The process of agricultural modernisation was actively stimulated by the government (Lowe et al. 1993; Ploeg 2003; Wals et al. 2012; Grin 2012). Modernisation allowed farm production to bypass the limitations of locally available resources and the presence of local markets. Modernisation of agriculture has been highly successful in increasing production; however, there were negative effects as well. Scale enlargement and intensification of agricultural production had a negative impact on environmental quality and landscape and biodiversity values (Knickel 1990; RIVM 2002; Marsden 2003; Wiskerke and Roep 2007; Primdahl and Kristensen 2011; Wästfelt et al. 2012) and also resulted in a growing tension in sociocultural sustainability, especially for animal production systems (Boogaard et al. 2011). The location of the farm became an address for production, loosening the connection between product, production and location. These processes have been described as dis-connecting, dis-embedding and dis-entwining of food production (Wiskerke 2009). In many regions the farmer is expected to take into account the quality of the landscape in making decisions on farm development which easily creates tensions with the dynamics in farm practices (Wästfelt et al. 2012). Especially in regions with high natural or cultural-historical value, or areas close to urban areas, the traditional growth path of farms is confronted by changing societal demand. Alongside scale enlargement and intensification farmers have developed new services and functions of rural areas for urban dwellers (Roep 2000; OECD 2006; Horlings 2010). New value chains have been developed based on regional products 
and on the characteristics of the farm and the rural context such as farmers' markets, care and recreation (Potter and Tilzey 2005; Oostindie 2015). These new value chains are also a response to the 'cost price squeeze': an increase in the cost of the resources and a decrease in the price of the products delivered by the farm (Ploeg 2000).

For a farmer, the development of new value chains and new products and services (diversification of farming) increases the number of possibilities for farm development. This further means that the process of strategic decision-making (SDM) is of increased importance to balance the various interests and needs. For this paper we draw on literature on SDM in small businesses to study its application in farm development. 'Strategy' is defined in this study as 'a choice out of available routes and means in order to realise a goal' (Encyclo 2012). Family farms share important characteristics with small businesses, as the farm is an independent business, managed by its owner or part owners and has a small market share (Culkin and Smith 2000). Farmers operate like small business owners in a complex combination of tasks and responsibilities because they need to combine the entrepreneurial, managerial and technical role as a craftsman (Chandler and Jansen 1992). Farmers personally learn from the experience of running the farm, as do small business owners (Atherton 2003). This paper answers the call made in the literature to pay more attention to the contextualisation of entrepreneurship by studying entrepreneurship in connection with the context of the everyday and real life situations of business owners (Bjerke 2007, 31; Johannisson 2011; Watson 2013).

In rural areas large parts of the land are in use by farmers (Berkhout and van Bruchem 2006), making farmers important stakeholders in regional development (Lauwere et al. 2006). Policy schemes and development programmes of local governments influence business development, e.g. by supporting the diversification of small business (Liberman-Yaconi et al. 2010) or in the adaptation to changes in the environment (Feola et al. 2015). Policies and support programmes are important for rural economic development which aims for a sustainable land use, a key challenge for rural areas (Woods 2012). However, the final strategic decision for the development of a farm is made by the farmer in the role of owner-manager who has an autonomous position in decision-making (Culkin and Smith 2000; Pietola and Lansink 2001; Jocumsen 2004; Hang and Wang 2012). This means that in order to be effective, policies and programmes need to connect to the 'world' of the decision maker (Pietola and Lansink 2001). Therefore it is important to understand how farmers' strategic decisionmaking is related to the socio-material context in which the farm operates (Korsgaard et al. 2015). SDM by the farmer takes place in a complex system and needs to be 
studied in an integrated way; it is not a purely economic driven decision (Hansson and Ferguson 2011; Welter 2011; McKeever et al. 2015). SDM in the context of small business is complex and heterogeneous which makes it less predictable than, and different from, SDM in large business (Jocumsen 2004; Liberman-Yaconi et al. 2010). SDM in small business does not necessarily follow economic logic (Farmar-Bowers and Lane 2009; Custafsson 2009) and is influenced by the personal characteristics of the ownermanager (Begley and Boyd 1986; Jocumsen 2004; Liberman-Yaconi et al. 2010; Curseu et al. 2008, 42). However, studying the personal characteristics in relation to business strategies is complex as the same strategy can be followed by owner-managers with different characteristics (Bjerke and Hultman 2002, 66). Looking more closely at SDM in the context of small business, it is known to be an iterative process of informing, option generating and deliberating that starts at the moment decision-making is triggered (Jocumsen 2004; Liberman-Yaconi et al. 2010; Hang and Wang 2012). The small business owner's perception of the situation has been found to be more decisive for the outcome of SDM than formal analyses (Parnell et al. 2000; García-Pérez et al. 2014). The perception of entrepreneurial opportunities is affected by the environment in which a small business operates (Sutcliffe and Zaheer 1998; Yanes-Estévez et al. 2010). This means that at the start of a SDM process, the owner-manager already has a perception of the opportunities for business development, the 'room for manoeuvre'

To study the differences between owner-managers' perceptions of the opportunities for business development, we designed the analytical concept perceived Room for Manoeuvre (pRfM). We defined the pRfM as 'the opportunities perceived as viable in order to obtain a (substantial part of) business income' (Methorst et al. 2016). The label 'perceived Room for Manoeuvre' was chosen as it connects closely to the real life world of the farmer as entrepreneur deliberating about the question: 'what are my opportunities, what is my room for manoeuvre'. Based on the pRfM, the farmer assesses the opportunities deemed viable as an input for strategic decision-making. The pRfM may include opportunities that might be viable, yet are not preferred by the farmer Continuation of current activities is seen as an opportunity as well, as it can be perceived as a way to realize the goal. In the context of a farm as a running business, opportunities may include the adaptation of ideas and opportunities already in practice on other farms. The pRfM was tested in the context of family dairy farming operating in a highly similar socio-material context. Significant differences between farmers were found (Methorst et al. 2016). The farmers differed in three dimensions (or income strategies) of the pRfM: (1) 'diversifying'; (2) 'ending'; and (3) 'maximising' production. Using twostage cluster analysis for the scores on the three dimensions, four clusters (or patterns 
of farm development) of farmers were found. These patterns of farm development proved to be coherent in their characteristics, consistent over a longer period of time and they were meaningful to stakeholders in dairy farming. This means the pRfM appears to act as a pre-filter for farmers in their selection of opportunities for further assessment in the SDM process. The analytical concept pRfM thus allows farmers to be distinguished in their perceptions of opportunities for farm development. This opens the question on the drivers behind these differences in pRfM. Understanding these drivers is of practical relevance for the design and implementation of policies and support programmes for small business development. In this paper we use an empirical study in the context of family dairy farmers. Dairy farming faces structural changes that increase the importance of SDM due to liberalisation and globalisation of the markets (Clark 2009; Hansson et al. 2010)

In the theoretical background, we describe the analytical framework for this study followed by the methodology section which presents the characteristics of the case study, the operationalisation of the framework and the statistical methods used for data analysis. The results and the discussion section will show that the driver 'personal view and preference' plays an important role which has important implications for future policy making.

\subsection{Theoretical background of pRfM and the drivers}

The heterogeneity in farm development in relation to the context in which the farmers operate is described in literature on farming styles (Long and Ploeg 1994; Ploeg 2003; Ploeg and Ventura 2014). Farming styles research has shown that the explanation for the existing heterogeneity in farm development cannot be reduced to 'external' structural forces such as 'markets' or 'nature' impacting on farming, even when these are mediated by capable farmers into all their farming practices and decisionmaking. The socio-cultural embeddedness of farmers, their shared values and norms and how they see themselves as 'a farmer' or like to be seen do matter significantly in explaining different farm development strategies and result in different patterns of farm development. The farmer has agency, a room for manoeuvre, to act within the structures that confine the choices. Or, as described in an article on the resilience of family farms (Darnhofer et al. 2016, 116): 'the structures - both on- and off-farm, both material and social-constrain choices. But their influence is mediated by farmer's beliefs, and the potentials farmers perceive in a dynamically changing context'. The agency of the farmer, the 
room for manoeuvre, is the centre of the pRFM. The analysis of the pRfM by the business owner, the viability of the opportunities for business development, is influenced by the business owner's perception. This perception is influenced by dominant paradigms, lock-in effects and path dependencies (Vanloqueren and Baret 2009; Lamine et al. 2012; Cowan and Cunby 1996). pRfM is an operationalisation of the concept 'evoked set of opportunities' which is defined as 'the full set of possibilities perceived as (entrepreneurial) opportunities by a decision maker' (Krueger et al. 2009, 122). We use as the definition of entrepreneurial opportunities: 'feasible means to obtain benefits for the firm' (Hansen et al. 2011, 14). The pRfM is related to the strategic awareness capability which is defined as the process of continuously improving how one identifies and conceptualises one's own world, recognises events in this world, interprets these events and makes decisions for appropriate action to achieve positive business outcome' (Hannon and Atherton 1998, 112). To construct our analytical framework we used a combination of a literature study and an exploratory study in the context of the case study. The latter is relevant to connect entrepreneurship research to the real life context (Bjerke 2007, 31; Watson 2013; Johannisson 2011). The resulting analytical framework has seven drivers which reflect the subjective perception of the farmer.

The first driver is the personal view and preference: how owner-managers view themselves and their preferences (Farmar-Bowers and Lane 2009), their personal motivations (Alsos et al. 2003; Vik and McElwee 2011) and self-conceptualisation (Burton and Wilson 2006). The second driver is personal development, consisting of education level (Jongeneel et al. 2008; Carter 1998), experience (Hansson and Ferguson 2011) and networks of the owner-manager (Granovetter 1973; Clark 2009; Thornton et al. 2011; Ferguson and Hansson 2015). The third driver is view on entrepreneurial competences relating to the business strategy (Bergevoet 2005; Bergevoet et al. 2004; Lans et al. 2011). The fourth driver is the view on continuation of the firm. In familyowned business the influence of the family is important for the owner's view on continuation (Gasson et al. 1988). The fifth driver is view on current business situation, based on material resources (Shucksmith and Herrmann 2002) and path dependency as a result of earlier selected strategies (Clark 2009). The sixth driver is the view on market development, that is whether and how the market is expected to change (Shucksmith and Herrmann 2002; Hansson and Ferguson 2011). The seventh (and last) driver is the view on urban-rural relation. The change in societal views over the last few decades on the urban-rural relation and the role of agriculture have created a market for diversification strategies (Atterton and Ward 2007), especially in peri-urban situations (Zasada 2011). 
The seven drivers of $\mathrm{pRFM}$ span a wide range of influencing factors as it is based in the real life context. The farmer's perceptions of these seven drivers influence his subjective view on the situation of his farm, this in turn influences his SDM process. The pRfM is not static, pRfM evolves with changes in the situation of the business and the owner-manager. The three income strategies which were found in the pRfM reflect possible development and not necessarily actual farm development. In other words, it is a measure of opportunities perceived as viable. Opportunities perceived as viable are however not necessarily put into practice (Zwan et al. 2012).

\subsection{Methodology}

This section describes the characteristics of the case study, the operationalisation of the seven drivers of pRfM and the methods used for data analysis.

\section{The case study}

The value of Kampereiland as the case study is the highly comparable situation in which all dairy farmers operate. Differences between farms are therefore more likely to be the result of differences between the farmers. The context of a farm does affect farm development, for this reason the context of farming in the case study area needs to be described.

Kampereiland ('the island of Kampen') is a river delta where the river IJssel meets the lake IJsselmeer, which was created when the former sea was closed by a dam in 1932. The town of Kampen owns the islands in the river delta since 1363. Using land reclamation techniques, the amount of land was expanded to around 4,000 ha of agricultural land and 800 ha water, roads and nature areas. The main activity is dairy farming (102 of the total $108 \mathrm{farms}$ ). The isolation aspect of being an island is no longer a physical reality due to bridges and two new polders in the former sea. The history as an island has, however, influenced the culture and identity of Kampereiland, even though the town of Kampen was less than $10 \mathrm{~km}$ away. The 600 people have good social connections with an active community centre, a church, a primary school, a quarterly journal and various social and leisure groups. A yearly harvest festival is organised around the museum farm and attracts thousands of visitors. The former coastal areas were designated as Natura 2000 nature reserves (2011) and Kampereiland became part of a National Landscape (2005) due to its characteristic Dutch river delta landscape influenced by centuries of farming. 
All farms are tenant farms with the town of Kampen as the lessor. The lessor's policy is to take care of the 'heritage of our fathers' using four guiding principles: 1) retain property of Kampereiland; 2) obtain a reasonable financial return; 3) take care of nature and landscape values; and 4) conduct a loyal tenancy policy. After an increase to 170 in the 1950 s when around 60 new farms were built, the number of active farms decreased to 108 in the year 2012 (of which 102 dairy farms). A farm has on average around 45 ha in use including land owned or rented outside of Kampereiland. The tenancy situation affects the land market in Kampereiland as there is no free land market. To buy land the farmer needs to go to neighbouring areas $(5+\mathrm{km})$. The economy of the farms in Kampereiland strongly relies on dairy farming, though farm income is often supplemented by an off-farm job by the farmer or a family member. Dairy farms in Kampereiland until the 1980s were known for their larger than average size and high economic return; however, the development of farm income in Kampereiland became worrisome in the last decade (Duitman 2005; Methorst 2013). There are no organic dairy farms at the time of the survey and fewer than 10 farmers are engaged in diversification of their farm. The milk is delivered to (inter)nationally operating dairy organisations, mostly cooperatives.

The policies and legislation concerning the two Natura 2000 areas and the National Landscape affect the development potential of dairy farming in Kampereiland. To support the sustainable development of Kampereiland, the lessor developed a programme aiming to support long term economic viability of the farmers while strengthening the nature and landscape values. Dairy farming in Kampereiland is affected as well by national and supranational legislation on environment, animal health and animal welfare. The abolishment of the European Union milk quota system in 2015 is expected to lead to scale enlargement and specialisation of production in Dutch dairy farming (Meulen et al. 2012). The change in EU dairy market policies has increased price volatility while accessibility of capital for investment decreased due to the financial crisis. The combination of the developments in the context of the dairy farm increase the economic challenge for dairy farmers in the development of their farm.

The uniqueness of the case study is the highly comparable context of the farms in the case study area, which allows the study of differences between individual farmers. An important question is to what extent will the specific context of this case study affect the results in such a way that it limits their general validity. The Kampereiland case study is in many aspects a 'normal' area with specialised dairy farmers. For people who are not aware of this specific context, it will look like an 'ordinary' Dutch dairy farm 
region. Two aspects are specific for the case study: 1) all farmers are tenant farmers, and 2) there is no free land market in the direct surroundings of the farms as the lessor owns all the land. This situation does affect farm development opportunities for the farmers in the case study, yet it does not necessarily limit the general validity of the findings. Firstly, this study does not aim to compare the effects of a specific condition in the context on the perception of development opportunities. The aim is to understand the differences between farmers operating in a comparable context. Secondly, the clusters of farmers that were identified were acknowledged by the stakeholders as being valid for dairy farming in general. There is therefore no reason why the results would not represent general (Dutch dairy) farming.

\section{Operationalisation of $\mathrm{pRfM}$ and the drivers}

The main analytical concept pRFM was defined as: 'the opportunities perceived as viable in order to obtain a (substantial part of) farm income.' The pRfM was operationalised by listing 15 opportunities of farm development that are known as routes for farm development in Dutch dairy farming in general and in the case study area in particular. The opportunities for farm development are grouped as follows (opportunities may be combined on the same farm):

$\begin{array}{ll}\text { Dairy production system } & \begin{array}{l}\text { intensive, extensive, certified } \\ \text { organic } \\ \text { care, recreation, farm shop, dairy } \\ \text { processing }\end{array} \\ \text { Diversification - people oriented } & \begin{array}{l}\text { energy, nature, other company, } \\ \text { off-farm job }\end{array} \\ \text { Diversification - not people oriented from other source } \\ \text { End to dairy production } \\ \text { Other } & \begin{array}{l}\text { Joint farming, relocating the } \\ \text { farm, other option }\end{array}\end{array}$

A 16th, blank, option was included to allow farmers to introduce opportunities not yet named; however, this did not lead to new opportunities outside of the 15 listed. Respondents were asked to indicate on a Likert scale from 1 to 5 for each option their perception on the viability of the option in their situation, the so-called 'firstperson opportunity' (McMullen and Shepherd 2006). The seven drivers influencing the pRfM were operationalised in the context of the case study using a set of questions for each driver in the questionnaire with a 5-point Likert scale ('certainly not agree' 
to 'certainly agree'). The questions were carefully phrased to make the question and answer independent from the specific situation of the farm(er) and to make sure the respondents would not be faced with inconsistencies in the questions. The questions were designed in such a way that a farmer should be able to respond without needing extra information from sources apart from his own operational knowledge. In the creation of the questionnaire expertise was used from experienced sociologists, an expert in questionnaire development and from an independent advisor active in Kampereiland. The questionnaire was tested by two dairy farmers situated close to Kampereiland. The total questionnaire consists of 95 questions and would take between 40 to 60 minutes to complete. The questionnaire was designed as a booklet in order to give it an attractive appeal. The questionnaire was both printed and available on the internet leaving the choice to the farmer which one to use. Each farmer received a personalised printed version of the questionnaire including an individual code and password to be used for the internet version of the questionnaire. Next to the printed version by mail, all farmers also received a personalised e-mail with a direct link to the internet version of the questionnaire.

The results were analysed using Principal Component Analysis (PCA); this allows sets of questions to be determined which are related and can be combined in one measure. To establish the number of factors to be retained we used Eigen values and the suggestions of the scree plot in combination with an analysis on the theoretical sound and reliable interpretation of the factors. To facilitate interpretation of the factors, the factor solution was rotated. The resulting set of measures alongside individual questions are presented in Table 4.3 (including the number of questions, the variance accounted for, and the reliability of the measure using Cronbach Alpha value (Field 2009)). The reliability of the two measures for networks (driver 2, personal development) was low, likely due to the similar socio-cultural situation leading to small differences between farmers. This means it is not possible to differentiate for networks between respondents in a highly reliable manner (Cronbach Alpha values of .48 and .33). However, as these measures are the best estimate available and the analytical framework aims to represent the real life context, they were included in the analysis. The PCA on the questions on competences showed goal-orientedness as the primary measure and analysing, networking and pursuing as secondary, meaning these three will be correlated. This correlation means it is hard to determine the individual effect of each of the three measures. However, as the measures are based on literature (Lans et al. 2011) and the statistics are good (Cronbach Alpha values of .83, .71, .82), the measures for the three competences were used in the analysis. 


\section{Data analysis}

The questionnaire was sent to all 102 dairy farmers resulting in 78 completed questionnaires. The 24 non-respondents were deemed to be similar to the respondents by local experts. Using multiple regression analysis, we studied the contribution of each driver as part of the total model. The dependent variables are the three dimensions of pRfM: 'diversifying', 'ending' and 'maximising' of production (Methorst et al. 2016). As independent variables we used the 22 variables which represent the seven drivers for the pRfM (Table 4.3). Stepwise regression (F-change analysis) was used to determine the explanatory value of each of the 7 drivers in the total model. In this analysis the explanatory variables of a specific driver are both included and excluded in the regression model to establish the change in F-value as a result of adding this set of explanatory variables. F-change analysis is used to determine the contribution of each of the seven drivers to the explanatory value of the model. To determine the influence of each of the 22 individual independent variables, the Beta value of each variable resulting from the regression analysis is used (see Table 4.3). The analytical framework spans a large range of variables as it reflects the complexity of real life for an entrepreneur. This results in seven drivers which are described by 22 independent variables which are used in the regression analysis. To test whether multiple regression analysis is an appropriate tool in this setting (22 independent variables and 78 cases), we performed extensive testing on the assumptions for the use of multiple regression analysis: (1) multicollinearity: a VIF value of 10 for an individual variable indicates a possible problem; (2) independence of the Standardized residuals: the Durbin-Watson statistic needs to be between 1 and 3 and close to the value 2; (3) effect of outliers: max $5 \%$ of the cases may have a value of the standardized residual above 2 and $1 \%$ above 2.5; and (4) the effect of influential cases on the model: Cook's distance needs to be smaller than 1 and DFBeta value needs to be within the range of -1 to +1 (based on Field 2009, 214-224). The results showed a positive result for the assumptions. The regression analysis for the three dimensions resulted in a relative large standard error as part of the regression model, and this can be interpreted as a confirmation of considerable variance between the respondents. This is important as the farmers are operating in a highly comparable context. A small standard error would indicate a high degree of predictability of farm development due to small differences between the farmers in their answers. This in turn would indicate that farmers share their rationale which points towards a strong external influence on the farmers' views, indicating that all farms react in a similar way to the environment in which they operate. In reverse reasoning, the combination of a relative small sample size with the relative high 
standard error in the regression models combined with the high coherency in the quantitative and qualitative results indicates that the farmers operate in the same, highly comparable context, yet operate as independent individuals.

\subsection{Results}

The three regression models proved highly significant (at 0.001 or less) in explaining the differences between farmers in all three dimensions of perceived room for manoeuvre (pRfM). Significant effects are found for the dimension diversifying (with an F-change of 2.98), for the dimension ending (3.81) and for the dimension maximising production (3.18). The statistics to test for the assumptions are all within the acceptable range (see Table 4.1 for results).

Table 4.1 Regression models for the three dimensions of perceived Room for Manoeuvre

\begin{tabular}{lllllllll}
\hline Dimension of pRfM & R2 & F-change & Sig & $\begin{array}{l}\text { Durbin- } \\
\text { Watson }\end{array}$ & $\begin{array}{l}\text { Cook's } \\
\text { dist (max) }\end{array}$ & $\begin{array}{l}\text { DFBeta } \\
\text { min }\end{array}$ & $\begin{array}{l}\text { DFBeta } \\
\text { max }\end{array}$ & $\begin{array}{l}\text { \# cases St } \\
\text { Resid }>2\end{array}$ \\
\hline 1 Diversifying & 0.544 & 2.983 & 0.001 & 2.186 & 0.129 & -0.71 & 0.75 & 1 \\
2 Ending & 0.604 & 3.806 & 0.000 & 1.818 & 0.252 & -1.00 & 1.00 & 1 \\
3 Maximising & 0.560 & 3.179 & 0.000 & 1.837 & 0.256 & -0.97 & 0.94 & 0 \\
\hline
\end{tabular}

$\mathrm{df}_{1} 22, \mathrm{df}_{2} 55$

The only driver that is significant for all three dimensions and the most important for all three is personal views and preferences (F-change values are the highest for all three dimensions (resp. 2.62, 4.91, 3.71, see Table 4.2 for complete results). For 'diversifying', the only other significant driver is personal development (2.08), this shows that the perception of 'diversifying' as an option is mainly related to the personal views and development of the farmer. For 'maximising' the other significant drivers are: view on own competences, view on current farm situation and view on markets (resp. 2.70, 1.89, 2.48). This shows that the drivers for 'maximising' clearly differ from 'diversifying', Looking at 'ending', the other drivers we see besides personal views and preferences are view on continuation/family in combination with personal development and view on current farm situation (resp. 4.41, 2.23, and 2.47). The perception of ending the farm as an option is most influenced by the current farm situation and the view on the continuation of the farm. Looking specifically at the driver view on continuation/family, we see (higher F-change value for 'diversifying' as for 'maximising') that the view on continuation 
and the connection with the farmer's family is more of importance for 'diversifying'. However, neither value is significant. Notable as well is that the driver view on urbanrural relation is the least important in the total set of drivers, being the only one that is not significant for any of the three dimensions. Next to the term 'driver', this chapter uses as well the word 'determinant' for the influencing factors. The word determinants describes the influencing factors from a statistical analysis viewpoint.

Table 4.2 F-change values for seven determinants of influence on the three dimensions of perceived Room for Manoeuvre of dairy farming

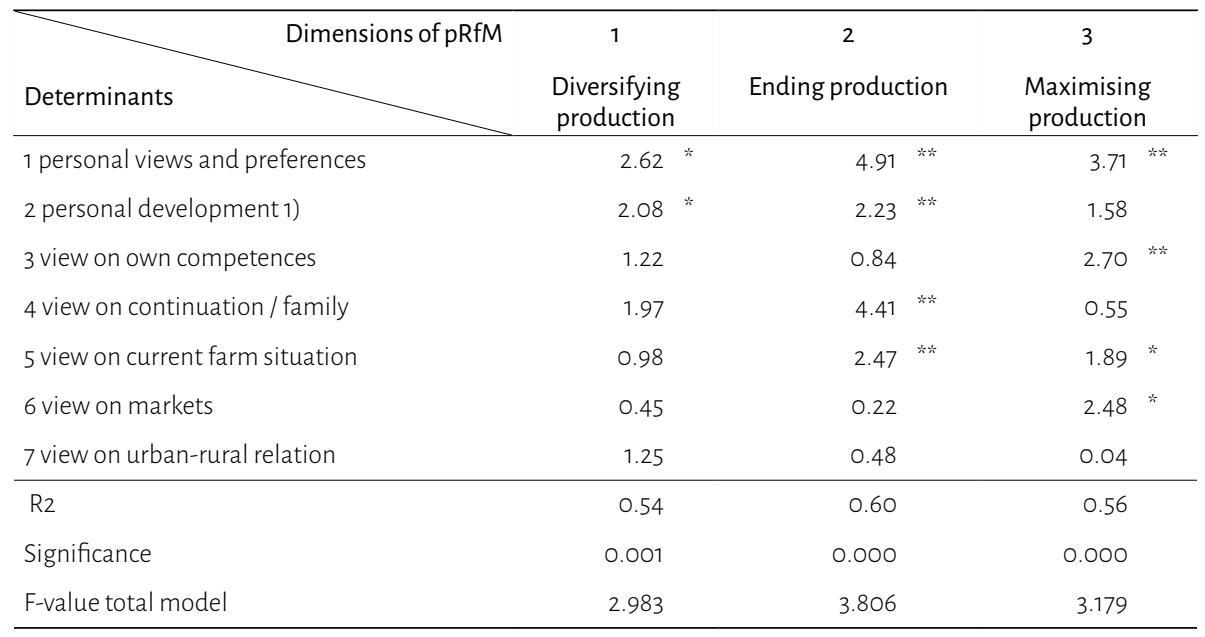

${ }^{*} \mathrm{p}<0,10{ }^{* * *} \mathrm{p}<0,05^{1)}$ education, experience, networks

The correlations between the 22 independent variables and each of the three dimensions offer a closer look at the differences between the dimensions (the Beta values, see Table 4.3).

Table 4.3 Beta values regression models on three dimensions of perceived Room for Manoeuvre

\begin{tabular}{|c|c|c|c|c|c|c|c|}
\hline & Dimensions of & 1 & 2 & 3 & & & \\
\hline $\begin{array}{c}\text { Determinants } \\
\text { Variables }\end{array}$ & & $\begin{array}{l}\text { Diversifying } \\
\text { production }\end{array}$ & $\begin{array}{l}\text { Ending } \\
\text { production }\end{array}$ & $\begin{array}{l}\text { Maximising } \\
\text { production }\end{array}$ & $\begin{array}{c}\text { No of } \\
\text { questions }\end{array}$ & $\begin{array}{l}\text { Variance } \\
\text { acc. for }\end{array}$ & $\begin{array}{c}\text { Cronbach's } \\
\text { Alfa }\end{array}$ \\
\hline
\end{tabular}

1 personal views and preferences

I want to be part of the top $10 \%$ dairy farmers

Dairy and nature should be separated

I find nature on my farm important

$\begin{array}{cccc}.03 & -.34 * * & .23 * & 1 \\ -.29 * * & -.24 * & -.37^{* * *} & 1\end{array}$

$\begin{array}{llllll}.15 & .05 & -.07 & 4 & 57 \% & 0.75\end{array}$


Table 4.3 continued

\begin{tabular}{|c|c|c|c|c|c|c|c|c|}
\hline \multirow{2}{*}{$\begin{array}{r}\text { Determinants } \\
\text { Variables }\end{array}$} & 1 & \multicolumn{2}{|l|}{2} & \multicolumn{2}{|l|}{3} & \multirow[b]{2}{*}{$\begin{array}{c}\text { No of } \\
\text { questions }\end{array}$} & \multirow[b]{2}{*}{$\begin{array}{l}\text { Variance } \\
\text { acc. for }\end{array}$} & \multirow[b]{2}{*}{$\begin{array}{c}\text { Cronbach's } \\
\text { Alfa }\end{array}$} \\
\hline & $\begin{array}{l}\text { Diversifying } \\
\text { production }\end{array}$ & \multicolumn{2}{|c|}{$\begin{array}{l}\text { Ending } \\
\text { production }\end{array}$} & \multicolumn{2}{|c|}{$\begin{array}{l}\text { Maximising } \\
\text { production }\end{array}$} & & & \\
\hline \multicolumn{9}{|l|}{2 personal development } \\
\hline Highest level of education & $-.28 *$ & .00 & & .05 & & 1 & & - \\
\hline $\begin{array}{l}\text { Are you part of the local } \\
\text { agricultural network }\end{array}$ & .16 & -.21 & $* *$ & -.20 & $* *$ & 3 & $50 \%$ & 0.48 \\
\hline $\begin{array}{l}\text { Are you part of social and } \\
\text { societal networks }\end{array}$ & -.01 & -.19 & $*$ & -.14 & & 2 & $60 \%$ & 0.33 \\
\hline $\begin{array}{l}\text { Is there experience with } \\
\text { new activities }\end{array}$ & .14 & .09 & & .12 & & 3 & & - \\
\hline \multicolumn{9}{|l|}{3 view on own competences } \\
\hline $\begin{array}{l}\text { Self image on the } \\
\text { competence analysing }\end{array}$ & .07 & .19 & & -.35 & $* n$ & 7 & $51 \%$ & 0.83 \\
\hline $\begin{array}{l}\text { Self image on the } \\
\text { competence networking }\end{array}$ & -.21 & .10 & & .28 & $*$ & 5 & $48 \%$ & 0.71 \\
\hline $\begin{array}{l}\text { Self image on the } \\
\text { competence pursuing }\end{array}$ & .22 & -.22 & & .25 & & 6 & $53 \%$ & 0.82 \\
\hline \multicolumn{9}{|l|}{4 view on continuation / family } \\
\hline $\begin{array}{l}\text { Will you stop as } \\
\text { entrepreneur within } \\
10-15 \mathrm{yr}\end{array}$ & -.08 & .23 & $* *$ & -.03 & & 1 & & - \\
\hline $\begin{array}{l}\text { Will the dairy farm } \\
\text { continue when you stop }\end{array}$ & $.28^{*} * *$ & -.25 & $* *$ & -.12 & & 1 & & - \\
\hline $\begin{array}{l}\text { Are there more people } \\
\text { living on the farm }\end{array}$ & .07 & -.18 & * & -.06 & & 1 & & - \\
\hline \multicolumn{9}{|l|}{5 view on current farm situation } \\
\hline $\begin{array}{l}\text { The income from dairy is } \\
\text { sufficient }\end{array}$ & -.16 & -.39 & $* *$ & -.12 & & 1 & & - \\
\hline $\begin{array}{l}\text { My dairy farm has } \\
\text { sufficient room to grow }\end{array}$ & .00 & .06 & & -.08 & & 1 & & - \\
\hline $\begin{array}{l}\text { My location is suitable for } \\
\text { diversification }\end{array}$ & .20 & .12 & & -.01 & & 1 & & - \\
\hline $\begin{array}{l}\text { I like to be active besides } \\
\text { dairy farming }\end{array}$ & -.01 & -.03 & & .14 & & 2 & $92 \%$ & 0.91 \\
\hline $\begin{array}{l}\text { Growing of dairy farm is } \\
\text { needed but difficult }\end{array}$ & .01 & -.08 & & -.06 & & 2 & $72 \%$ & 0.62 \\
\hline $\begin{array}{l}\text { The actual farm location } \\
\text { not relevant for me }\end{array}$ & .07 & -.05 & & .27 & $* *$ & 2 & $78 \%$ & 0.71 \\
\hline \multicolumn{9}{|l|}{6 view on markets } \\
\hline $\begin{array}{l}\text { I see dairy+diversification } \\
\text { in general as viable }\end{array}$ & .13 & -.06 & & -.22 & & 4 & $50 \%$ & 0.66 \\
\hline $\begin{array}{l}\text { Growth of a dairy farm is a } \\
\text { necessity }\end{array}$ & -.01 & .04 & & .14 & & 2 & $73 \%$ & 0.62 \\
\hline \multicolumn{9}{|l|}{7 view on urban-rural relation } \\
\hline $\begin{array}{l}\text { View on involvement } \\
\text { citizens with rural areas }\end{array}$ & .15 & .09 & & .03 & & 6 & $59 \%$ & 0.86 \\
\hline
\end{tabular}

* $p<0,10{ }^{* *} p<0,05$ 
As the cause and effect relation can be both ways, we use 'correlation between' and not 'the effect of'. The variable I want to be part of the top 10\% dairy farmers is significant and positive for 'maximising' (.23) and not significant for 'diversifying' (.03) indicating a difference in the personal preference. Education level is significantly negative correlated with 'diversifying' (-.28) and is not significantly correlated with 'maximising' (.05) which will be further discussed in the light of literature. Will the farm continue when you stop is significant for 'diversifying' (.28) and 'ending' (-.25), but not significant for 'maximising' $(-.12)$. This indicates a stronger relation between the view on farm continuation and diversification as an option than to maximising. The view on sufficiency ofincome is highly significant for 'ending' (-.39), but not significant for either 'diversifying' or 'maximising' $(-.16$ and -.12). The variable farm location is not relevant for me is only significant for 'maximising' (.27) indicating a different relation to the location of the farm. The view on the general viability of diversification differs between 'diversifying' and 'maximising' (.13 and -.22) but is for both not significant. The differences between the three dimensions for growth of the farm is a necessity and view on involvement of citizens with rural areas are small and not significant.

Overall, the results show different sets of drivers that are of importance for the three dimensions. Two drivers which are often labelled as 'farm-external' (markets and urban-rural developments) are least important and the personal views and preferences of the farmer are of most importance.

\subsection{Discussion, conclusions and outlook}

This empirical study explored the influence of seven drivers in relation to the farmer's perceived room for manoeuvre for farm development (the pRfM). The pRfM acts as a pre-filter in a strategic decision-making process. Farmers differ in three dimensions (or income strategies): 'diversifying' (e.g. care, education, farmers' markets), 'ending' (i.e leaving the dairy farming sector), or 'maximising' (using farm external inputs to maximise yields per ha) of production. The most influential driver is the personal views and preference on either maximising or diversifying of production. Further qualitative research is needed on the rationale of the farmers behind these perceptions. However, the data do suggest a connection between the perception on the viability of opportunities and the view on one's identity as a farmer (see also Burton and Wilson 2006; Hansson et al. 2012). How the farmer identifies the position as farmer is revealed in literature to influence the perception of diversification of farm activities. 
Diversification refers to the diversion of resources from conventional agricultural production to alternative enterprises on the farm, excluding off-farm work (Vik and McElwee 2011), or the development of non-traditional (alternative) enterprises on the farm (McElwee and Bosworth 2010). Several researchers have pointed to the primary focus of agricultural firms on improving current conditions rather than exploring new ideas (McElwee 2006; Haugen and Vik 2008; Morgan et al. 2010; Vesala and Vesala 2010). The situation with price stability and economic support programmes may have induced a loss of the ability to critically assess the situation of the farm (McElwee and Bosworth 2010). The findings of this paper confirm other studies on the driving factor to change the farm development strategy, revealing that personal motivation to look outside the dairy sector is not the most important factor (Vik and McElwee 2011). So when farmers do consider opportunities that lie outside of their personal preference, this is driven by a need to change the strategy (push) rather than a desire to change the strategy (pull). In agriculture, the shift towards diversification is seen as a shift towards more entrepreneurial behaviour (Grande et al. 2011). For small businesses in general though, diversification of production is found to indicate a survival strategy (Robson et al. 1993). The context of dairy farming is likely to have affected this finding due to: 1) path dependency (Wilson 2008); 2) the lack of urgency for a critical assessment due to protected markets (McElwee and Bosworth 2010); and 3) the primary focus on improving current conditions rather than exploring new ideas (Haugen and Vik 2008; McElwee 2006; Morgan et al. 2010; Vesala and Vesala 2010).

Higher education level was not positively correlated with 'diversifying' which opposes the findings of Carter (1998). In our study most farmers with higher education studied agriculture which is likely linked to a preference for modernisation and maximisation of production. Higher education as such is not a clear variable, it has to be viewed in combination with the type of education followed, which in turn connects to personal preference. The differences in perception on farm development are likely to affect programmes related to the conservation of nature and landscape values as community assets. Farmers who perceive maximising production as the best option are less connected to the location of the farm. This separation between production strategy and farm location is expected to create a more stressful relation with policy schemes aiming to protect nature and landscape values for the strategy of maximising production. The diversifying production strategy is more connected to the location of the farm and to the family farm context. Diversifying production benefits from nature and landscape values, as it contributes to the rural setting on which their image is based in urban oriented markets. Therefore, local shareholders in favour of nature 
and landscape values are more likely to find a partner in farmers with a diversifying production strategy. For farms moving towards ending dairy production, the relation with policies on nature and landscape protection is less tense as there is no expansion of activities foreseen. However, there will be a transfer of production factors to other farmers or stakeholders when the farm closes. For local stakeholders this transfer presents a momentum to represent the interest of nature and landscape as vulnerable community assets.

This study shows that strategic decision-making in farm development is not so much a rational process in which economic parameters are of primary importance. Presenting diversification opportunities for farm development to farmers experiencing limitations on income strategies is less likely to be successful. An opportunity will only be perceived as a viable opportunity by a farmer when it is in line with their personal view and preference. This means the discussion about the future of farming needs to address the personal views and preferences in relation to farm development and its effect on public goods. For an individual farm the number of opportunities perceived as viable is important; a farm business is more likely to be able to absorb changes in the market or in the business situation when it has more than one opportunity for business development (Darnhofer et al. 2010).

An important question for further research is the rationale of farmers for their perceptions on the viability of opportunities for farm development. An interesting option is to study how the perception of the opportunities for farm development relates to possible differences in the embeddedness of the farm in the context in which the farm operates. The implication of our findings is that policy schemes and support programmes which do not address the personal preference of farmers are less likely to be successful. Differences in the embeddedness may offer a route to study the personal preferences of the farmer. And personal preferences can and do change, which opens routes for policy schemes which focus on the attitudes and intentions of farmers in the light of changes in the context that lead to changing opportunities for farm development. Addressing personal views and preferences can be linked to supporting the development of networks in which business owners operate, an issue raised by Moyes et al. (2012). A programme focusing on merely informing about the opportunities which are favoured by policy makers is less likely to be effective. 


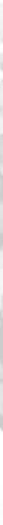
bet rom 


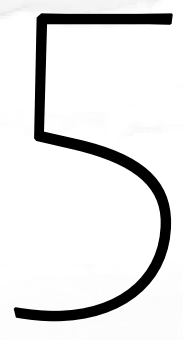

Three-fold embedding of farm development 



\section{Abstract}

Farm development strategies are affected by, and affect, the socio-material context of the farm. For effective policies and support programmes it is important to understand what drives strategies for farm development. Three-fold embeddedness is used to study how the family farm relates to the context in which it operates. The characteristic farm practices of three clusters of farmers were constructed for the ideal-typical farms representing the clusters. These clusters of farms are based on a quantitative study of dairy farmers operating in a highly comparable socio-material context. The clusters are 1) "Milk Max" maximising total milk production; 2) "Milk Balance" optimising milk production based on own resources; and 3) "Milk Plus" diversified on-farm production. The three dimensions of three-fold embeddedness were conceptualised as: 1) value chain relations; 2) socio-cultural relations; and 3) natural resource relations. The extent of the embeddedness for the three dimensions has been determined on a scale ranging from a Close to a Stretched set of relations. These ideal-typical farm types showed to have different sets of relations for the three dimensions. A set of relations that is stretched outside the everyday routine of dairy farming appears to be important for farmers' perception of opportunities for farm development.

This chapter will be submitted for Agriculture and Human Values as:

R.C. (Ron) Methorst, D. (Dirk) Roep, F.J.H., J.A.A.M. (Jos) Verstegen and J.S.C. (Han) Wiskerke. Three-fold embedding of farm development 


\subsection{Introduction}

Diversity or heterogeneity is, as many studies have shown in the past 25 years (Ploeg 1994; Pender et al. 2004; Beyene et al. 2006; Ploeg and Ventura 2014; Oostindie 2015), one of the main features of farming and farm development. But why do farming practices differ and why are there different farm development strategies? And how do farmers and their families deal with the challenges that arise from the interaction with the dynamic and complex context they operate in? These questions have prompted and guided this paper.

Earlier as well as more recent research on farming styles has shown that diversity in farming practices and in farm development cannot be explained by 'external' structural factors such as 'markets', 'technology' or 'nature' (Ploeg 1994, 2003; Ploeg and Ventura 2014). Farmers make decisions about the everyday management of their farm as well as strategic decisions about farm development. The practices resulting from these decisions in turn affect the perceived opportunities and new strategic decisions. In this iterative process of strategic decision-making in farm development, the farmer tries to anticipate and balance the effect of developments in the context of the farm with the needs and aims of the family farm. The decisions made by the farmer will structure farm practices and the embedding of farming in its context. The resulting farm development path in turn affects the perceived opportunities for further farm development and future strategic decisions.

The context of the farm is shaped by social (e.g. policies, values, markets) as well as material (e.g. soil, climate, topography) factors. These factors are in many ways interwoven as they co-evolve. Due to the interaction and co-evolution of social and natural ordering processes, the social and material are seamlessly interwoven into the socio-material context (Roep 2000) of the family farm. In the process of decisionmaking on farm strategies, the family farm is inherently intertwined with pre-existing socio-material structures; the farmer does not and cannot make strategic decisions as on a blank canvas. The existing socio-material context both enables and restricts farm development as it offers limitations and opportunities (Giddens 1984). In other words, there is a 'room for manoeuvre' to act within the socio-material context. The farmer enacts and thus influences the socio-material context and thereby the room for manoeuvre for farm development. 
The farmers' perception of the room for manoeuvre for farm development is likely to affect the strategic decision-making of the farmer for the development of the farm. Studying differences in their perception between individual farmers is however difficult as the perceptions are affected by the socio-material context in which farmers operate (Sutcliffe and Zaheer 1998; Yanes-Estévez et al. 2010). To better understand diversity in practices and in perceptions of opportunities we have conducted a unique case study of a dairy farming region (Kampereiland in The Netherlands), in which all 102 dairy farmers operate in a highly comparable socio material context of the farms in the case study area. This allows for an in-depth empirical study of differences between dairy farmers in their perception of opportunities. In the study of strategic decisionmaking in small business, the perception of opportunities is found to be more decisive for the outcome than the formal analyses (Parnell et al. 2000; García-Pérez et al. 2014).

The following part elaborates on the theoretical background of both farm development and the embeddedness of farming in the socio-material context. The methodology section describes the context of the case study, the collection of the data and the operationalisation of embeddedness. This is followed by the results in which the differences found are described and analysed. Finally the results are discussed and the conclusions of this study are drawn .

\subsection{Theoretical background}

As mentioned in the introduction farm development is affected by differences in the socio-material context (Bieleman 1987) and by the strategy chosen by the farmer to acquire a satisfactory farm income (Ploeg and Ventura 2014). Modernisation of agriculture has resulted in significantly higher production levels as production levels were no longer limited by the local availability of resources nor the logistics to reach the markets. Agricultural modernisation resulted as well in a negative effect on the quality of the landscape and of biodiversity values (Marsden 2003; Wiskerke and Roep 2007) and in a more distant relation between the location of food production and the location of food consumption. This process is described as dis-connecting (production and consumption have become separated, through physical distance), dis-embedding (the place of production is losing its influence on the quality and nature of products) and dis-entwining (production and supply chains become more and more specialized and separated (Wiskerke 2009). Alternative farm strategies have been developed over the past decades that emphasise the localness of food and the multi-functionality of 
farms. These farm strategies are based on the connection between the characteristics of the farm and its local rural context leading to new value chains such as farmers' markets and new business opportunities like green care, education and tourism (Potter and Tilzey 2005; Oostindie 2015). These developments mean that there are different strategies for a farm to develop, depending on how they relate to the socio-material context. Which farm strategy to pursue is an important question in the decisionmaking process of farmers and is part of an explicit or implicit farm development strategy. Studying this decision-making process needs to be done in an integral way as farming is embedded in a context shaped by interrelated social and material factors (Welter 2011; Hansson and Ferguson 2011; McKeever et al. 2015) which constitutes a room for manoeuvre (RfM) for farm development within which the farmer develops a strategy. This RfM is by definition perceived and therefore subjective. A farmer can (attempt to) actively enlarge the RfM by developing and implementing new strategies.

\section{Three-fold Embedding}

Studying Embedding originates from the inclusion of the social dimension in the study of economic activity using the analytical concept Embeddedness. Granovetter (1985) is widely acknowledged for revitalising the concept in the field of economic sociology as the incorporation of social relations into economic action (Dequech 2003). In literature the concept Embeddedness is used from different angles and perspectives, often focusing on a specific aspect of the embedding of economic activity in its context. Jack and Anderson (2002) focus for example specifically on the meaning of an individual's ties to the local social structure to explain differences in economic activities. Looking at literature on food networks, the concept Embeddedness is used to theorise the development of alternative food networks (Morgan et al. 2006; Akgún et al. 2010; Roep and Wiskerke 2012b). Embeddedness is here used to study the social dimension and the ecological and cultural relationships of a food system in the territorial context of food production (Sonnino 2007, 63). Embedding of food production is then seen as 'the re-placement' of food and food production in its local context in response to the 'dis-embedding' forces of conventional food networks (Coodman and Coodman 2009, 208). Focusing on a specific aspect of Embedding introduces the risk of a binary division, for example between 'good' local-embedded and 'bad' global dis-embedded food systems (Sonnino 2007). Being embedded then easily becomes a normative characteristic as it is seen as a 'unique, distinguishing, almost magical' attribute of alternative food strategies (Hinrichs 2000, 297). To avoid using embeddedness in a normative and binary approach it can best be viewed as a dynamic process that can 
vary and is object of management choices (Sonnino 2007; Moragues-Faus and Sonnino 2012). The dynamic process approach places the emphasis on the agency of an actor in making decisions in relation to the context in which the actor operates. In line with the view of embeddedness as a dynamic process, the word embedding is preferred in this thesis. Where embeddedness reflects a state of being as it is a noun, the word embedding is a verb, reflecting an active process. Resulting from a study on the different uses of embeddedness in literature, Hess $(2004,176)$ states that a reconnection to the original meaning of embeddedness is needed: 'the social relationships between both economic and non-economic actors', or plainly stated: 'who is embedded in what'. This view focuses on the extent of the embedding as the result of a process that can vary and the use of a scale means it is opposed to a binary approach, an actor is always embedded.

Hess extracts threegeneral dimensions to be used in thestudy of embeddedness: 1) Societal embeddedness that signifies the importance of where an actor comes from, considering the societal (i.e., cultural, political, etc.) background; 2) Network embeddedness that describes the network of actors a person or organization is involved in; and 3) Territorial embeddedness that considers the extent to which an actor is 'anchored' in particular territories or places (Hess 2004, 177). These three dimensions are used to study the Embedding of the patterns of farm development that were found in the case study (chapter 3). The dimensions are carefully re-conceptualised in the specific context of dairy farming to ensure a clear and meaningful understanding of each dimension. The societal embedding is re-conceptualised as socio-cultural relations of the farmer, asking how farmers view themselves as a farmer, what 'culture' of farming does the farmer 'belong' to, what is the identity in values, norms and opinions. The network embedding is re-conceptualised as the value chain relations, asking which value chain the farm is a part of or linked to, or which networks or spheres of influence affect farm development. The territorial embedding is re-conceptualised as the resource relations of the farm, asking about the origin of the natural resources for farm production. The following question is how to measure the extent of embedding for each of the dimensions; this will be further explained in the methodology section. 


\subsection{Methodology}

\section{The case study context}

The Kampereiland case study offers a highly comparable context for all dairy farmers, which allows to study differences between farmers. Kampereiland ('the island of Kampen') is a Dutch river delta where the landscape is influenced by centuries of farming. The town of Kampen owns the islands in the river delta since 1363. Using land reclamation techniques the amount of land was expanded to around 4,000 ha of agricultural land and 800 ha water, roads and nature areas. The main activity is dairy farming (102 of the total 108 farms). The culture and identity of Kampereiland is influenced by its history as an island, even though the town of Kampen was less than 10 kmaway. The 600 people have good social connections with an active community centre, a church, a primary school, various social and leisure groups, a quarterly journal and a yearly harvest festival. The case study area became part of a National Landscape (2005) due to its characteristic Dutch river delta landscape influenced by centuries of farming and the former coastal areas bordering Kampereiland were designated as Natura 2000 nature reserves (2011) and Kampereiland. The policies and legislation concerning Natura 2000 and the National Landscape limit the possibility of scale enlargement. The strategy of scale enlargement and specialisation has been and still largely is the predominant strategy in Dutch dairy farming in response to the abolishment of the European Union milk quota system (Meulen et al. 2012). As a result of the change in EU dairy market policies the price volatility has increased while accessibility of capital for investment decreased due to the financial crisis. Dairy farming in Kampereiland is as well affected by national and supranational legislation on environment, animal health and animal welfare. Dairy farms in Kampereiland were until the 1980 s known for their larger than average size and high economic return, however, in the last decade farm income in Kampereiland became worrisome, especially when compared to dairy farms outside the area (Duitman 2005; Methorst 2013).

All farms are tenant farms with the town of Kampen as the lessor. The lessor's policy is to take care of the 'heritage of our fathers' using four guiding principles: 1) retain property of Kampereiland; 2 ) obtain a reasonable financial return; 3) maintain nature and landscape values; and 4) conduct a loyal tenancy policy. The number of farms increased to 170 farms in the 1950 s when around 60 farms in the city of Kampen were outplaced to Kampereiland followed by a gradual decrease of the active farms to 108 in the year 2012 (of which 102 dairy farms). In 2012 a farm had on average around 45 ha in use including land owned or rented outside of Kampereiland. The tenancy 
situation affects the land market in Kampereiland as there is no free land market. To buy land the farmer needs to go to neighbouring areas $(5+\mathrm{km})$. The economy of the farms in Kampereiland strongly relies on dairy farming, though farm income is often supplemented by an off-farm job by the farmer or a family member. There are no organic dairy farms at the time of the survey and less than 10 farmers are engaged in diversification of their farm. The milk is delivered to (inter)nationally operating dairy organisations, mostly cooperatives.

\section{Data collection and processing}

This paper builds on the results of an earlier study in which 79 dairy farmers (out of 102) indicated on a 5-point Likert scale their perception of 15 opportunities for farm development to generate a substantial part of farm income. The indication was made for the opportunity given their own situation, the so-called first-person opportunity (McMullen and Shepherd 2006). The 23 non-respondents were assessed by local experts as not being different from the respondents. The data were analysed using principal component analysis (Varimax with Kaizer Normalisation) resulting in three factors that were subsequently used in a two-stage cluster analysis leading to four clusters of farmers that represent coherent, consistent patterns of farm development that are meaningful to stakeholders (Methorst et al. 2016b). The patterns of farm development were identified on the differences in the perception of opportunities for farm development, the 'perceived Room for Manoeuvre' (pRfM). The analytical concept pRFM is defined as 'the opportunities perceived as viable in order to obtain a (substantial part of) business income' (Methorst et al. 2016b). For this paper the threefold embeddedness of the patterns of farm development is studied using the idealtypical farm practices of the patterns. Ideal-types are a coherent theoretical concept that is 'formed from characteristics and elements of the given phenomena but it is not meant to correspond to all of the characteristics of any one specific case' (Soliva 2007, 63 ). Ideal-types can help to identify patterns of variance (Doty and Click 1994) and to give meaning to the patterns found. The ideal-typical farm practices of each pattern were determined using information from three sources: 1) the average score of the farmers for the 15 opportunities that were presented in the survey; 2) the average production characteristics of the farmers; and 3) interviews with 15 dairy farmers and 16 stakeholders of dairy farm development on the characteristics of the patterns of farm development. The dairy farmers were selected at random from all four clusters and the stakeholders were selected from different backgrounds (advisory, farm supply, veterinary, the lessor and farmers' organisations). The interviews were recorded and transcribed for further analysis. 


\section{The scale to measure embeddedness}

Using the ideal-typical characteristics of the different patterns, the extent of the threefold embedding was determined from the viewpoint of the family farm at the address where the farm is located. This viewpoint is taken as each farm has a location with its own local supply of resources of a social, cultural, human and natural character (Casini et al. 2012, 197). To estimate the extent of the embeddedness a scale was used ranging from a 'Close' set of relations to a 'Stretched' set of relations. The scale is operationalised for each of three dimensions. For socio-cultural relations, Close refers to networks that are based in the familiar, agricultural production oriented context. The connection in a Close set of relation is often based on long standing, personal relations. A Stretched set of socio-cultural relations refers to relations in networks that are distanced from the familiar, agricultural production oriented networks. For value chain relations a Close set of relations refers to a connection between the farm's product and the consumer in which the consumer is able to know on which farm the product is produced and the value of the product for the client is based on the quality characteristics in combination with the location of production. A Stretched set of value chain relations refers to a distanced relation between the farm's product and the client, the value of the product for the client is defined by the quality characteristics of the product. For resource relations a Close set of relations refers to a focus on using the on-farm available resources for production, production has a natural limit in the availability of these resources. A Stretched set of resource relations refers to an active sourcing for resources from all available sources.

The words Close and Stretched have been selected to avoid a geographical connotation. The element of geographical distance is to a certain degree represented in all sets of relations for the three dimensions of embeddedness. However, the primary characterisation of the relation is not based on physical distance. The words Close and Stretched are as well neutral and therefore not linked to a positive or negative connotation. The combination of Close and Stretched allows for use in a scale and thus supports avoiding a binary view on embeddedness and viewing it as a process of embedding. Close and Stretched are positioned on the far ends of the scale for each dimensions of embedding. The position on these three scales was determined for each ideal-typical pattern of farm development based on an informed judgment of the researcher. This informed judgment is based on the data from interviews with 15 farmers and 16 stakeholders on the differences between the patterns in the drivers to organise their farm the way they do. In what way does one type of farm differ from the other types of farms. The position on the scale between Close and Stretched resembles the position of a slider on a sound mixing panel. The combined positioning for the 
three dimensions of embedding represents the overall embedding of the family farm. The positioning of the slider does not represent an exact and calculated positioning, it includes a range that respects the variation that can still be found in the characteristics of the farms that are all regarded to be part of the same pattern of farm development.

The following guidelines were developed to determine the extent of the embedding between Close or Stretched. Socio-cultural relations of the family farm: to what extent do they represent an attachment to the land in use and to the direct surroundings of the farm, both physical and social. Does the farmer 'belong' to this location (Close) or could the farmer easily move to another farm in a different location (Stretched). How does the farmer position himself, as caretaker of the farm and its land (Close) or as manager of an economic activity (Stretched). Value chain relations of the farm: how is the relation of the farm with the market outlets of its product. Are the products part of a globalised value chain where products are marketed anywhere in or outside Europe (Stretched) or is it a value chain where products are marketed using a brand linked to the farm or the region (Close). Is the family farm primarily connected to a value chain network that views the on-farm produced milk as raw material for further processing in either dairy or non-dairy products (Stretched) or is the farm primarily connected to a value chain network that views the on-farm produced milk as basis for dairy products that can be linked to its origin (Close). Resource relations of the farm: where do the resources come from (mainly feed and fertilizer). Is it primarily based on the agro-ecological view to be self-proficient in producing feed using only limited farm-external resources (Close) or is it primarily based on agro-industrial view to select a mix of resources for production out of all available resources (Stretched).

\subsection{Results}

\subsubsection{Ideal-typical characteristics of the clusters}

The statistical analysis resulted in four clusters representing different consistent and coherent patterns of farm development. These four patterns were labelled Milk Max, Milk Balance, Milk Plus and End Milk (Methorst et al. 2016):

1. Milk Max (29 of 79 farms): farms aiming for maximisation of total farm milk production within economic parameters using high levels of input to create a high output. Their view on dairy farming is primarily technical and financial. 
2. Milk Balance (21 farms): farms aiming to optimise total farm milk production within the limits of feed produced on own land, limited additional inputs are used to optimise milk production. The production costs are kept relatively low.

3. Milk Plus (21 farms): farmers which are open for other sources of income from on-farm activities (e.g. like care, recreation and nature) next to a Milk Balance strategy. The farm is based on relative extensive production that reduces the pressure on operational management and in turn allows to spend time and energy on other activities.

4. End Milk (8 farms): farms aiming to end milk production in the coming years, either due to pension without a successor or due to the economic situation of the farm. Farmers often aim to remain living in the farmhouse while the land will be used by other farmers and the farm facilities are taken out of (dairy) production. The pattern End Milk is not used for further analysis on embeddedness due to the low number of farms in the pattern in combination with the diversity in motivations to end production.

Table 5.1 presents the average production characteristics of the four patterns. Milk Max shows the highest production per cow, per ha and per farm which corresponds to an intensive dairy production using high external inputs as by-products and concentrates. The characteristics of Milk Balance show production levels that optimise production per cow, per ha and per farm based on own roughage production with additional concentrates. For Milk Plus the production levels are clearly lower per cow and per ha, yet total production per farm is relative high. The relative extensive way of organising production on Milk Plus farms, allows spending time and energy on other activities. In interviews with farmers and stakeholders in dairy farming, the clusters proved to be coherent in their characteristics, consistent over a longer period of time and meaningful in the practice of dairy farming.

Table 5.1 Production characteristics of the four patterns in dairy farming in Kampereiland (year $2012, \times 1000$ kg)

\begin{tabular}{lccc}
\hline Pattern & Milk/cow & Milk/ha & Milk/farm \\
\hline Milk Max & 9.0 & 17.9 & 893 \\
Milk Balance & 8.3 & 14.1 & 543 \\
Milk Plus & 7.5 & 11.9 & 622 \\
End Milk & 7.2 & 10.7 & 410 \\
\hline
\end{tabular}


The next section focuses on the three-fold embedding for Milk Max, Milk Balance and Milk Plus, the ideal-typical farm characteristics of the patterns that aim to continue dairy farming. The results are based on an informed judgment of the researcher using the interviews with farmers and stakeholders. The ideal-typical characteristics are illustrated by quotes from farmers and stakeholders in dairy farm development in Kampereiland. The quotes were translated to English in phrases and words that are as close as possible to the meaning in Dutch. The results are described in the following paragraphs and summarised in Table 5.2.

\subsubsection{Three-fold Embedding ofMilk Max}

\section{Socio-cultural relations}

The farm is seen as an enterprise and the farmer as entrepreneur and business owner The farmer gets satisfaction from a well-managed, smoothly running farm operation. The farmer takes pride in the practices on the farm and positions it as their active choice to do so. The farm and the family of the farmer are not necessarily connected. The farmer is interested in general business networks. The position on the scale is on the far end of the Stretched side on the scale.

\begin{tabular}{|c|c|}
\hline \multicolumn{2}{|c|}{ Milk Max-socio-cultural relations } \\
\hline \multirow[t]{2}{*}{ Self } & $\begin{array}{l}\text { We need to separate the farm and the family, the time that the whole family needed to support the farm needs } \\
\text { to be over (fiz) }\end{array}$ \\
\hline & We should be going away more, when you look at this wharf here nearby, they fly all over the world (fi2) \\
\hline \multirow{3}{*}{$\begin{array}{l}\text { Other } \\
\text { Farmers }\end{array}$} & These farmers are really good managers, they need to be good in quick decision making ( $\left.f_{2} 6\right)$ \\
\hline & There is as well an element of showing off what real farming is like (f37) \\
\hline & $\begin{array}{l}\text { The larger farmers are no longer interested in local organisations, they can still be found in boards, but than as } \\
\left.\text { a paid board member ( } f_{2} 4\right)\end{array}$ \\
\hline \multirow[t]{2}{*}{$\begin{array}{l}\text { Stake- } \\
\text { holders }\end{array}$} & $\begin{array}{l}\text { When I'm called for a cow to calve, I can find the cow in the stable and I can call the farmer when needed, in Milk } \\
\text { Balance farms the family would come to watch (s11) }\end{array}$ \\
\hline & They are not the easy going farmers who like to chat, they do have time, but in the evenings (s2) \\
\hline
\end{tabular}

\section{Value chain relations}

The farm has a primary focus on producing dairy as commodity product for dairy industry while practising a high input production system. The farm is aimed to produce as much milk as possible within the legal and economic constraints and the farmer aims for scale enlargement. The farm functions as a production unit with economic parameters as guiding principle in decision-making. The farmers are actively related to advisory organisations in business management, both general and in the (dairy) farm sector. This translates in a position on the Stretched end of the scale. 


\begin{tabular}{|c|c|}
\hline Milk Ma & $x$-value chain relations \\
\hline Self & We want to focus fully on production and to minimise side activities (fi3) \\
\hline $\begin{array}{l}\text { Other } \\
\text { Farmers }\end{array}$ & $\begin{array}{l}\text { They see it as a challenge, going to the max. When you give them the choice for less or more cows with the same } \\
\text { financial profit, they opt for the higher number of cows. It is as well a competition in their network to be on top } \\
\text { of the lists (f34) }\end{array}$ \\
\hline & $\begin{array}{l}\text { Their decisions are based on economy, their aim for the farm is to earn money and they love to continuously } \\
\text { develop their farm (f41) }\end{array}$ \\
\hline & The larger the farm, the more easy it is to deal with investments, you need numbers (f26) \\
\hline & When foreign capital is to the max, you need to maximise production, it has to be repaid ( $f 26$ ) \\
\hline Stake- & They are well connected to advisory services, but they do follow their own plan and goals (S13) \\
\hline holders & The farmers actively look for new techniques to lower the costs (s4) \\
\hline & When foreign capital is to the max, you need to maximise production, it has to be repaid (s7) \\
\hline
\end{tabular}

\section{Natural resources relations}

The viewpoint of the farmer towards resources is based on the economic usefulness as resource for production. The decision which resources to use is the result of an economic calculation. Local surrounding is primarily seen through the lens of usefulness for production. The position is towards the Stretched end of the scale, as the farm does use feeds from own land it is not positioned in the far end of the scale.

\begin{tabular}{|l|}
\hline MilkMax-natural resources relations \\
\hline Self We have always milked to the max, we scrape together the feed we can get to have enough feed, a more extensive \\
approach just would not fit (fi3) \\
As much milk as possible using concentrates and by-products ( $f 11)$ \\
Farmland birds programmes? We only participate when it is economically feasible (fi4) \\
\hline
\end{tabular}

\subsubsection{Three-fold Embedding ofMilk Balance}

\section{Socio-cultural relations}

Dairy farming is a way of life with a strong base in local culture. The farmer gets satisfaction from being part of the farming culture, working with land and animals. The farmer tends to focus on doing it the way he is used to do. The farm and the farm family are connected. The farmer is open for co-operation in wider goals like sustaining landscape and nature values as long as it is not too much limiting the process of his farm. This co-operation is more seen as a co-production than as a service for which a payment is needed. The urban-rural connection is acknowledged as important, yet not seen as viable (next to dairy) for their farm. The position is quite outspoken to the Close end of the scale. 


\begin{tabular}{|ll|}
\hline Milk Balance-socio-cultural relations \\
\hline Self & $\begin{array}{l}\text { Farmers may very well be too much farm yard oriented, there are too many of those still around (f25) } \\
\text { I was born and raised on this farm, my great-grandfather started here, my grandfather was born here, we are } \\
\text { here since } 1890 \text { (f22) } \\
\text { I farm the way I want to farm, no matter what other people say, my family is very involved, they enjoy it and love } \\
\text { to help, that is very rewarding (f24) } \\
\text { Working with people from nature organisations was not a success, I cannot get along with them, even though I } \\
\text { still look out to protect farmland birds (f23) }\end{array}$ \\
$\begin{array}{ll}\text { Other } \\
\text { Farmers }\end{array}$ & These people are more working based on an ideology, the connection with family, looking more at sustainability, \\
\hline $\begin{array}{l}\text { Stake- } \\
\text { holders }\end{array}$ & I do believe that farmers who are more oriented on the craftsmanship in farming more enjoy farming (s4)
\end{tabular}

\section{Value chain relations}

The farm is focused on the conventional dairy value chain where milk is a commodity while practising a production system based on relative low external inputs. Economic return is the result of all decisions and activities, not the primary goal. Participating in an added value dairy value chain is an option, e.g. organic dairy. The farmer is critical about the general trend towards both scale enlargement and diversification of the farm. The farmer does not believe in other on-farm income sources, hesitates partly because investments are needed, partly because of how it will affect their farm business activities. The position on the scale is towards the Stretched side, though not as outspoken as Milk Max. For Milk Balance the position on the scale for value chain is Stretched, yet is less of an active choice to do so, it has evolved over time to be like it is.

\begin{tabular}{|l}
\hline Milk Balance-value chain relations \\
Self \\
We could become part of a separate dairy value chain, but we would not be the ones to initiate a new value chain \\
(f21) \\
The media wants to convince us that big farmers are the entrepreneurs with beautiful new farms, I believe that it \\
is more a feat to get yourself an income from 60 cows (f23) \\
Diversification like regional products is not what I like, it takes away the attention that I need for my cows. Society \\
may ask for it, but as long as we can farm the way we want we will do so (f21) \\
Like care or energy production, well, you need to invest first and wait and see if it will give a profit (f25) \\
Milk Balance farmers are first of all farmer. They like to do a good job in producing milk by focusing on own feed \\
Other \\
Farmers \\
Milk Balance farmers are less focused on the financial results, much less as Milk Max farmers. These farmers do \\
not strive for a bigger farm, it is not their preference (s11) \\
These farmers invest less capital, they try to keep costs low (s13)
\end{tabular}

\section{Natural resources relations}

The farmers have more of a low external input oriented view on farming. The farm and its natural setting is the base for production. The focus on natural parameters translates in less use of inputs, the farm itself is the primary resource for production and the farmer attempts to optimize within the resources available. The success of the 
farm can be measured as the amount of inputs needed to maintain the productivity of the farm; the less inputs needed, the better. Additional resources are used, but with the aim of optimising production. Nature and landscape is more a constraint than resource, though they are as such much appreciated. The farmer does feel connected to and part of his surroundings. The farm belongs to the place where it is and is part of the heritage of farming in the area. The surroundings are in principle seen as 'outside of my farm, as a separate world that may negatively affect your farm. Farmers have over time been surprised by and confronted with unexpected limitations in connection to nature and landscape values which makes them careful now. The position on the scale is toward Close, as the farm does make use of additional off-farm resources the position is not fully on the Close side.

\begin{tabular}{|ll|}
\hline Milk Balance-natural resources relations \\
\hline Self & $\begin{array}{l}\text { I have as many cows as my land can handle, I would even prefer to have less cows per ha but some legall limitations } \\
\text { mean that I need to have more cows than I would prefer to have ( } f_{34} \text { ) } \\
\text { Patience, patience, give the land its time, farmers give too much priority to working fast (f37) } \\
\text { To turn some agricultural land into water retention areas is fine in itself, but then you will see that those nature } \\
\left.\quad \text { people will turn it into nature area over time ( } f_{33}\right)\end{array}$ \\
\hline $\begin{array}{l}\text { Other } \\
\text { Farmers }\end{array}$ & Farming skills are very important, some farmers can harvest the double as much from one ha as other farmers \\
\hline
\end{tabular}

\subsubsection{Three-fold Embedding of Milk Plus}

\section{Socio-cultural relations}

The farmer identifies the farm and farming as more than a production location, it is as well a source of wellbeing for (local) society. The farmer values (societal) recognition for the positive effects of his work on the urban-rural relation, the farmer is very motivated to contribute to the region and add societal value. Monetary value is needed, but not the primary goal, personal life experiences may play a role, some may even risk to invest too much of themselves. The farm is a family business. The farmer is open towards nonfarming socio-cultural developments and networks. The position for socio-cultural relations is a mix of Close and Stretched. The farm actively seeks relations outside of the traditional farm production networks (Stretched) and at the same time the connection to the local community is strong (Close). 


\begin{tabular}{|c|c|}
\hline MilkPlus & socio-cultural relations \\
\hline Self & $\begin{array}{l}\text { We do not need to get the last drop of every cow, we cherish the social contacts. As a farmer it is easy to be } \\
\text { isolated on the farm, it is good to see other things (f37) }\end{array}$ \\
\hline & $\begin{array}{l}\text { I indeed prefer a farm that enables me to give room to my idealism than a farm that delivers a high income. } \\
\text { Contact with people, all the stories you hear. That gives insights as well (f34) }\end{array}$ \\
\hline & $\begin{array}{l}\text { We have both worked in other occupations and we have seen that there are other worlds. The contact with } \\
\text { other people made us aware of the value of farm life (f33) }\end{array}$ \\
\hline & A network outside agriculture helps you to stay creative, they say things that make you think (f31) \\
\hline Other & On these farms you often see that family is, they are actively involved in running and developing the farm (fi4) \\
\hline Farmers & The family is really part of the farm and they work on and talk about the farm (fi5) \\
\hline Stake- & These farmers find other things in the world more important than just farming (s2) \\
\hline holders & Sometimes you see farmers that are maybe too social, they give too much of themselves (s10) \\
\hline & $\begin{array}{l}\text { You often see that the partner of the farmer worked in for example care, and then develops green care on the } \\
\text { farm (s12) }\end{array}$ \\
\hline & You need inspiration as well, are you open for it, is it part of the farmer's character (s4) \\
\hline
\end{tabular}

\section{Value chain relations}

The farm is part of more than one value chain, be it that dairy production still is the main income source. Next to dairy farming, the farmer operates a value chain of products and services directly addressing clients. This value chain is based on the characteristics of the farm and the appeal of the rural setting as valued by the broader society. This type of farm requires a combination of skills and entrepreneurial competences. The success of the farm cannot be measured in the same production characteristics as for Milk Balance or Milk Max due to the diversity in activities. The approach to dairy farming resembles Milk Balance, with a relative low external input view on farming with the farm and its natural setting as base for production. The position on the scale is towards the Close end of the scale. As products may be part of a national marketing system it is not necessarily on the far end towards Close.

\begin{tabular}{|c|c|}
\hline \multicolumn{2}{|c|}{ MilkPlus-value chain relations } \\
\hline Self & We are surprised how farmers cannot see the chances in the society around them (f33) \\
\hline & $\begin{array}{l}\text { Milk Max and Milk Plus in some ways resemble each other, they both have entrepreneurial competences, the one } \\
\text { sees chances in the surroundings and the other sees the production potential on his farm (f33) }\end{array}$ \\
\hline $\begin{array}{l}\text { Other } \\
\text { Farmers }\end{array}$ & Those farmers really dare to take entrepreneurial risks, they are not just continuing their farm activity (fi4) \\
\hline \multirow[t]{2}{*}{$\begin{array}{l}\text { Stake- } \\
\text { holders }\end{array}$} & $\begin{array}{l}\text { In the nineties I talked with farmers about choosing to opt for an off farm job or to start a BEB on the farm, } \\
\text { they decided to do the B\&B as it increased the activity on the farm. Now it is good for a complete income. The } \\
\text { diversification, you see the effect of more activity on the farm ( }(512)\end{array}$ \\
\hline & This is the real entrepreneurship as you need to act on societal developments (S12) \\
\hline
\end{tabular}

\section{Natural resources relations}

The primary resource base for dairy farming is local and resembles the Milk Balance farmers. In addition the farmers are open for alternative use of resources in the area, 
the farm itself, the farming lifestyle and the rural context is seen as a resource as well. The farmers like to see a farm that is well embedded in a landscape and that connects farming with nature and landscape. The farmer thinks about and actively connects the farm with the surroundings. The farmer is open for and may initiate a co-operation in wider goals like sustaining landscape or nature values. The position on the scale is towards Close, additional resources are however used for optimisation of production meaning it is not on the farm end of the scale towards Close.

\begin{tabular}{|l}
\hline Milk Plus-natural resources relations \\
\hline Self \\
We think this part of the polder has potential for nature and farmland birds (f31) \\
We had plans to rent out small boats as well, but we were not allowed to organise a location on the water side \\
for the boats (f31)
\end{tabular}

In Table 5.2 the results of this study are summarised for each cluster. The extent of the embeddedness for each dimensions is visualised by positioning a 'slider' on the scale ranging from 'Close' to 'Stretched'. The slider resembles a slider on a sound mixing table which reflects the range of possibilities for the embeddedness on the scale. The selected position of the slider results from an informed judgment by the researcher on the basis of the results. For Milk Max the three sliders are most oriented towards Stretched, for Milk Plus the sliders are most oriented towards Close and for Milk Balance the position of the three sliders show the biggest difference between the three sliders.

Both Milk Max and Milk Plus show more signs of an explicit reasoning of the farmer about his positioning on all three dimensions. For Milk Balance the positioning on natural resources relations is explicit, for the other dimensions the positioning has an implicit character. The difference between the clusters Milk Plus and Milk Balance is the positioning for value chain and for socio cultural relations. In value chain the Milk Balance farmer is implicitly oriented towards the 'normal' dairy value chain which has a Stretched character whereas Milk Plus is explicitly oriented towards local relations and networks meaning it has a Close character. For socio-cultural relations the Milk Balance farmer is implicitly oriented towards the local, traditional networks (Close) whereas the Milk Plus farmer is explicitly oriented as well on networks outside agriculture and in other regions or parts of society (Stretched). This difference in the orientation for sociocultural relations could be the key to understand the difference in personal views and preference between the Milk Balance and Milk Plus farmer. The findings will be discussed in the following section in the light of our research problem. 
Table 5.2 Extent of the Three-fold Embedding for the three ideal-typical patterns of dairy farming

\begin{tabular}{|c|c|c|c|}
\hline & Milk Max & Milk Balance & Milk Plus \\
\hline & $\begin{array}{l}\text { Focus on producing dairy as } \\
\text { commodity product for dairy } \\
\text { industry }\end{array}$ & $\begin{array}{l}\text { Focus on dairy as commodity, } \\
\text { possibly part of added value } \\
\text { chain (eg organic) }\end{array}$ & $\begin{array}{l}\text { Focus on multiple value chains: } \\
\text { 'normal' dairy plus an extra on- } \\
\text { farm activity }\end{array}$ \\
\hline Value & $\begin{array}{l}\text { Explicit high input, high output } \\
\text { view, farm is production unit, } \\
\text { focus on benefits from scale } \\
\text { and intensity }\end{array}$ & $\begin{array}{l}\text { Implicit low external input } \\
\text { view, farm is production } \\
\text { unit, focus on benefits from } \\
\text { optimising land assets }\end{array}$ & $\begin{array}{l}\text { Explicit agro-societal view, } \\
\text { farm is a unit with multiple } \\
\text { functions, focus on multiple } \\
\text { use of assets }\end{array}$ \\
\hline $\begin{array}{l}\text { Chain } \\
\text { Relations }\end{array}$ & $\begin{array}{l}\text { (Pro-)active related to } \\
\text { organisations in the value } \\
\text { chain, network oriented }\end{array}$ & $\begin{array}{l}\text { Passive related to organisations } \\
\text { in value chain, farm internal } \\
\text { oriented }\end{array}$ & $\begin{array}{l}\text { (Pro-)active related to broader } \\
\text { set of networks }\end{array}$ \\
\hline & $\begin{array}{l}\text { Explicitly refers to his position } \\
\text { in value chain as an active }\end{array}$ & $\begin{array}{l}\text { Implicitly refers to current value } \\
\text { chain as 'the normal thing to do' }\end{array}$ & $\begin{array}{l}\text { Explicitly refers to added value } \\
\text { the farm has to offer }\end{array}$ \\
\hline
\end{tabular}
choice

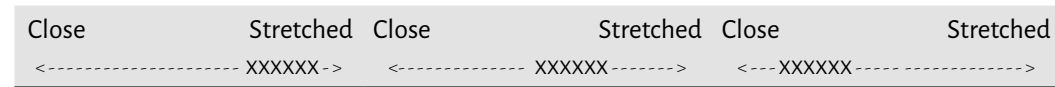

Positions as dairy farmer Positions as dairy farmer as a Positions as (dairy) farmer with runningabusiness way of life strongly based in multiple services on offer for local culture society

Farm and family not necessarily Farm and family are connected, Farm and family are connected, linked less life style farming life style farming the farm is seen as a family business

Socio- Focus on (agri-)business Focus on agricultural networks, Focus in- and outside Cultural networks, local relations are mainly local or supplier related agriculture, has interest in Relations personal rather than farm agriculture, has interest in
(developing) local and suprarelated local networks

Explicitly refers to the socio- Implicitly refers to 'traditional Explicitly refers to farm as cultural relations using a farming' in the socio-cultural active connector in sociorational approach context cultural relations

\begin{tabular}{|c|c|c|c|c|c|}
\hline Close & Stretched & Close & Stretched & Close & Stretched \\
\hline$<-\ldots$ & $x x x x X \ldots>$ & $<--x$ & 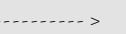 & $<-\cdots$ & - \\
\hline
\end{tabular}

Decision which resources to Decision which resources to Decision which resources to use is an active choice based use is an active choice, feed use is a passive choice, feed on an economic calculation from own land with added from own land with added aiming to maximise output concentrated feed concentrated feed

Local nature and landscape is Local nature and landscape is Local nature and landscape is seen as potential constraint for valued, yet seen as possible valued as added value in the development constraint context for the farm

Natural

Resource Relations
Origin of resources is of secondary importance
Resol

Resource base is primarily local, additional resources to optimise

Explicitly evaluates resources Explicitly evaluates resources

on economic added value as part of the cycle of nature to maximise a cost effective production

\begin{tabular}{|c|c|c|c|c|c|}
\hline Close & Stretched & Close & Stretched & Close & Stretched \\
\hline$<\ldots$ & XXXXX -...> & $<\ldots$ & . n . > > & $<-$. & - n \\
\hline
\end{tabular}




\subsection{Discussion and conclusions}

This paper studied the three-fold embedding of the three ideal-typical patterns of dairy farming that were found in a case study of dairy farmers operating in a highly comparable context. The aim of the paper is to enhance our understanding of the heterogeneity in farm development. The patterns were found to differ in the extent of their embedding for the three dimensions. In this section we will discuss the methodology and the findings and draw our conclusions.

\section{The methodology}

The plausibility of the results of this study to be generalizable for (Dutch) dairy farming in general is high. Kampereiland as case study has specific characteristics due to its location close to nature protection areas, its socio-material history and all farmers being tenant farmers, this situation affects the challenges for the farmers in farm development. However, the challenges for the farmers in Kampereiland are in itself not unique, dairy farmers all over the Netherlands face these sort of challenges. The uniqueness of the case study is the highly comparable context for all dairy farmers in the case study area that does allow to study differences between farmers. The focus of this study is not on the relation between the context and the pRfM of the farmer but on the differences between farmers in their pRfM while operating in a highly comparable context. The different patterns that were found on the basis of differences in the pRfM were acknowledged by farming experts as valid for Dutch dairy farming in general. In other regions the percentage of farmers that is part of a specific pattern may very well be different or a sub-pattern might be identified as a separate pattern. This means that for use in practice the results cannot be copied without adaption to other regions. From a theoretical perspective there is however no decisive argument affect the plausibility for a generalization of the findings.

A second question is whether the use of ideal-types is suitable as most family farms will differ to some extent from the ideal-typical farm and farmer. Using idealtypical farmers places the focus on a specific set of characteristics. In reality a mixture of characteristics and motivations will be found as was the case in the Kampereiland case study. The aim of this study is however to study patterns of variance in empirical observations which are in itself complex and diffuse (Soliva 2007, 64). Ideal-types have been found to be a useful tool to study patterns of variance (Doty and Click 1994). The findings of this study need to be interpreted as a study on differences between different 
development patterns of farmers. The results are not to be interpreted as a description of specific farmers with a fixed set of characteristics.

\section{The findings}

Heterogeneity in farm development is well documented in literature on farming styles (Long and Ploeg 1994; Ploeg 2003; Ploeg and Ventura 2014) and in relation to resilience of farms (Darnhofer 2010). Heterogeneity in farm development cannot be reduced to 'external' structural forces such as 'markets' or 'nature' impacting on farming, even when these are mediated by capable farmers into their every farming practices and decisionmaking. The socio-cultural embedding of farmers, their shared values and norms and how they see themselves as a farmer or like to be seen, do matter significantly in explaining different farm development strategies and result in different patterns of farm development. And as this study has shown, this includes farmers' perception of opportunities for (future) farm development. The combination of socio-cultural embedding, value chain embedding and the natural resources embedding does matter for the development of the farm. This three-fold embedding of farming offers a new perspective on different patterns of farm development, more specifically on the coherent strategic and operational decisions that farmers make in line with their mix of being embedded. When looking at the differences in the embedding found in this study it is clear that embedding is indeed better served by viewing it as gradual and not binary in nature. Farmers do vary the 'sliders' of their 'mixing panel' in how they express their embedding in each dimension of three-fold embedding. The farmers do so according to their views and capacities, and their perceptions of opportunities for farm development, while taking into account the dynamic setting they operate in The three-fold perspective offers as well the possibility for a symmetrical analysis of embedding and highlights the differences as gradual in contrast to a binary approach. This helps to avoid the binary view of farming as being either (locally) embedded or (locally) dis-embedded. The results show to what extent farmers differ in their threefold embedding on a scale between a Close and a Stretched set of relations. The three ideal-typical farms differ in the rationale presented by farmers and stakeholders when asked to describing the characteristics of the three patterns of farm development The findings show that no strict lines can be drawn in the demarcation of farm development strategies, the transition from one strategy to another is not on a fixed position in three-fold embedding. Different levels of embedding may even result in similar visible farm characteristics, but in effect reflect different rationales. There is a 
difference between patterns in the explicitness of the reasoning for the positioning in three-fold embeddedness. Both Milk Max and Milk Plus are explicit in the positioning for all three dimensions. For Milk Balance, however, the positioning is only explicit for the use of resources, this positioning is in line with their emphasis on optimising the on-farm available resources and a focus on the craftsmanship of dairy farming. Milk Balance is more implicit in the positioning in the embedding in the value chain and socio-cultural relations, it appears that an explicit positioning is not needed as their farm practices are for them the 'obvious' practices for running a dairy farm. However, an explicit reasoning not necessarily means that farmers' perception of opportunities for farm development is the most preferred farm development strategy. The findings do show that farmers who perceive a Milk Max or Milk Plus strategy as viable appear to be more explicit and more pro-active in their positioning in value chains than a farmer with a Milk Balance strategy. This indicates a more pro-active approach towards creating room for manoeuvre for farm development. This is likely to be in line with being active in networks outside the traditional, local oriented agriculture network.

\section{Three-fold embedding as analytical tool}

The three-fold embedding focusses on the different sets of relations of which farming is part of, and embedded in. It thus takes a relational approach to farming and farm development (Darnhofer et al. 2016). How the family farm is related to the value chains, the socio-cultural relations and the natural resources is strongly connected to the perception of the opportunities for farm development. These differences can then be related to differences in farm development and to dealing with pressures on farm development, e.g. protection of landscape or nature values. The range of pressures on farm development (Feola et al. 2015) makes it a difficult task for a farmer to fully pursue his desires. Especially diversifying production (Milk Plus) is not a straightforward and easy decision and the motives for diversifying are complex and include non-economic aspects (Hansson et al. 2013). Three-fold embeddedness offers an avenue for further research on these motives for diversifying. A next step in the research can focus on the agency of the farmer in creating room for manoeuvre for farm development. Does the farmer create the favourable conditions in line with the mission, strategy and goals, or does the farmer perceive the local socio-material conditions as a given situation within which the mission, strategy and goals can be defined and realised? Whether farmers are able or not to enlarge their room for manoeuvre is of interest for both farm and regional development, especially in regions with natural and landscape values as amenities. The development of a farm, and the developments of different 
farms, in such a region affect the local surrounding and thus the valued assets. A better understanding of the different strategies and the different ways in which farming practices are embedded in value chains, socio-cultural relations and natural resources can help to support the development of adequate policies and support programs. 


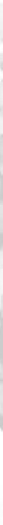
bet rom 


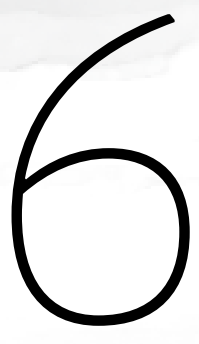

Discussion and conclusion

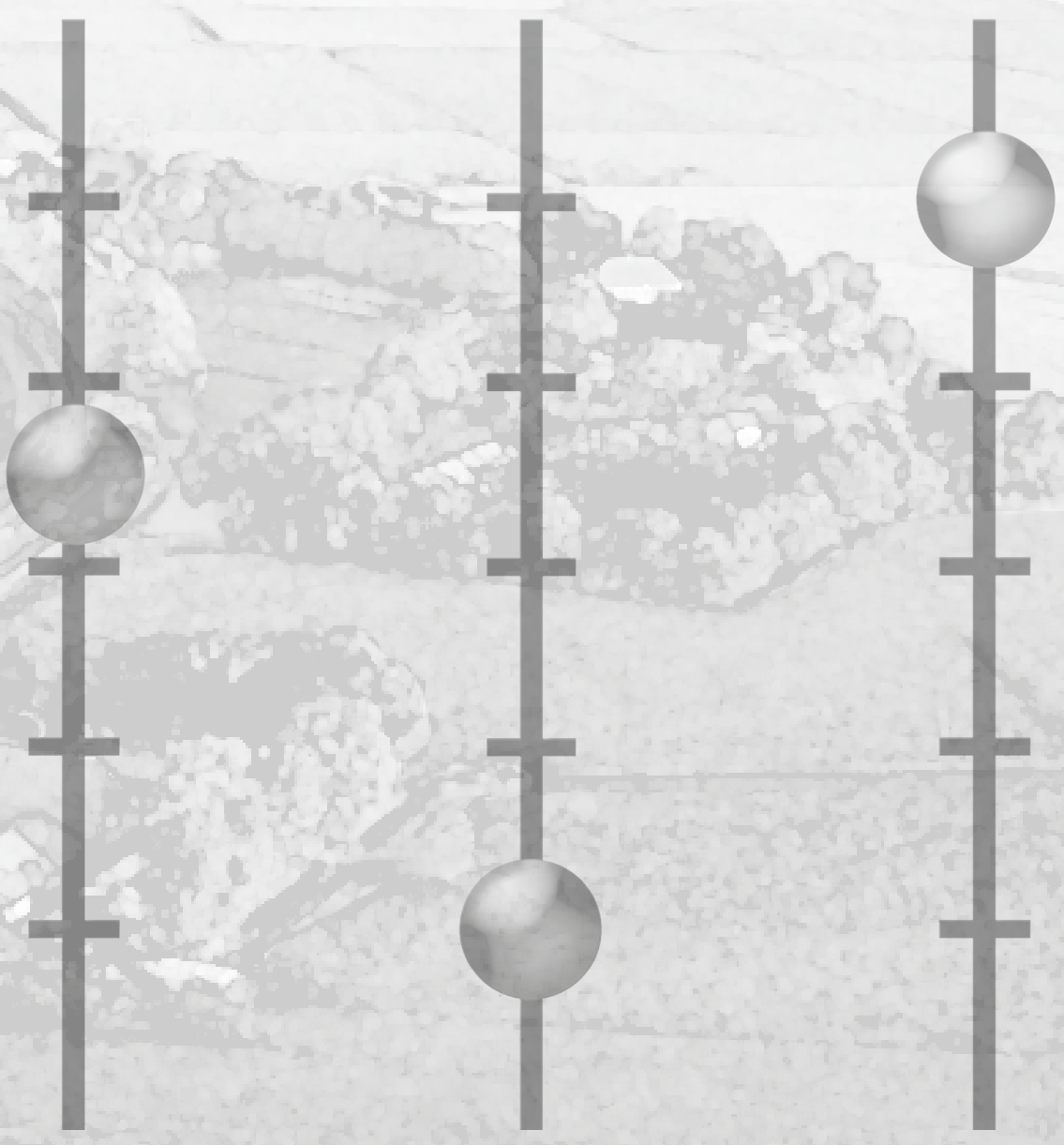



In this final chapter, the findings are presented to discuss the contribution of this thesis in the light of the problem definition: the need to advance the understanding of the Sociology of Entrepreneurship in the context of farm development, as it offers an avenue to better understand Strategic Decision-Making as a subjective process that is related to the embedding of the farm in its socio-material context. Sociology of Entrepreneurship approach was expected to open an avenue to study differences in farmers' perception of opportunities for farm development and to study how these differences are related to differences in the embedding of their farm in the socio-material context. Paragraph 6.1 briefly presents the background of the research questions and then presents the findings in the light of the problem definition. Paragraph 6.2 takes a critical perspective of the methodology used in this study. Paragraph 6.3 describes the contribution this thesis makes to the development a view on Sociology of Entrepreneurship. Paragraph 6.4 describes the implications of the findings for further research followed by Paragraph 6.5 that describes the implications of this thesis for practice.

\subsection{Findings}

This thesis builds on research views from rural sociology, small business development and entrepreneurship research to study the heterogeneity in farm development. Firstly, farmers are knowledgeable and interpretive actors whose actions are guided by, but not determined by, the social structures. Farmers have a room for manoeuvre to select farm strategies in order to balance the different interests they need to handle. Secondly, farmers' perceptions of opportunities are important to understand the strategic decision-making process (SDM) that lead to strategic decisions on farm development The subjective perception of the set of opportunities for farm development is more important for strategic decision-making than a formal analysis. This means that there is a need to further develop a subjectivist view of entrepreneurship, more specifically on the identification of opportunities as part of the strategic decision-making process. Thirdly, more knowledge is needed on how family farms are embedded in their socio-material context and on how the embedding of the farm relates to the farmers' perception of the room for manoeuvre for farm development.

This thesis therefore looks at two aspects to study the heterogeneity in farm development: 1) farmers' perception of opportunities; and 2) the embedding of farm practices in the socio-material context. For this purpose two analytical concepts are used: the perceived Room for Manoeuvre (pRfM) and Three-fold embedding. The 
analytical concept pRfM is defined as: 'the opportunities perceived as viable by the farmer in order to obtain a (substantial part of) farm income' (see paragraph 2.4) and Three-fold embedding is used to study the extent of embedding of the farm in three dimensions: socio-cultural relations, resources relations and value chain relations (see paragraph 2.3). The aim is to contribute to the understanding of the heterogeneity in farm development by studying how farmers are different in their pRfM, what drives these differences and how do the farmers differ in the embedding of farm practices. This is translated in the following three research questions:

1. What are the differences in farmers' perception of opportunities for farm development while operating in a highly comparable context?

2. What are the most important drivers for differences in farmers' perception of opportunities for farm development?

3. What are the differences in the embedding of the farm practices that are linked to differences in farmers' perception of opportunities for farm development?

A unique case study of family dairy farms operating in a highly comparable sociomaterial context of the farms in the case study area allowed for a combination of quantitative and qualitative methods to answer the research questions (see paragraph 2.5). The results are described in full in chapter three, four and five. Below the answers to the three questions are presented in perspective to the broader research aim.

\section{RQ1: Differences in farmers' perception of opportunities for farm development}

In the case study of family dairy farmers operating in a highly comparable sociomaterial context, difference were found in farmers' perception of opportunities for farm development. Farmers differ in their perception in three dimensions: 1) opportunities to diversify farm production; 2) opportunities to end farm production; and 3) opportunities to maximise farm production. The individual position of a farmer on these three dimensions signifies the pRfM of the farmer. Looking more closely at the differences between farmers, four clusters were found that represent different patterns of farm development, the patterns of farm development were consistent and coherent and were as well recognised by relevant stakeholders as representing meaningful differences. These differences in perceptions are meaningful as they coincide with distinct differences in farm development strategies, strategies that are part of the heterogeneity in strategies that is known to exist in family dairy farms. 
The following four farm development patterns were found in the total of 79 family dairy farmers:

1: $\quad$ Milk Max: Maximising production $(\mathrm{n}=29)$

Focus on maximising production per ha using imports of feed next to own feed production. Joint farming is seen as 'maybe possible'. Energy production may add to farm income.

2: $\quad$ Milk Balance: Optimising resources $(n=21)$

Focus on milk production using on-farm produced feed with limited inputs of (concentrated) feed. The use of the farm as production unit is optimised. Off-farm job and energy production are seen as possible opportunities.

3: $\quad$ Milk Plus: Diversifying production $(n=21)$

Focuson milkproduction possiblycombined with on-farm diversification. The use of the place where the farm is located is optimised. Dairy farming is based primarily on own produced feed, comparable to Milk Balance.

\section{4: $\quad$ End Milk: Ending production $(n=8)$}

Focus on ending dairy farming in the near future, income from other activities (possibly retirement). Currently optimising on-farm resources, possibly an off-farm job or another company.

These findings confirm the differences that have been found in earlier research on farming styles in family farming. Being able to identify farming styles using the analytical concept pRFM underlines and strengthens the understanding that a farming style is a coherent set of characteristics and that the views and preferences of the farmer is a vital driver for the differences between the farming styles. The patterns of farm development that were found should however not be interpreted as a blueprint, farmers within one cluster may have different motivations for their strategic choices, farmers may be 'in between' different patterns or share parts of the characteristics or motivation with other clusters. The latter might be a reason why some studies found it hard to distinguish farming styles (Vanclay et al. 2006).

As concluding answer to this research questions it is clear that the analytical concept of pRfM allows to distinguish differences in family dairy farmers' perception of opportunities for farm development. Secondly this finding confirms that there are differences in farmers' perception of their room for manoeuvre for farm development, even when operating in a situation of a comparable socio-material context of the farm. 
Being able to identify meaningful differences in farmers' perception opens the route to study the drivers for the differences that were found.

\section{RQ2: Drivers for differences in farmers' perception of opportunities for farm development}

Based on the explorative phase of this study a range of seven drivers was identified: 1) personal views and preferences; 2) personal development; 3) view on entrepreneurial competences; 4) view on continuation of the farm; 5) view on current business situation; 6) view on market developments; and 7) view on urban-rural relations. In the combined set of drivers on the three dimensions of pRfM, the most influential driver and the only driver significant for all three dimensions is personal view and preferences. The total set of significant drivers is as well different for all three dimensions. For the dimension 'diversifying' the only other driver is personal development, which points to a strong link to the personal characteristics of the farmer as important for 'diversifying'. For the dimension 'maximising' the other drivers are view on own competences, view on current farm situation and view on markets. This set of drivers is clearly different from the set of drivers for 'diversifying'. For the dimension 'ending' the other drivers are view on continuation/ family in combination with personal development and view on current farm situation.

When taken together, the influence of the driver personal views and preferences is more important than the economic drivers which underlines that the perception of opportunities is highly influenced by subjective drivers. In searching for the room for manoeuvre, the opportunities for farm development, the agency of the farmer is highly influenced by the personal views and preferences of the farmer. This indicates that the personal views and preferences act as a sorter in selecting opportunities to be analysed in a strategic decision-making process. The identification of all possible opportunities does not seem to be the primary goal, but rather to look for opportunities that are in line with personal views and preferences.

\section{RQ3: Differences in the three-fold embedding of farm practices}

The ideal-typical characteristics of the three patters of farm development (based on differences in the pRfM), show differences in the embedding in value chain relations, the socio-cultural relations and the natural resources relations. For each of these three dimension the ideal-typical farm is positioned on a scale between a 'Close' or a 'Stretched' set of relations. The combination of the three dimensions of embeddedness makes a 'fit' with the ideal-typical characteristics. This combination can be viewed as three sliders on a mixing panel, the farmer positions the sliders as a result of strategic 
decision made on farm development in relation to the socio-material context. An important difference between the three patterns of farm development is whether the positioning in relation to the socio-material context is made in an explicit or in an implicit manner. When the embedding is based on an implicit positioning, it might be argued that the farmer is less aware of the agency in creating the relations. The results underline that embedding is a process under influence of changes and development and not a state of being that is fixed. This is expressed in using the word 'embedding' as opposed to the word 'embeddedness', the embeddedness (as noun) is the result of the activity of embedding (as verb). When the embeddedness of a farm is described, it is like taking a photo at a specific moment in time. A new photo taken at a later moment can show a different embeddedness as a result of the on-going process of embedding.

Approaching three-fold embedding using a scale proved to offer potential. Based on the characteristics of the ideal-typical farm for the three patterns, different positions on this scale could be determined. It is as well clear that this positioning is not an exact measurement, it needs an informed judgment. Using three-fold embeddedness and the approach of placing embedding on a scale does allow for a non-binary and non-normative view on embedding. The specific three-fold embedding of a farm can be linked to the farm development strategy, the three ideal-typical characteristics showed to be different in their three-fold embedding in the socio-material context. This offers potential to further study the nature of the relation between embedding and farm development strategy using the perspective of the farmer. There seems to be a difference in what relation is most important for the family farms in making their decisions. The total mix of relations does need to fit the farm strategy and some relations can be adapted to make them fit, some relations however cannot be changed which may create a tension with the chosen farm development strategy.

These findings answer the three research questions. Family owned dairy farmers differ in their perception of opportunities for farm development and use their agency in strategic decision-making in different ways leading to different farm practices. The personal views and preferences of the farmer is the most important driver for differences in farmers' perception of opportunities for farm development. The range of other drivers do affect the perception, yet the personal aspect is the most important for the perception of the developments in the socio-material context of the farm. Based on differences in the pRfM, different farm development patterns were identified that are different in the three-fold embedding in the socio-material context of the farm. There appears to be a relation between the perception of the farmer of the opportunities for farm development and the three-fold embedding of the family farm. 
The findings thus support the validity of the analytical framework presented in figure 2.1. The reiterative nature of the relation between strategic decision-making, farm practices and embedding is created by the link with opportunity identification in the early phase of the strategic decision-making process. The farmers' perception of opportunities, the perceived room for manoeuvre, is importantforthestrategicdecisionmaking process and, as this thesis has shown, this perception is strongly affected by the personal views and preferences of the farmer. The views and preferences of the farmer are in turn affected by the farmers' experiences and the influence of the networks in which the farmer operates and participates. This means that the embedding of the farm and the pRfM are related. When a farmer changes the positioning of the farm in the sets of relations it leads to a change in the influence of actors and developments in the socio-material context. A changing influence affects the farmers' perception of the context and this in turn affects the pRFM. When taking a step back from these results, it can be stated that strategic decision-making is in fact the process of embedding the farm practices in the socio-material context.

The relation between embedding and perceived room for manoeuvre is not a linear relation in the way that a specific change in the embedding will lead to a predictable effect on the perceived room for manoeuvre. The same is true for the influence of the farmers' personal views and preferences on the perceived room for manoeuvre. This thesis did find the personal views and preferences to be the most dominant driver to explain differences in the pRfM. However, the personal views and preferences cannot be seen in isolation from the effect of other drivers in the sociomaterial context on the pRfM. What can be stated is that the results underline that the influence of the combined set of drivers on the pRfM is mediated by the farmers subjective view on these drivers. In line with this reasoning it is clear that fully external factors only exist in a theoretical view of strategic decision-making. In processing the information, the farmers' perception of the 'farm-external' situation is influenced by the 'farmer-internal' views and this make the 'farm-external' situation subjective. A step forward would be to use the words internal and external in combination with the word influence when discussing strategic decision-making.

\subsection{Reflection on methodology and generalizabilty}

This research uses both quantitative and qualitative methods in the context of a case study. The case study, dairy farmers on Kampereiland, was selected for its highly comparable socio-material context of the farms in the case study area. This highly 
comparable context offered a unique possibility to study differences in farmers' perception of opportunities for farm development. The combination of quantitative and qualitative methods in the context of the Kampereiland case study proved successful in answering the research questions. However, a critical review of the methods used is needed to verify how the methods used may have influenced the results and how this affects the generalizability of the findings. The generalization involves two main findings: 1) the finding of personal views and preferences being the most influential driver for the perceived room for manoeuvre of farm (business) development, and 2) the revealed patterns in perception of opportunities that were found in dairy farm development in Kampereiland. The generalization of these two findings needs to be considered at the following levels: a) are the findings representative for the whole of Kampereiland, and b) can the findings be generalized to Dutch dairy farming, and in last instance c) can the findings be generalized to other small family businesses. In the following section the topic of possible influencing characteristics of the selected case study will be discussed followed by a section on the method of acquiring data and data analysis. This paragraph will be concluded by a section addressing the generalizability of the findings.

\section{The selected case study}

As described in paragraph 2.5.1 the context of dairy farming in the Kampereiland case study is unique in being highly comparable for all dairy farms at the level the case study area. The context as such is however not very different from the general context in which Dutch dairy farmers operate. Three aspects of the specific context of the case study area of Kampereiland do however need to be examined as these aspects possibly affect the generalizability of the findings: 1) the situation of farm tenancy; 2) the absence of organic farmers; and 3) the situation in the family farms in relation to gender and inter-generational situation.

Looking at the first issue, the situation of farm tenancy, this needs attention as this aspects makes the context markedly different from most other dairy farm regions. All the land is owned by one party and given in tenancy to the farmers. The first, explorative phase of the research pointed to two important aspects of the tenancy situation that affect dairy farm development: 1) the high number of farmers still active; 2) less access to capital as land in tenancy cannot provide security for a bank. These aspects will be discussed on the possible influence on the findings.

The number of farms still active is affected by tenancy in two ways: 1) less farmers stop farming, and 2) more young farmers continue the family farm. Looking at the first issue, farmers are less inclined to stop farming as less capital comes available for other 
purposes when the farm stops as the farmer cannot sell the land in tenancy. For farms with land in ownership the sale of land creates free capital that can be used to either start a new activity or for pension. This means that a farmer in Kampereiland is less likely to stop early for retirement. To continue farming is indeed a financially attractive option, especially when a 'roll out' strategy is followed, a term used by stakeholders pointing to the strategy to continue farming without investing in the assets of the farm. This strategy lowers the costs of farming and thus leaves a bigger part of farm income for the farmer. This argument is however not exclusive for tenant farmers. In tenant farms it is easier for young farmers to continue the family farm as the need for capital to take over the assets is much smaller than in a situation where the land is owned. A young farmer takes over the tenancy contract and can continue without the need of big loans to acquire the land. For Kampereiland this means that out of the original 170 farms in the 1960 's, 110 farms, or $65 \%$, are still active in 2013. This percentage is $11 \%$ for the Netherlands in total, coming down from 180.000 dairy farms in 1960 to 19.000 in 2014 (LEI 2016). The comparison is however not fully valid, as in 1960 the farms in Kampereiland were already specialised dairy farms with on average more land and cows per farm (Dijksterhuis 1968). In the Netherlands in total most dairy farms were mixed farms of which many had a small number of cows making it more likely to end dairy farming. However, most interviewed stakeholders indicate that in their opinion the number of farms still active in 2013 is positively affected by the situation of tenancy. This means that there is, and was, less possibility in Kampereiland to enlarge the farm by taking over the neighbouring farm. Since 2005 the lessor does allow joint-farming by two or more farms. In joint-farming the land of two or more farms is combined and the dairy cows are concentrated on one farm leading to scale enlargement. A small number of farmers have used this possibility.

Lower access to capital for investments is due to the fact that a dairy farm cannot use the land in use as security for loans by a bank. This means that it is more difficult to get a loan form a bank and that loans have a higher interest rate and a shorter payback period (Methorst 2013). Not having land in ownership therefore decreases the perspectives for acquiring capital for investments. It is therefore likely that a farm in Kampereiland that does own land besides the land in tenancy, the perception of opportunities for farm development is influenced by the easier access to capital. In the case study area a number of farmers do have land in ownership (outside of the case study area) and a number of farms do not have land in ownership. In interviews with farmers that fact of owning land was often described as important for being able to invest in the farm. So there is a difference between farmers in Kampereiland 
in the access of capital for investments. Differences between farmers in the financial position and in the investment possibilities are in itself not remarkable. In the reality of farming, differences in the financial situation can be the result of differences in farm management, differences in farm development strategy, experiencing misfortune or merely benefitting from accidental benefits like an inheritance. This means that differences in the access to capital is an issue to take into account. This thesis has integrated the differences in the financial situation of the farm in the analytical framework via the driver 'view on business situation'. In case the differences in being able to acquire capital were of major importance it would have shown in the results.

The second issue is the absence of organic farmers in the Kampereiland case study. In the Netherlands $1.9 \%$ of the dairy farmers is organic and in the Kampereiland there was no organic dairy farmer in 2013. One farmer had started the conversion period however and later became certified organic. Three farms in Kampereiland were not certified organic but did take part in a concept of dairy farming based on maximizing milk production based on own grass production with as little as possible import of feeds from other sources. This type of farming in many aspects reflects the principles of organic farming in being oriented towards low input farming. All four farmers participated in the survey. This means that four out of the 102 farmers were close to the principles of organic farming which is within the normal range as can be expected based on the Dutch average of $1.9 \%$.

The third issue is whether the gender and generational situation in the case study area affects the findings and therefore the generalizability. In the strategic development of family farms, the influence of woman in the farm is very important, particularly in the case of diversifying into a multifunctional farm (Seuneke and Bock 2015; Bock 2004). And as Hansson (2007) showed, the family situation affects the outcome of micro level network discussions on farm development. A study by Van Meulen et al (2015) showed that young people active in farming in the Netherlands were ambitious and versatile in their approach to farming. This means that it is important to know if the situation in the Kampereiland case study regarding gender and generational issues is different from other dairy farms in the Netherlands. The interviews and desk study in the explorative phase of this research did not lead to indications that the situation in the case study area regarding gender and generational issues in dairy farming is markedly different from the situation in the Dutch dairy sector in general. 


\section{Data and data analysis}

In this thesis the perception of the farmer is a central issue. The central analytical concept is the perceived Room for Manoeuvre and the drivers mentioned in the analytical framework as well mostly relate to the views or perceptions of the farmer. The answers presented by the farmer provided the data for the analysis. When asking for views and perceptions the answer is a subjective answer and the given answer cannot be checked on representing an objective truth. This makes the dataset vulnerable for either a misunderstanding of the question asked or for an attempt to influence the results by providing information that would steer the results in a certain direction. On the questionnaire used in this thesis the following aspects need discussing: 1) is the questionnaire answered by the right person; 2 ) is there a possibility that presenting a list of opportunities influenced the answers; and 3) the quality of the answers.

The first question is whether the questionnaire is answered by the right person. Family dairy farms predominantly have shared ownership with one or more family members. Different owners may differ in their perceptions on viability of opportunities for farm development, especially when ownership is shared between different generations. The covering letter for the questionnaire specifically noted that the questions were meant for the person most involved in strategic decisions on farm development. It can however not be guaranteed that this was the case for all respondents. Nevertheless, the overall consistency of the results supports the validity of the answers given. The second question is whether presenting a list of opportunities may have affected the answers given. To avoid problems with data analysis by missing values, it was important that all farmers would indicate their perception of the viability for all opportunities. In designing the questionnaire the results of the interviews in the exploratory phase were used which showed that the opportunities presented to the farmers werewell-known. Presenting the listwould therefore not affect their knowledge prior to answering the question. To ensure that the list represents 'the total playing field' of dairy farm development the questions were based on the explorative, ethnographic study of the context of dairy farming in Kampereiland in Phase 1. The questionnaire was discussed and tested with both experts and farmers. The blank option presented to the farmers did not bring forward opportunities outside the list of opportunities presented. The third question is about the quality of the answers given. Does the answer reflect the view on the reality of the situation of the farm or is the answer a reflection of their view on the most desired farm development. The questionnaire asks farmers to answer on a 5-point Likert scale. In designing the questionnaire care was given to the formulation of the questions to avoid any hint to a positive or negative judgment 
about an option or a development. The questionnaire was tested with farmers on the meaning of the questions and adapted if necessary. Specific attention was paid to be clear and specific in the questions so that the answer would be straightforward and the question would be interpreted as much as possible as it was meant to be. However, answering questions in a survey is in essence a communication between the researcher and the person answering the question (Niska et al. 2012, 6), even when it means to tick a box in answering a question. Part of the questions will touch on subjects that reflect a position on what farming is all about and therefore the answer will be influenced by the values of the farmer. However, in essence that is exactly the core of this thesis, studying the perception of the farmer of the opportunities for farm development. In the light of this discussion the finding that farmer's views and preferences are very important for the perception of the opportunities confirms the fact that a situation or a question cannot be answered fully neutral. The internal coherency of the data resulting from the survey do underline that the farmers answered in a consistent way and that the way the questions were phrased as such was neutral in its effect on the results.

For this thesis a mix of statistical methods was used: Principal Component analysis to determine the factors which is described by a number of questions, two-step cluster analysis to determine whether there are clusters of farmers with comparable factor scores and multiple regression analysis to determine the relative effect of a range of independent variables on the model that best explains the outcome of three factor scores that are underlying for the clusters of farmers which were found. The statistical methods allowed a quantitative analysis of the data resulting from the questionnaire. The results indicate that by asking farmers their perception of the viability of a number of opportunities for the development of their farm, a quantitative measurement of the perceived Room for Manoeuvre of the farmer is possible. In the scope of this research the methods were successful to answer the research questions. An important aspect to support the validity of the methods is the internal coherency of the results. The coherency was tested using triangulating of the results based on: 1) the statistical analysis of the answers of the questions in the survey; 2) the available data on the farm production characteristics of the farmers; and 3) the interviews with farmers and stakeholders in farm development. Combining the information from these three sources supported the internal coherency and consistency and the meaningfulness of the result for all stakeholders involved. This triangulation of results validates the methodology used and shows that the methodology developed for this thesis allows to answer the research questions. This does not mean however that the questionnaire is automatically validated for use in other studies. In case a validated measure is aimed 
for, a different validation process is needed including testing the sets of questions on different populations. The internal validation that is part of this thesis is however sufficient to reach the aim of this thesis.

\section{Ceneralizability of the findings}

In addressing the generalizability of the findings there are two main findings that need to be discussed: 1) the finding of personal views and preferences being the most influential driver for the perceived room for manoeuvre of farm (business) development, and 2) the revealed patterns in perception of opportunities that were found in dairy farm development in Kampereiland. When looking at these two findings the generalization needs to be considered at the following three levels: a) are the findings representative for the whole of Kampereiland, and b) can the findings be generalized to Dutch dairy farming outside of the case study area, and in last instance c) can the findings be generalized to other small family businesses. In the following part the generalizability of the two main findings is described for each of the three levels.

For the first level, are the findings representative for all farmers in Kampereiland, the findings are assessed as valid for all farmers of Kampereiland as the return rate of the questionnaire is nearly $80 \%$. The $20 \%$ non-respondents were assessed by local experts and found to be like the $80 \%$ respondents. This level of participation means the findings for Kampereiland are based on census and therefore have a high validity for dairy farms in Kampereiland. This means that for both the finding that personal views and preferences are most influential for the pRfM and for the revealed patterns in perception of opportunities, these findings can be deemed as valid for the whole case study area. The percentage of farmers for each of the revealed patters might change lightly, though given the relative low number of the non-respondents the effects are deemed to be small.

For the second level, the generalizability for Dutch dairy farms in general, the first remark is that within Dutch dairy farming large differences in degree of specialisation in dairy farming exist, both at farm level and at regional level. Secondly there are differences in the regions in terms of the local context: two important differences are whether there are more or less nature areas in the region and whether the region is more or less urbanised. These differences will affect the local context and therefore farmers' perception of opportunities for farm development. The plausibility of the patterns of farm development was tested by presenting the patterns to a number of stakeholders of dairy farming who work both in Kampereiland and in other regions in the Netherlands. These stakeholders acknowledged the general validity of the four clusters for Dutch family dairy farming in general. In different regions the percentage 
of farmers for each cluster is likely to differ as the context is different. There may as well be a situation where one of the clusters is split in two sub clusters which slightly differ. The finding that patterns of farm development can be found is therefore to be deemed as plausible for Dutch dairy farming. The characteristics of the patterns can be expected to be generally the same, yet the percentage of farmers for each of the patterns is likely to differ in different contexts. Depending on the local context an orientation more towards diversification of farming (in more urbanised regions) or an orientation towards more specialisation and intensification of production (in less urbanised regions that are not close to nature protection areas) can be expected. Looking at the main finding of personal views and preferences being the most influential driver for the perceived Room for Manoeuvre, there does not appear to be a clear reason to doubt the plausibility of generalizing this finding for Dutch dairy farming. Especially as the finding that personal views and preferences was most influential for all three dimensions of the pRfM: diversifying, intensifying and ending production.

For the third level, the generalizability for family run small businesses in general, more care is needed. In small businesses a range of different sectors can be found, each with very different characteristics. Dairy farming as small business is characterised by working with natural resources, living animals and a capital intensive infrastructure which gives them a high resource dependency (Bjerke 2007, 75). Dairy farms have a strong connection to the location due to the link with land and the use of capital intensive assets and therefore do not move easily. This means family dairy farming is a specific type of small business and the results need to be interpreted with these characteristics in mind. However, as described in paragraph 2.2, family farms do share important characteristics with small businesses as the farmer needs to fulfil different roles in the business in a complex combination of tasks and responsibilities combining the entrepreneurial, managerial and technical role as craftsman (Chandler and Jansen 1992). Farmers personally learn from the experience of running the farm, as do small business owners (Atherton 2003). This supports the plausibility that the personal views and preference of the business owner is as well most the influential driver for non-farming family run small business. There is no clear reason why differences in the perception of opportunities based on differences in the views and preferences of the business owner would not be found in other sectors. Testing the analytical concept pRfM in a different context of small businesses would be interesting. Such a test would require an operationalisation of the pRfM that is appropriate for the context of those small business owners. This bring as well the second issue in the discussion, the relation between differences in the perception of opportunities with specific patterns 
for business development cannot be transferred to other sectors. This is highly linked to the specific conditions and context in which a family business operates.

\subsection{Contribution to Sociology of Entrepreneurship}

The contribution of this thesis to a Sociology of Entrepreneurship is in showing the relevance of developing a relational perspective on farm development. In this relational perspective, strategic decision-making is viewed as the embedding of farm practices in the socio-material context, whilst the entrepreneurial actor interacts with all relevant aspects of this context. In this view, strategic decision-making is a reiterative process of embedding farm practices in the different sets of relations of the farm within the socio-material context. This context both enables and restrains farming practices, opportunity identification and strategic decision-making and thus farm development. The socio-material context is enacted in the effects of the strategic decisions made by the farmer. The farmer's interpretation of the complex and dynamic relations in the socio-material context affects the identification of opportunities for farm development. This perspective on entrepreneurship is presented in Figure 6.1. The contribution to a Sociology of Entrepreneurship is further elaborated in three parts: 1) strategic decisionmaking as a process of embedding (entrepreneurial) farm practices in complex and dynamic relations; 2) the entrepreneurial actor; and 3) a relational approach to study (farm) business development.

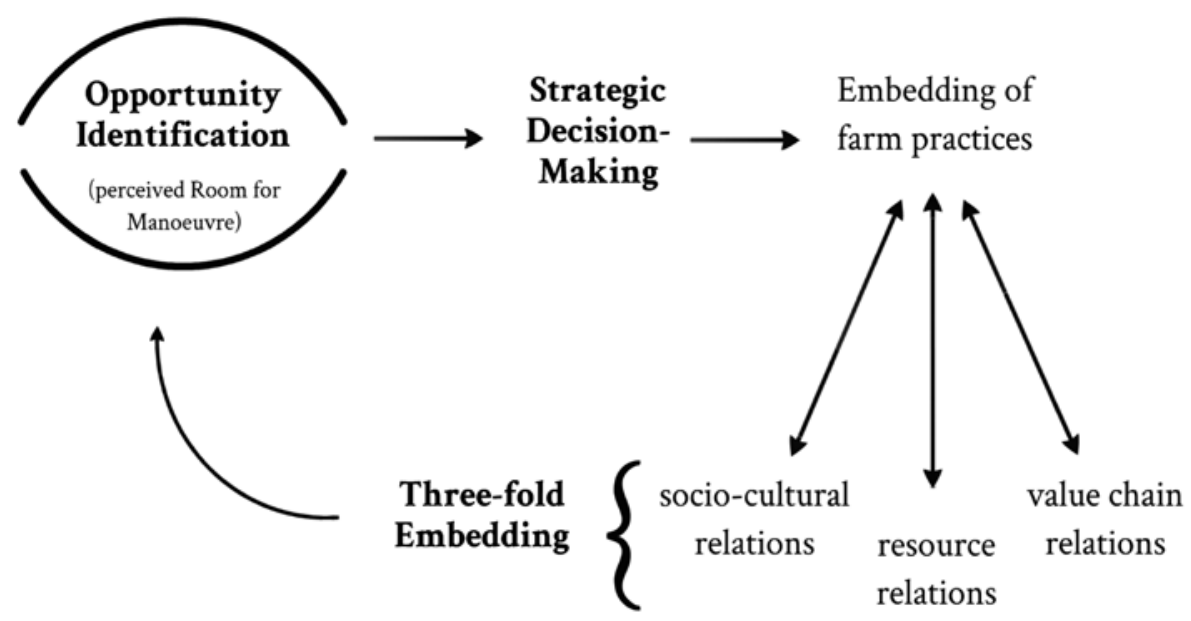

Figure 6.1 Strategic Decision-Making in relation to Opportunity Identification and Three-fold Embedding of farm practices 
1) Strategic decision-making as a process of embedding

Strategic decision-making is a reiterative process of an explicit or implicit embedding of the farming practices in complex and dynamic sets of relations that shape the sociomaterial context of the farm business. The socio-material characteristics of a farm, thus, result from, and reflect how it is embedded in a set of heterogeneous relations. Embedding the farming practices is the result of implicit or explicit decision in how to relate to the sets of relations in the different dimensions of the socio-material context. The embedding of the farm leads to spheres of influences that affect farmers' perception of the opportunities for farm development, this perception, in turn, affects the strategic decision-making process. Embedding is a reiterative process, the decisions made in the embedding in the sets of relations affect strategic decision-making and the strategic decisions influence the embedding in the sets of relations. Embedding offers a promising perspective in studying how an entrepreneurial agent relates the individual's business activities to the socio-material context and how, in using the agency, the business owner co-constructs the operational context, both in the business and its embedding in the wider context. This relation is a topic of growing interest in literature (McKeever et al. 2015; Thornton et al. 2011; Watson 2013).

2) The entrepreneurial actor

As an entrepreneurial actor a farmers embeds his entrepreneurial/farming practices and farm in the complex and dynamic socio-material context. A farmer cannot make decisions as though operating on a blank canvas, the socio-material context offers room for manoeuvre for farm development, as it both enables and constrains farm development. In this room for manoeuvre, the Embedding of the farm affects the exploration of opportunities for farm development that leads to the farmer's perceived room for manoeuvre. The farmer influences the spheres of influence for the identification of opportunities in the decisions on embedding the farm in the sets of relations in the socio-material context. The opportunities for farm development are enacted by the farmer: the farmer as an entrepreneurial actor cannot be separated from the identification of opportunities, just as the dancer cannot be separated from the dance (Sarason et al. 2010). The ability to identify different opportunities for farm development is named in literature as vital to be able to adapt to changes in the sociomaterial context (Darnhofer et al. 2010; Feola et al. 2015), an ability that is as well influenced by the decisions on the embedding of the farm. 
3) A relational approach to farm development

A farm and the wider context are co-shaped in complex, interrelated and dynamic relations, in which the farmer makes an effort to manage the relations in a certain direction. A relational approach to farm development offers an interesting perspective for a Sociology of Entrepreneurship to further study the relations of the farm with the complex and dynamic context as part of the agency of an entrepreneurial actor. The positioning in the relations shape both farm practices, and the context, in which the farm operates. Following a relational approach, the farm and its context cannot be separated, and the boundaries between internal- and external farm factors cannot be objectively defined. All factors are mediated by the farmer and the agency of the farm, and drawing boundaries is part of making sense of all interconnections. Making a distinction between internal and external might be useful the purpose of analysing yet it does to some extend obscure the specific interrelatedness and co-construction of the farm and its wider context. The support in this thesis for the development of a relational approach as part of a sociology of entrepreneurship is in line with a broader interest for a relational approach in literature (Woods 2011 in Heley and Jones 2012; Jones et al. 2013; Watson 2013).

In looking at the interrelations and interconnectivity between the family farm and the wider socio-material context and how this affects opportunity identification, strategic decision-making and in the end farm development, this thesis supports the view that the family farm can be seen as the materialisation of the implicit and explicit positioning in the relations of the farm with the socio-material context. The characteristics of the family farm and of the socio-material context are the result of a co-construction in the sets of relations. In these sets of relations, the farmer aims to manage the relations in order to balance the aims and needs of the family farm. In doing so, the personal views and preferences of the farmer are highly influential for the perception of opportunities for farm development.

\subsection{Implications for further research}

The research in this thesis on heterogeneity in family farm development within a dynamic and complex socio-material context is part of an on-going journey and the answers found in this thesis lead to new avenues for research. This paragraph will present three lines of interest for further study: 1) differences in perception of opportunities in other sectors of farming and small business; 2) personal views and 
preferences as driver for differences in the perception of opportunities; and 3) threefold embedding in the socio-material context in relation to development strategies.

1) Differences in perception of opportunities in other sectors of farming and small business

Theanalytical concept perceived Room for Manoeuvre proved useful to study differences in farmers' perception of opportunities for farm development. An interesting question is whether the concept allows to differentiate between farmers as well in other sectors of agriculture. An interesting sector is arable farming as the complexity is higher in both the range of products and in the marketing channels compared to dairy farming. A focus on small business outside agriculture is as well interesting as it can test whether the concept allows to differentiate in a meaningful way between business owners. The questionnaire would need to be operationalised according to the specific context of the (farm) business owners. Specifically for family dairy farmers it is interesting to study a possible effect of farm tenancy by comparing the results of this thesis with a case study of dairy farmers who have most of the land in use in ownership.

\section{2) Personal views and preferences as driver for differences in the perception of opportunities}

An important subjective element of opportunity identification is the influence of the personal views and preferences. Further research is needed to better understand the process that form and change personal views and preferences. This research can benefit from the work on farmer's self-identity (Burton and Wilson 2006; Hansson et al. 2012) and farmers' values (Niska et al. 2012). To what extent personal views and preferences can and do change is as well an interesting topic for education programmes purposes.

3) Three-fold embedding in the socio-material context

The analytical concept of Tree-fold Embedding opens a tool to study differences between farmers or business owners in their embedding in the socio-material context. A first question is if the analytical concept is meaningful in the context of small business outside the context of agriculture. This step would require a reconceptualization of the original three dimensions in the specific context of study. An interesting question is what triggers a change in farm development strategy and to what extent this is triggered by a change in the embedding. Is there a 'tipping' point where the embedding in one or more dimensions changes to an extent that it will translate to a change in farm strategy. This research can benefit amongst others from the work on trigger 
events (Sutherland et al. 2012). The three-fold embedding is as well a useful tool to further explore the view of farm practices as the result of a co-creation of the farmer and the socio-material context via the embedding in the sets or relations.

Apart from these three research avenues it is very interesting to use the research in this thesis as the start of a longitudinal research in farm development in the context of the Kampereiland case study. A longitudinal study can follow the development in the farm strategy over a period of ten or twenty years from now.

\subsection{Implications for practice}

Based on the findings in this thesis, practical implications can be drawn for both nonfarming stakeholders and for farmers and farmers' organisations.

\section{For non-farming stakeholders}

The findings in this thesis show that the perception of opportunities for farm development is highly affected by subjective parameters and therefore a very individual matter which means it is important to address the issue of views and preferences when discussing opportunities for farm development. In many regions a regional development programme is put in place to address the challenges facing the stakeholders in the region. A regional development programmes can be described as a dynamic process in a specific geographical area/region, with a certain amount of organizational direction, in which various stakeholders/actors, each with its own perspectives and goals, jointly and individually determine the challenges and opportunities for future development of the area/region in order to reconsider their joint and individual strategies. To be successful as development programs in the rural context, the decisions made by the farmers are vital as the farmers use most of the land (Berkhout and van Bruchem 2006). Farmers may be organised in a farmers' union that takes part in discussions on developments that affect farming, yet the farmers' union is not the final decision-maker for each individual farm. Each individual farmer makes the strategic decisions for the development of the individual farm. Most other stakeholder in a regional development process do have a central decision structure for strategic views and decisions. For regional development and support programmes to be successful, it is therefore important to connect on the level of the individual farmer in all aspects of communication and to address the topic of views and preference of the farmer. It is important to avoid a normative approach to certain developments, 
discussing the embedding of the farms in the socio-material context may very well open routes to discuss farm development in a non-normative and non-binary manner. This is especially of importance for the farmers that are not the forerunners in new developments but are inclined to hold on to traditional views of farming and farm development. Merely presenting opportunities for farm development that are preferred by other stakeholders (in practice this often involves diversification of farming) is more likely to result in resistance rather than an open discussion of the current situations and the opportunities to move forward.

Farmers who perceive maximising production as the best opportunity are less connected to the location of the farm. This separation between production strategy and farm location is expected to create a more tensed relation with policy schemes aiming to protect nature and landscape values for the maximising of production strategy. The diversifying production strategy is more connected to the location of the farm and to the family farm context. Diversifying production benefits from nature and landscape values, as it contributes to the rural setting on which their image is based in urban oriented markets. Therefore, local shareholders in favour of nature and landscape values are more likely to find a partner in farmers with a diversifying production strategy. For farms developing towards ending dairy production, the relation with policies on nature and landscape protection is less tensed as there is no expansion of activities foreseen. However, there will be a transfer of production factors to other farmers or stakeholders when the farm ends. For local stakeholders this transfer presents a momentum to represent the interest of nature and landscape as vulnerable community assets.

\section{For farmers and farmer's organisations}

This thesis shows that farmers' perception of opportunities for farm development is highly influenced by the personal views and preferences of the farmer. Obviously the personal view and preference is part of a range of influences on farmers' perception of opportunities. A farmer is far from free of influences in the socio-material context that have an effect on farm development. This thesis is however a reminder that the farmers' perception of opportunities in the given situation of the farm in the sociomaterial context is indeed subjective. This means that the farmers' perception of the opportunities is not the only perception that might make sense and that a change in view of the situation may change the perception of opportunities. The second important finding is the relation between the embedding of the farm in the sociomaterial context with farmers' perception of opportunities. Further research is needed 
to understand the nature of the relation: is the embedding of the farm the result of the strategies or is the strategy the result of the embedding of the farm in its sociomaterial context? Viewing the embedding of the farm as a three-fold embedding with three 'sliders on a mixing panel' may support the personal influence on the embedding of the farm. This personal influence than in turn connects to the personal views and preferences. For farmers and farmer's organisations it is important to acknowledge that farmers' views and preferences on farm development are subjective. This brings as well the responsibility for education programmes to focus on the subjective part of strategic decision-making in farm development. Challenging the personal views and preferences is a necessity for education programmes. Views and preferences do not necessarily need to change, however, challenging the views and preferences in a non-normative manner will support a more explicit positioning in the views and preferences. A non-normative manner can be found in the approach of three-fold embedding as it offers an avenue for discussing the views and preferences by looking at the three dimension of embedding in the socio-material context. Exploring different ways of three-fold embedding by farmers allows to reflect on the reasoning behind one's own positioning. 


\section{References}

Agriholland. Dossier Multifunctionele / Verbrede landbouw. Agriholland 2016 [cited September 8, 2016. Available from http://www.agriholland.nl/dossiers/verbredelandbouw/home.html.

Akgún, A. A., P. Nijkamp, T. Baycan, and M. Brons. 2010. Embeddedness of entrepreneurs in rural areas: a comparative rough set data analysis. Tijdschrift voor economische en sociale geografie 101 (5): 538-553.

Alsos, G. A., S. Carter, E. Ljunggren, and F. Welter. 2011. “Introduction: researching entrepreneurship in agriculture and rural development." In The Handbook of Research on Entrepreneurship and Rural Development, edited by C.A. Alsos, S. Carter, E. Ljunggren and F. Welter, 1-18. Cheltenham, UK: Edward Elgar.

Alsos, C. A., E. Ljunggren, and L. T. Pettersen. 2003. Farm-based entrepreneurs: what triggers the start-up of new business activities? Journal of Small Business and Enterprise Development 10 (4): 435-443.

Amit, R., and E. Muller. 1995. "Push" and "Pull" entrepreneurship. Journal of Small Business \& Entrepreneurship 12 (4): 64-80.

Anderson, A. 2013. Keynote at the 11th Rural Enterprise Conference, June 2013, Dumfries Scotland.

Ardichvili, A., R. Cardozo, and S. Ray. 2003. A theory of entrepreneurial opportunity identification and development. Journal of Business Venturing 18 (1): 105-123.

Atherton, A. 2003. The Uncertainty of Knowing: An Analysis of the Nature of Knowledge in a Small Business Context. Human Relations 56 (11): 1379-1398.

Atterton, J., and N. Ward. 2007. Diversification and innovation in traditional land-based industries. Rural Innovation, National Endowment for Science Technology and the Arts (NESTA): London.

Begley, T. M., and D. P. Boyd. 1986. Executive and corporate correlates of financial performance in smaller firms. Journal of Small Business Management 24: 8.

Benvenuti, B. 1989. "The autonomy in contemporary western commercial farming and the emerging of TATE." In Technology and small enterprises - technology, autonomy and industrial organisation, edited by Erik. Poutsma and Arnold. Walravens, 83-104. Delft: Delft University Press.

Bergevoet, R. H. M. 2005. Entrepreneurship of Dutch dairy farmers. PhD thesis, Wageningen University, Wageningen.

Bergevoet, R. H. M., C. J. M. Ondersteijn, H. W. Saatkamp, C. M. J. Van Woerkum, and R. B. M. Huirne. 2004 Entrepreneurial behaviour of dutch dairy farmers under a milk quota system: Coals, objectives and attitudes Agricultural Systems 80 (1): 1-21.

Bergevoet, R. H. M., and C. v. Woerkum. 2006. Improving the Entrepreneurial Competencies of Dutch Dairy Farmers through the Use of Study Groups. The Journal of Agricultural Education and Extension 12 (1): 25-39.

Berkhout, P., and C. van Bruchem. 2006. Landbouw Economisch Bericht 2006. Wageningen UR-LEI, Den Haag.

Beyene, A., D. Cibbon, and M. Haile. 2006. Heterogeneity in land resources and diversity in farming practices in Tigray, Ethiopia. Agricultural systems 88 (1): 61-74.

Bieleman, J. 1987. Boeren op het Drentse zand 1600-1910. Een nieuwe visie op de 'oude'landbouw. PhD thesis, Agricultural History, Wageningen University, Wageningen

Bjerke, B. 2007. Understanding entrepreneurship. Cheltenham, UK: Edward Elgar Publishing.

Bjerke, B., and C. Hultman. 2002. Entrepreneurial marketing: the growth of small firms in the new economic era. Cheltenham, UK: Edward Elgar Publishing.

Bock, B. B. 2004. Fitting in and Multi-tasking: Dutch Farm Women's Strategies in Rural Entrepreneurship. Sociologia Ruralis 44 (3): 245-260

Boogaard, B. K., S. J. Oosting, B. B. Bock, and J. S. C. Wiskerke. 2011. The sociocultural sustainability of livestock farming: an inquiry into social perceptions of dairy farming. animal 5 (09): 1458-1466.

Burton, R. J. F., and G. A. Wilson. 2006. Injecting social psychology theory into conceptualisations of agricultural agency: Towards a post-productivist farmer self-identity? Journal of Rural Studies 22 (1): 95-115.

Carter, S. 1998. Portfolio entrepreneurship in the farm sector: indigenous growth in rural areas? Entrepreneurship 8 Regional Development 10 (1): 17-32.

Casini, L., C. Contini, and C. Romano. 2012. Paths to developing multifunctional agriculture: insights for rural development policies. International Journal of Agricultural Resources, Covernance and Ecology 9 (3-4): 185-203.

CBS. 2016. 2016 [cited Sep 8, 2016 2016]. Available from http://statline.cbs.n//StatWeb/publication/?VW=T\&DM= SLNL\&PA $=81517 N E D \& D 1=a \& D 2=a \& D 3=a \& H D=131218-0854 \& H D R=G 2, G 1 \& S T B=T$. 
Chandler, C. N., and E. Jansen. 1992. The founder's self-assessed competence and venture performance. Journal of Business Venturing 7 (3): 223-236.

Chetty, S. 1996. The case study method for research in small-and medium-sized firms. International small business journal 15 (1): 73-86.

Clark, J. 2009. Entrepreneurship and diversification on English farms: Identifying business enterprise characteristics and change processes. Entrepreneurship \& Regional Development 21 (2): 213-236.

Cowan, R., and P. Gunby. 1996. Sprayed to Death: Path Dependence, Lock-in and Pest Control Strategies. The Economic Journal 106 (436): 521-542.

Culkin, N., and D. Smith. 2000. An emotional business: a guide to understanding the motivations of small business decision takers. Qualitative Market Research: An International Journal 3 (3): 145-157.

Curseu, P. L., P. A. Vermeulen, and R. M. Bakker. 2008. "The psychology of entrepreneurial strategic decisions." In Entrepreneurial strategic decision-making: A cognitive perspective, edited by Patrick AM Vermeulen and Petru L Curseu, 41-67. Cheltenham: Edward Elgar.

Darnhofer, I. 2010. Strategies of family farms to strengthen their resilience. Environmental Policy and Governance 20 (4): 212-222.

Darnhofer, I., S. Bellon, B. Dedieu, and R. Milestad. 2010. Adaptiveness to enhance the sustainability of farming systems. A review. Agronomy for sustainable development 30: 545-555.

Darnhofer, I., C. Lamine, A. Strauss, and M. Navarrete. 2016. The resilience of family farms: Towards a relational approach. Journal of Rural Studies 44: 111-122.

Dequech, D. 2003. Cognitive and Cultural Embeddedness: Combining Institutional Economics and Economic Sociology. Journal of Economic Issues 37 (2): 461-470.

Devereaux Jennings, P., R. Greenwood, M. D. Lounsbury, and R. Suddaby. 2013. Institutions, entrepreneurs, and communities: A special issue on entrepreneurship. Journal of Business Venturing 28 (1): 1-9.

Dijksterhuis, F. L. 1968. Ruilverkaveling "Kampereiland c.a.": rapport over de voorgeschiedenis, uitvoering en resultaten 19531966. Kampen: Cemeentebestuur Kampen.

Doty, D. H., and W. H. Click. 1994. Typologies as a Unique Form of Theory Building: Toward Improved Understanding and Modeling. The Academy of Management Review 19 (2): 230-251.

Duitman, L. 2005. Analyse melkveebedrijven op Kampereiland. Alfa-Berk-Countus, Kampen.

Edwards-Jones, C. 2006. Modelling farmer decision-making: concepts, progress and challenges. Animal Science 82 (06): 783-790

Eisenhardt, K. M., and M. E. Graebner. 2007. Theory Building from Cases: Opportunities and Challenges. The Academy of Management Journal 50 (1): 25-32.

Encyclo. 2012. Encyclo online encyclopedie. Slot Webcommerce bv 2012 [cited 15-08-2012 2012]. Available from http:// www.encyclo.nl/begrip/strategie.

Farmar-Bowers, Q., and R. Lane. 2009. Understanding farmers' strategic decision-making processes and the implications for biodiversity conservation policy. Journal of Environmental Management 90 (2): 1135-1144.

Feola, G., A. M. Lerner, M. Jain, M. J. F. Montefrio, and K. A. Nicholas. 2015. Researching farmer behaviour in climate change adaptation and sustainable agriculture: Lessons learned from five case studies. Journal of Rural Studies 39 (0): 74-84.

Ferguson, R., and H. Hansson. 2015. Measuring Embeddedness and Its Effect on New Venture Creation—A Study of Farm Diversification. Managerial and Decision Economics 36 (5): 314-325.

Field, A. 2009. Discovering statistics using SPSS. London: Sage publications.

Gaglio, C. M., and J. A. Katz. 2001. The Psychological Basis of Opportunity Identification: Entrepreneurial Alertness. Small Business Economics 16 (2): 95-111.

García-Pérez, M., A. Yanes-Estévez, V. R. Oreja-Rodríguez, and E. J. Conzález-Dávila. 2014. Strategic positioning and strategic types of small firms. Journal of Small Business and Enterprise Development 21 (3): 431-449.

Gartner, W. B., N. M. Carter, and G. E. Hills. 2003. "The language of opportunity." In Newmovements in entrepreneurship, edited by Chris Steyaert and Daniel Hjorth, 103-124. Cheltenham, UK: Edward Elgar.

Gasson, R., G. Crow, A. Errington, J. Hutson, T. Marsden, and D. M. Winter. 1988. The farm as family business: a review. Journal of Agricultural Economics 39 (1): 1-41.

Giddens, A. 1984. The constitution of society: Outline of the theory of structuration. Berkeley Univ of California Press

Goodman, D., and M. K. Goodman. 2009. "Alternative Food Networks" In International Encyclopedia of Human Ceography, edited by Nigel Thrift and Rob Kitchin, 208-220. Oxford: Elsevier. 
Grande, J., E. L. Madsen, and O. J. Borch. 2011. The relationship between resources, entrepreneurial orientation and performance in farm-based ventures. Entrepreneurship \& Regional Development 23 (3-4): 89-111.

Granovetter, M. 1985. Economic Action and Social Structure: The Problem of Embeddedness. American Journal of Sociology 91 (3): 481-510.

Granovetter, M. S. 1973. The strenght of weak ties. The American Journal of Sociology 78 (6): 1360-1380.

Grin, ]. 2012. The politics of transition governance in Dutch agriculture. Conceptual understanding and implications for transition management. Int ]. Sustainable Development 15 (1/2): 72-89.

Gustafsson, V. 2009. "Entrepreneurial decision-making: thinking under uncertainty." In Understanding the Entrepreneurial Mind: Opening the Black Box, edited by Alan L Carsrud and Malin Brännback, 285-304. New York: Springer-Verlag.

Hang, X., and C. Wang. 2012. Strategic decision-making in small and medium-sized enterprises: Evidence from Australia. International Journal of Business Studies: A Publication of the Faculty of Business Administration, Edith Cowan University 20 (1): 91.

Hannon, P. D., and A. Atherton. 1998. Small firm success and the art of orienteering: the value of plans, planning, and strategic awareness in the competitive small firm. Journal of Small Business and Enterprise Development 5 (2): 102-119

Hansen, D. J., R. Shrader, and J. Monllor. 2011. Defragmenting Definitions of Entrepreneurial Opportunity. Journal of Small Business Management 49 (2): 283-304

Hansson, H. 2007. Strategy factors as drivers and restraints on dairy farm performance: Evidence from Sweden. Agricultural Systems 94 (3): 726-737.

Hansson, H., and R. Ferguson. 2011. Factors influencing the strategic decision to further develop dairy production - A study of farmers in central Sweden. Livestock Science 135 (2): 110-123.

Hansson, H., R. Ferguson, and C. Olofsson. 2010. Understanding the diversification and specialization of farm businesses. Agricultural and Food Science 19 (4): 269-283.

-.----2012. Psychological Constructs Underlying Farmers' Decisions to Diversify or Specialise their Businesses-An Application of Theory of Planned Behaviour. Journal of Agricultural Economics 63 (2): 465-482.

Hansson, H., R. Ferguson, C. Olofsson, and L. Rantamäki-Lahtinen. 2013. Farmers' motives for diversifying their farm business The influence of family. Journal of Rural Studies 32: 240-250.

Haugen, M. S., and J. Vik. 2008. Farmers as entrepreneurs: the case of farm-based tourism. International Journal of Entrepreneurship \& Small Business 6 (3): 321-336

Heley, J., and L. Jones. 2012. Relational rurals: Some thoughts on relating things and theory in rural studies. Journal of Rural Studies 28 (3): 208-217.

Hendriks, G. 1953. Een stad en haar boeren, een sociografische studie. PhD Thesis, Letteren en Wijsbegeerte, Universiteit van Utrecht, Kok Kampen.

Hess, M. 2004. 'Spatial relationships? Towards a reconceptualization of embeddedness. Progress in Human Geography 28 (2): 165-186.

Hinrichs, C. C. 2000 . Embeddedness and local food systems: notes on two types of direct agricultural market. Journal of Rural Studies 16 (3): 295-303

Horlings, I. 2010. Vital coalitions, vital regions Partnerships for regional development. Wageningen: Wageningen Academic Publishers.

Huirne, R. B. M. 2003. Strategy and risk in farming. NJAS-Wageningen Journal of Life Sciences 50 (2): 249-259.

Ireland, R. D., M. A. Hitt, S. M. Camp, and D. L. Sexton. 2001. Integrating entrepreneurship and strategic management actions to create firm wealth. The Academy of Management Executive 15 (1): 49-63.

Jack, S. L., and A. R. Anderson. 2002. The effects of embeddedness on the entrepreneurial process. Journal of Business Venturing 17 (5): 467-487.

Jocumsen, C. 2004. How do small business managers make strategic marketing decisions? European Journal of Marketing 38 (5/6): 659-674.

Johannisson, B. 2011. Towards a practice theory of entrepreneuring. Small Business Economics 36 (2): 135-150.

Johannisson, B., and A. L. Dahlstrand. 2009. Bridging the Functional and Territorial Views on Regional Entrepreneurship and Development: The Challenge, the Journey, the Lessons. European Planning Studies 17 (8): 1105-1115

Jones, L., R. Mann, and J. Heley. 2013. Doing space relationally: Exploring the meaningful geographies of local government in Wales. Geoforum 45: 190-200. 
Jongeneel, R. A., N. B. P. Polman, and L. H. G. Slangen. 2008. Why are Dutch farmers going multifunctional? Land Use Policy 25 (1): 81-94.

Knickel, K. 1990. Agricultural structural change: Impact on the rural environment. Journal of Rural Studies 6 (4): 383393.

Kor, Y. Y., J. T. Mahoney, and S. C. Michael. 2007. Resources, Capabilities and Entrepreneurial Perceptions*. Journal of Management Studies 44 (7): 1187-1212.

Korsgaard, S., R. Ferguson, and J. Gaddefors. 2015. The best of both worlds: how rural entrepreneurs use placial embeddedness and strategic networks to create opportunities. Entrepreneurship \& Regional Development 27 (9-10): 574-598.

Krueger, N., J. Kickul, L. K. Gundry, R. Verma, and F. Wilson. 2009. "Discrete choices, trade-offs, and advantages: Modeling social venture opportunities and intentions." In International perspectives on social entrepreneurship, edited by J.A. Robinson, J. Mair and K. Hockerts, 117-143. Basingstoke, UK: Palgrave Macmillan.

Lamine, C., H. Renting, A. Rossi, J. S. C. Wiskerke, and C. Brunori. 2012. "Agri-Food systems and territorial development: innovations, new dynamics and changing governance mechanisms." In Farming Systems Research into the 21st Century: The New Dynamic, edited by Ika Darnhofer, David Gibbon and Benoît Dedieu, 229-256. Springer Netherlands.

Lans, T., J. Verstegen, and M. Mulder. 2011. Analysing, pursuing and networking: Towards a validated three-factor framework for entrepreneurial competence from a small firm perspective. International Small Business Journal 29 (6): 695-713.

Lauwere, C. C. d., J. A. A. M. Verstegen, J. S. Buurma, E. H. Poot, P. F. M. M. Roelofs, J. W. v. d. Schans, M. Vrolijk, and W. Zaalmink. 2006. Ondernemers en de actoren in hun omgeving in beweging: zoektocht naar de rode draden in agrarische transitieprocessen. LEI, Den Haag.

LEI. 2016. Wet Verantwoorde groei melkveehouderij. LEI, part of Wageningen UR 2016 [cited April 20 2016]. Available from http://www.landbouweconomischbericht.nl/katern-melkveewet.html.

Liberman-Yaconi, L., T. Hooper, and K. Hutchings. 2010. Toward a Model of Understanding Strategic DecisionMaking in Micro-Firms: Exploring the Australian Information Technology Sector. Journal of Small Business Management 48 (1): 70-95.

Long, A. 2001. Development Sociology, Actor Perspectives. London: Routledge Taylor and Francis Croup.

Long, N., and J. D. v. d. Ploeg. 1994. "Heterogeneity, actor and structure: towards a reconstitution of the concept of structure." In Rethinking social development: theory, research \& practice, edited by D. Booth, 62-89. Essex Longman.

Lowe, P., J. Murdoch, T. Marsden, R. Munton, and A. Flynn. 1993. Regulating the new rural spaces: the uneven development of land. Journal of Rural Studies 9 (3): 205-222.

Marsden, T. 2003. The condition of rural sustainability. Assen: Royal Van Corcum

McElwee, G. 2006. The enterprising farmer: A review of entrepreneurship in agriculture. Journal of the Royal Agricultural Society of England 167 (1): 66-75.

McElwee, G., and G. Bosworth. 2010. Exploring the strategic skills of farmers across a typology of farm diversification approaches. Journal of Farm Management 13 (12): 819-838.

McKeever, E., S. Jack, and A. Anderson. 2015. Embedded entrepreneurship in the creative re-construction of place. Journal of Business Venturing 30 (1): 50-65.

McMullen, J. S., and D. A. Shepherd. 2006. Entrepreneurial action and the role of uncertainty in the theory of the entrepreneur. Academy of Management Review 31 (1): 132-152.

Merriam-Webster. Merriam Webster 2015 [cited Sep 3, 2015. Available from http://www.merriam-webster.com/ dictionary/perception.

Methorst, R. G. 2013. Monitoring economische ontwikkeling melkveehouderij Kampereiland. Publication 13-004PP, CAH Vilentum Department of Applied Science, Dronten.

Methorst, R. G., D. Roep, F. J. H. M. Verhees, and J. A. A. M. Verstegen. 2016. Differences in farmers' perception of opportunities for farm development. In Manuscript submitted.

Meulen, H. A. B. v. d., W. H. v. Everdingen, and A. B. Smit. 2012. Actuele ontwikkeling van resultaten en inkomens in de land-en tuinbouw in 2012. Publication LEI-rapport 2012-064, LEI Wageningen UR, Den Haag.

Meulen, H. A. B. v. d., I. Matser, C. Remery, I. J. Terluin, and J. Bouma. 2015. Agrarische jongeren: ambitieus en veelzijdig LEI Wageningen UR, Den Haag. 
Moragues-Faus, A. M., and R. Sonnino. 2012. Embedding Quality in the Agro-food System: The Dynamics and Implications of Place-Making Strategies in the Olive Oil Sector of Alto Palancia, Spain. Sociologia Ruralis 52 (2): $215-234$

Morgan, K., T. Marsden, and J. Murdoch. 2006. Worlds of Food: Place, Power and Provenance in the Food Chain. Oxford, UK: Oxford University Press.

Morgan, S. L., T. Marsden, M. Miele, and A. Morley. 2010. Agricultural multifunctionality and farmers' entrepreneurial skills: A study of Tuscan and Welsh farmers. Journal of Rural Studies 26 (2): 116-129.

Moyes, D., G. Whittam, and P. Ferri. 2012. A conceptualisation of the relationship capital of rural small service firms Local Economy 27 (2): 136-151.

Niska, M., H. T. Vesala, and K. M. Vesala. 2012. Peasantry and Entrepreneurship As Frames for Farming: Reflections on Farmers' Values and Agricultural Policy Discourses. Sociologia Ruralis 52 (4): 453-469.

OECD. 2006. The New Rural Paradigm. Paris: OECD Publishing.

Oostindie, H. 2015. Family farming futures : agrarian pathways to multifunctionality: flows of resistance, redesign and resilience. PhD thesis, Wageningen University, Wageningen.

Parnell, J. A., D. L. Lester, and M. L. Menefee. 2000. Strategy as a response to organizational uncertainty: an alternative perspective on the strategy-performance relationship. Management Decision 38 (8): 520-530.

Pender, J., P. Jagger, E. Nkonya, and D. Sserunkuuma. 2004. Development pathways and land management in Uganda. World Development 32 (5): 767-792.

Pietola, K., and A. Lansink. 2001. Farmer response to policies promoting organic farming technologies in Finland. European Review of Agricultural Economics 28 (1): 1-15.

Ploeg, J. D. v. d. 1994. "Styles of farming: an introductory note on concepts and methodology." In Born from within practice and perspectives of endogenous rural development, edited by ]. D. van der Ploeg and A. Long. Assen: Van Corcum.

------ 2000. Revitalizing Agriculture: Farming Economically as Starting Ground for Rural Development. Sociologia Ruralis 40 (4): 497-511.

--.-- . 2003. The virtual farmer. Past, present, and future of the Dutch peasantry. Assen: Royal van Corcum.

Ploeg, J. D. v. d., C. Laurent, F. Blondeau, and P. Bonnafous. 2009. Farm diversity, classification schemes and multifunctionality. Journal of Environmental Management 90, Supplement 2 (0): S124-S131.

Ploeg, J. D. v. d., and A. Long. 1994. Born from within-practice and perspectives of endogenous rural development. Edited by Circle for rural european studies, European perspectives on rural development. Assen: Van Corcum.

Ploeg, J. D. v. d., and D. Roep. 2003. "Multifunctionality and rural development: the actual situation in Europe." In Multifunctional Agriculture; A new paradigm for European Agriculture and Rural Development, edited by G. van Huylenbroeck and C. Durand, 37-53. Hampshire: Ashgate, England.

Ploeg, J. D. v. d., and F. Ventura. 2014. Heterogeneity reconsidered. Current Opinion in Environmental Sustainability 8: $23-28$

Portes, A., and J. Sensenbrenner. 1993. Embeddedness and Immigration: Notes on the Social Determinants of Economic Action. American Journal of Sociology 98 (6): 1320-1350.

Potter, C., and M. Tilzey. 2005. Agricultural policy discourses in the European post-Fordist transition: neoliberalism, neomercantilism and multifunctionality. Progress in Human Geography 29 (5): 581-600.

Primdahl, J., and L. S. Kristensen. 2011. The farmer as a landscape manager: Management roles and change patterns in a Danish region. Ceografisk Tidsskrift-Danish Journal of Ceography 111 (2): 107-116.

Primdahl, ]., and S. Swaffield. 2010. "Globalisation and the sustainability of agriculture landscapes." In Globalisation and agricultural landscapes: change patterns and policy trends in developed countries, 1-15. Cambridge: Cambridge University Press.

Renko, M., R. C. Shrader, and M. Simon. 2012. Perception of entrepreneurial opportunity: a general framework. Management Decision 50 (7): 1233-1251.

RIVM. 2002. Natuurbalans. Alphen aan de Rijn.

Robson, G., C. Gallagher, and M. Daly. 1993. Diversification Strategy and Practice in Small Firms. International Small Business Journal 11 (2): 37-53.

Roep, D. 2000. Vernieuwend werken, sporen van vermogen en onvermogen. PhD thesis, Rural Sociology, Wageningen Universiteit, Wageningen. 
Roep, D., and ]. C. Wiskerke. 2012a. On Governance, Embedding and Marketing: Reflections on the Construction of Alternative Sustainable Food Networks. Journal of Agricultural and Environmental Ethics 25 (2): 205-221.

Roep, D., and J. S. Wiskerke. 2012b. On governance, embedding and marketing: reflections on the construction of alternative sustainable food networks. Journal of agricultural and environmental ethics 25 (2): 205-221.

Samson, C. S., C. Gardebroek, and R. A. Jongeneel. 2016. Explaining production expansion decisions of Dutch dairy farmers. NJAS-Wageningen Journal of Life Sciences 76: 87-98.

Sarason, Y., T. Dean, and J. F. Dillard. 2006. Entrepreneurship as the nexus of individual and opportunity: A structuration view. Journal of Business Venturing 21 (3): 286-305.

Sarason, Y., J. F. Dillard, and T. Dean. 2010. How can we know the dancer from the dance?: Reply to "Entrepreneurship as the structuration of individual and opportunity: A response using a critical realist perspective". (Mole and Mole, 2008). Journal of Business Venturing 25 (2): 238-243.

Schans, F. C. v. d., and D. D. J. Keuper. 2013. Melkveehouderij na de quotering-grondgebonden en industriële bedrijven. Publication 837-2013, CLM, Culemborg.

Seuneke, P., and B. B. Bock. 2015. Exploring the roles of women in the development of multifunctional entrepreneurship on family farms: an entrepreneurial learning approach. NJAS - Wageningen Journal of Life Sciences 74-75: 41-50.

Shane, S., and S. Venkataraman. 2000. The promise of entrepreneurship as a field of research. Academy of Management Review 25 (1): 217-226.

Shane, S. A. 2008. The illusions of entrepreneurship: The costly myths that entrepreneurs, investors, and policy makers live by: Yale University Press.

Short, J. C., D. J. Ketchen, C. L. Shook, and R. D. Ireland. 2010. The Concept of "Opportunity" in Entrepreneurship Research: Past Accomplishments and Future Challenges. Journal of Management 36 (1): 40-65.

Shucksmith, M., and V. Herrmann. 2002. Future Changes in British Agriculture: Projecting Divergent Farm Household Behaviour. Journal of Agricultural Economics 53 (1): 37-50.

Simon, M., and S. M. Houghton. 2002. The Relationship Among Biases, Misperceptions, and the Introduction of Pioneering Products: Examining Differences in Venture Decision Contexts. Entrepreneurship Theory and Practice 27 (2): 105-124.

Soliva, R. 2007. Landscape stories: Using ideal type narratives as a heuristic device in rural studies. Journal of Rural Studies 23 (1): 62-74.

Sonnino, R. 2007. Embeddedness in action: Saffron and the making of the local in southern Tuscany. Agriculture and Human Values 24 (1): 61-74.

Sutcliffe, K. M., and A. Zaheer. 1998. Uncertainty in the transaction environment: an empirical test. Strategic Management Journal 19 (1): 1-23.

Sutherland, L.-A., R. J. F. Burton, J. Ingram, K. Blackstock, B. Slee, and N. Cotts. 2012. Triggering change: Towards a conceptualisation of major change processes in farm decision-making. Journal of Environmental Management 104: 142-151.

Thornton, P. H., D. Ribeiro-Soriano, and D. Urbano. 2011. Socio-cultural factors and entrepreneurial activity: An overview. International Small Business Journal 29 (2): 105-118.

Vanclay, F., P. Howden, L. Mesiti, and S. Glyde. 2006. The Social and Intellectual Construction of Farming Styles: Testing Dutch Ideas in Australian Agriculture. Sociologia Ruralis 46 (1): 61-82.

Vanloqueren, C., and P. V. Baret. 2009. How agricultural research systems shape a technological regime that develops genetic engineering but locks out agroecological innovations. Research Policy 38 (6): 971-983.

Verreynne, M.-L. 2006. Strategy-making process and firm performance in small firms. Journal of Management and Organization 12 (3): 209-222.

Vesala, H. T., and K. M. Vesala. 2010. Entrepreneurs and producers: Identities of Finnish farmers in 2001 and 2006. Journal of Rural Studies 26 (1): 21-30.

Vik, J., and C. McElwee. 2011. Diversification and the Entrepreneurial Motivations of Farmers in Norway. Journal of Small Business Management 49 (3): 390-410.

Wals, A. E. J., T. Lans, and H. Kupper. 2012. Blurring the boundaries between vocational education, business and research in the agri-food domain. Journal of Vocational Education \& Training 64 (1): 3-23.

Wästfelt, A., K. Saltzman, E. Gräslund Berg, and A. Dahlberg. 2012. Landscape care paradoxes: Swedish landscape care arrangements in a European context. Ceoforum 43 (6): 1171-1181.

Watson, T. J. 2013. Entrepreneurship in action: bringing together the individual, organizational and institutional 
dimensions of entrepreneurial action. Entrepreneurship \& Regional Development 25 (5-6): 404-422.

Welter, F. 2011. Contextualizing Entrepreneurship-Conceptual Challenges and Ways Forward. Entrepreneurship Theory and Practice 35 (1): 165-184.

Wilson, G. A. 2008. From 'weak' to 'strong' multifunctionality: Conceptualising farm-level multifunctional transitional pathways. Journal of Rural Studies 24 (3): 367-383.

Wiskerke, J. S. C. 2009. On places lost and places regained: reflections on the alternative food geography and sustainable regional development. International Planning Studies 14 (4): 369-387.

Wiskerke, J. S. C., and D. Roep. 2007. Constructing a sustainable pork supply chain: a case of technoinstitutional innovation. Journal of environmental policy \& planning 9 (1): 53-74.

Wolf, P. d., C. McElwee, and H. Schoorlemmer. 2007. The European farm entrepreneur: a comparative perspective. International Journal of Entrepreneurship \& Small Business 4 (6): 679-692.

Woods, M. 2012. New directions in rural studies? Journal of Rural Studies 28 (1): 1-4.

------ 2014. Family farming in the global countryside. Anthropological Notebooks 20 (3): 31-48.

Yakovleva, N., and A. Flynn. 2004. Innovation and sustainability in the food system: A case of chicken production and consumption in the UK. Journal of Environmental Policy \& Planning 6 (3-4): 227-250.

Yanes-Estévez, V., J. R. Oreja-Rodríguez, and A. M. García-Pérez. 2010. Perceived environmental uncertainty in the agrifood supply chain. British Food Journal 112 (7): 688-709.

Zasada, I. 2011. Multifunctional peri-urban agriculture-A review of societal demands and the provision of goods and services by farming. Land Use Policy 28 (4): 639-648.

ZuivelNL. 2016. Dutch dairy in figures 2013. ZuivelNL.

Zwan, P. v. d., I. Verheul, and A. R. Thurik. 2012. The entrepreneurial ladder, gender, and regional development Small Business Economics 39: 627-643. 


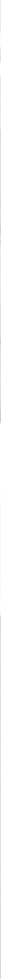




\section{Appendices}

The questionnaire

Summary

Samenvatting

\section{Acknowledgements / Dankwoord}

About the author

Curriculum Vitae

Completed Training and

Supervising Plan 

The questionnaire

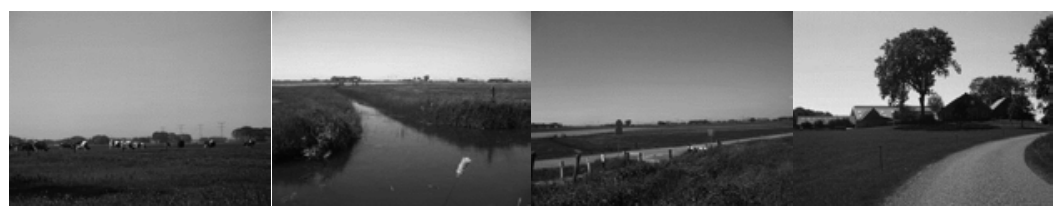

What is your view

on the development opportunities

on Kampereiland e.o.

Survey February 2013

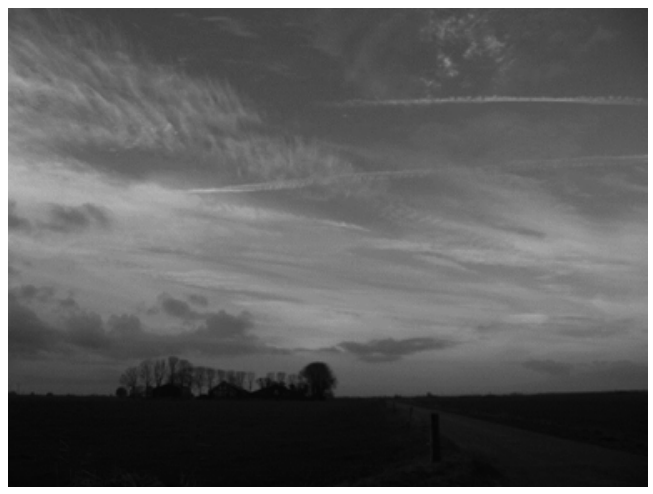
WAGENINGEN UNIVERSITY

CAHI Whenum

CAH Vilentum Hogeschool

Wageningen Universiteit 
This survey is conducted among agricultural entrepreneurs on Kampereiland e.o. and is a contribution in the discussion about future tenancy policy for this area.

The survey is a co-operation with the Tenants Union and the Association of Regional Interests Kampereiland and is part of the PhD study of ir. Ron Methorst. The study is a collaboration between $\mathrm{CAH}$ Dronten in Dronten and Wageningen University in Wageningen. The research is independent of the interests of stakeholders in the region and is paid for by $\mathrm{CAH}$ Vilentum.

The results will be presented anonymously.

Ron Methorst

February 2013 
What opportunities do you see for your farm?

For the development of the tenancy policy on Kampereiland it is important to know your view on the opportunities for the development of your farm. This survey is a co-operation with the Tenants Union and the Association of Regional Interests Kampereiland e.o. The economic development of the farms will be researched in co-operation with the Tenants Union and the 'ABC' accountancy firms. These two studies will offer a good total overview. The first results will be presented in March 2013 in a meeting of the Tenants Union. A report of the results will be made available to all participants of the survey.

This survey is for all entrepreneurs, including those who do not have a specific desire to develop the farm.

Important information:

- The survey is meant for the person most involved in decision-making on the development of the farm

- A digital version is available, more information is presented on the next page

- There are no right or wrong answers, one answer is not better than another answer. A tip would be to select the opportunities closest to your initial feeling when reading the question

- The data will be handled strictly anonymously

- All participants will receive a report of the results

This research is conducted by and paid for by CAH Vilentum Dronten. As a token of appreciation we will organise a special event in our new building. You will receive a lunch, an excursion through the new building and a presentation about developments in research and education.

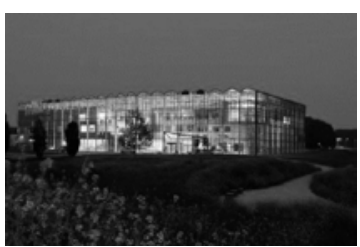

Please return before Monday February 18. An envelope is included, a stamp is not needed.

For further questions you can call me at 06-36226637 or via e-mail r.methorst@cahvilentum.nl

Thank you very much for your co-operation,

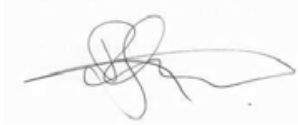

Ron Methorst

Teacher - PhD research Agriculture and its Environment

CAH Vilentum Dronten and Wageningen University

${ }^{*}$ ) The next page will present information about my personal background. 
Information for using the digital survey:

Around the same time as receiving this survey, you will receive an e-mail containing a direct link to the digital survey. As not all e-mail addresses are known it is possible that you will not receive this e-mail. Using the digital survey decreases the chance for mistakes in processing the data. For you it means that there is no need to post the envelop. Both the paper survey and the digital survey can be used.

In case you have not received the e-mail, you can use the following information to access the digital survey:

Internet address http://onderzoek.cahvilentum.nl (no www needed in the address)

or

http://www3.lei.wur.nl/kampereiland

Login name:

Password:

For those interested: information on the background of Ron Methorst

As a farmer's grandson from the Gelderse Vallei region, I went to study

Animal Science at Wageningen University. Between 1997 en 2001 I worked as an advisor for manure and environmental legislation for a compound feed factory. Later I worked as a teacher

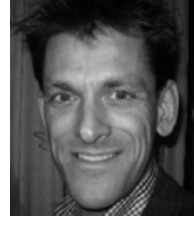
at CAH Dronten and as advisor in organic poultry farming. Together with my wife we were management of a DutchBosnian company in 2006-2007 after which I came back to work for CAH Vilentum Dronten.

Agricultural entrepreneurship in a changing environment, that is the topic of my $\mathrm{PhD}$ research, a co-operation between $\mathrm{CAH}$ Vilentum and Wageningen University. How do entrepreneurs view their opportunities for development and what are good methods to facilitate this development. These questions are relevant in the context of Kampereiland e.o.

I will post information about the research via http://promotieonderzoekkampereiland.blogspot.nl 
The survey

- The survey consists of 10 parts, each with a number of questions.

- The survey will take about 50 minutes on average. Part 1 likely to be most time consuming, the other parts will be quicker.

- An explanation about the question is presented inside a red frame.

- For the research it is important to answer all questions.

- The questions do not represent desirable opportunities neither the vision of the researcher.

Part 1 Development opportunities for your farm

Every dairy farmer makes choices in the development of his farm and takes into account both the private and the farm situation. In the table 15 opportunities for dairy farms to gain an income are presented.

The question is: to what extent could these 15 opportunities contribute to your income?

- Base the answer on your own opinion of what you think is viable in your situation

- The question is about the contribution to (a for you important part of) farm income

- In the situation you already have the opportunity in practice in your farm, then indicate to what extent it contributes to your income

- Base the answer on your knowledge at this moment

Select the answer of your choice for each of the 15 opportunities:

certainly NOT - probably NOT - maybe - probably YES - certainly YES 


\section{Question 1)}

To what extent could these 15 opportunities contribute to (a for you important part of) your income?

Select for every opportunity the answer of your choice:

a) 'Steady on' dairy farm: mainly using own fodder, few compound feed and byproducts, aiming for a cow with long longevity and minimal veterinary cost

b) 'Full power' dairy farm: intensive farm, high milk/ha, high input of compound feed and by-products, aiming for a cow with maximum milk yield

c) 'Organic dairy farm': according to the standards of organic agriculture

d) 'Joint farming': cooperation with 1 or more other dairy farms and operate as one combined farm

e) 'Mik and job': next to the dairy farm being employed outside the farm by at least one of the persons who own the farm

f) 'Milk and energy': next to the dairy farm producing energy

g) 'Milk and nature': next to the dairy farm as well income from nature preservation in the area (including on your own farm)

h) 'Milk and processing': selling (a part of) the milk via (regional) brand dairy product (processing can be off-farm)

i) 'Milk and clients': clients who spend money on your farm (eg a shop or workshops, course or excursions)

j) 'Milk and care': activities with care on your farm (incl. day care for children)

k) 'Milk and recreation': activities with recreation (including activities in the area and on your farm)

I) 'Milk and another company': running an enterprise next to the dairy farm, other than the opportunities already named

m) 'Relocating outside Kampereiland': relocating the dairy farm to a location outside Kampereiland

n) 'No milk anymore, something else': ending dairy farming and starting another business on the farm yard

o) 'Becoming a non-farming citizen: ending the dairy farm, remain living on the farm yard, (possibly) income from work elsewhere 


\section{Question 2) Do you see other opportunities?}

Do you see other opportunities that are not named yet and which you deem suitable to follow in order to obtain (an important part of) farm income? Please describe the opportunity below:

Opportunity ' $p$ ':

\section{Question 3) What opportunity is already in practice on your farm?}

Please encircle the letter that corresponds with the opportunities in the table of question 1 and that is already in practice on your farm. Multiple opportunities is possible:
a b c d e f g h i k l
$\mathrm{m} n \mathrm{n}$ $\mathrm{p}$

\section{Question 4) What will you be doing in the future or do you think of possibly doing at your farm}

Please encircle the letter that corresponds with the opportunities in the table of question 1 . Multiple opportunities is possible. You can select as well: 'I will not change my farm' or 'I do not know yet what I will do'

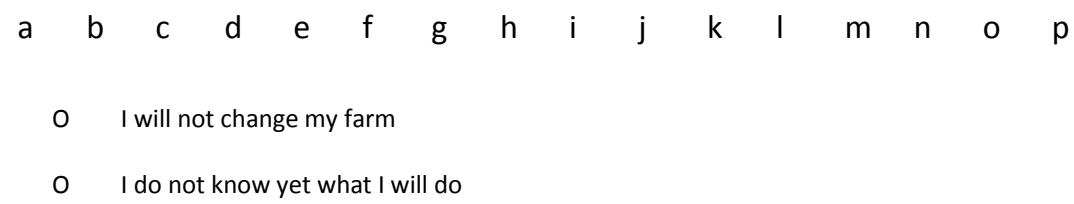

Question 5) Which of the opportunities would you prefer to do given there were no restrictions or limitations?

Please write down the letter that corresponds with the opportunity of your choice in the table of question 1

I would prefer the following opportunity:

(use a letter based on the table at Question 1) 
Part 2 Networks and experience

Below you find different societies or associations both inside and outside agriculture. Can you select what is the option which represents your situation for each organisation:

- Not a member $\quad \rightarrow$ not a member (at this moment)

- Member, less active $\rightarrow$ visit few to no activities or gatherings

- Member, more active $\rightarrow$ visit often to mostly the activities or gatherings

Can you indicate as well in the last box whether you are of have been a board member of this organisation. Two markings per organisation is possible.

Question 6)

Indicate in the first 3 columns what suits your situation and indicate in the 4 th column if you are of have been a board member

\begin{tabular}{|c|c|c|}
\hline No member & $\begin{array}{c}\text { member, } \\
\text { less active }\end{array}$ & $\begin{array}{c}\text { member, } \\
\text { more }\end{array}$ \\
& & active \\
& & \\
\hline
\end{tabular}

within agriculture

\begin{tabular}{|l|l|l|l|}
\hline a) Dairy cooperative & & & \\
\hline b) Cooperative bank & & & \\
\hline c) Tenant Union & & & \\
\hline d) Dutch Dairy Farmers Union & & & \\
\hline e) National Agricultural Union & & & \\
\hline f) Local Agr. Nature Association & & & \\
\hline g) Local hunt management association & & & \\
\hline h) Study group & & & \\
\hline i) Other organisation & & & \\
\hline \multicolumn{1}{|c|}{ outside agriculture } & & & \\
\hline j) Political party & & & \\
\hline k) Church & & & \\
\hline l) Sports club & & & \\
\hline m) Hobby association & & & \\
\hline n) Nature association & & & \\
\hline o) Societal organisation (e.g. education, care, & & & \\
\hline p) organisation & & & \\
\hline
\end{tabular}


Questions 7 - 14 refer to you as entrepreneur and possible family members

Can you select which answer best suits your situation?

You can choose: yes, myself - yes, others on the farm - no

Multiple answers are possible for each question.

\begin{tabular}{|c|c|c|c|c|}
\hline & & $\begin{array}{c}\text { yes, } \\
\text { myself }\end{array}$ & $\begin{array}{c}\text { yes, } \\
\text { others } \\
\text { on the } \\
\text { farm }\end{array}$ & no \\
\hline 7) & $\begin{array}{l}\text { There are persons who work or have worked on an agricultural business } \\
\text { outside dairy farming }\end{array}$ & & & \\
\hline 8) & There are person who work or have worked outside agriculture & & & \\
\hline 9) & $\begin{array}{l}\text { There are persons who work or have worked within the agricultural sector } \\
\text { in accountancy/advice/feed industry/livestock/education/ ... }\end{array}$ & & & \\
\hline 10) & There are persons who have an education outside agriculture & & & \\
\hline 11) & $\begin{array}{l}\text { There are persons with experience in starting a new business activity or a } \\
\text { new business }\end{array}$ & & & \\
\hline 12) & $\begin{array}{l}\text { There are persons with experience in the development or sale of products } \\
\text { or services }\end{array}$ & & & \\
\hline 13) & $\begin{array}{l}\text { There are persons who are in contact with farmers who run a diversified } \\
\text { farm }\end{array}$ & & & \\
\hline
\end{tabular}

14) What is the highest level of education among the owners of the farm?

\begin{tabular}{|l|l|l|l|}
\hline Lower & middle & higher & university \\
\hline & & & \\
\hline
\end{tabular}


Part 3 Home situation

\begin{tabular}{|c|c|c|c|c|}
\hline 15) & Do you think that you will end farming in $10-15$ year from now? & yes & no & $\begin{array}{l}\text { don't } \\
\text { know }\end{array}$ \\
\hline 16) & $\begin{array}{l}\text { Do you think that when you stop farming, the dairy farm on this location } \\
\text { will continue? }\end{array}$ & yes & no & $\begin{array}{l}\text { don't } \\
\text { know }\end{array}$ \\
\hline 17) & $\begin{array}{l}\text { Are there family members living on the farm who are not part of the farm } \\
\text { ownership? (excluding people in pension and children under 12)? }\end{array}$ & yes & no & \\
\hline
\end{tabular}

When the answer to Question 17 is 'no', you can proceed to Part 4

The next questions are about the involvement of family members in the farm.

Please select the answer that best represents your situation.

For questions 18-22 you can answer by selecting one of the boxes:

'certainly not agree' - 'not agree' - 'neutral' - 'agree' - 'certainly agree'

For question 23 and 24 you can answer by selecting the box with: yes / no / don't know

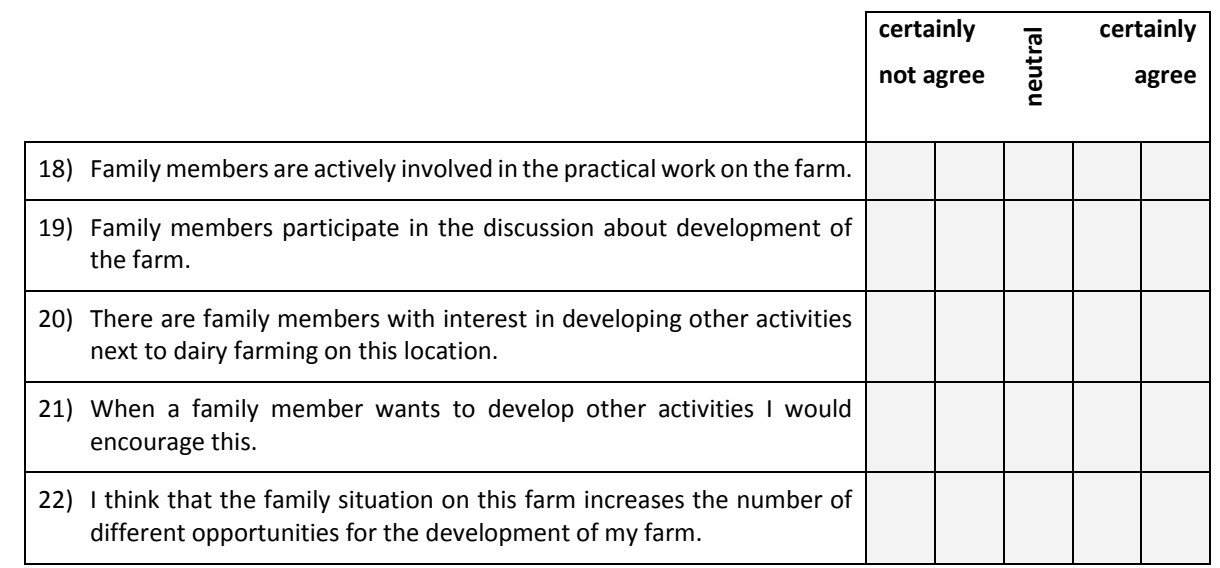

23) Are there, beside the entrepreneurs in ownership of the farm, family members who follow or have followed an education in agriculture?

24) Are there family members who take an interest in participating in the ownership of the farm and / or becoming a successor?

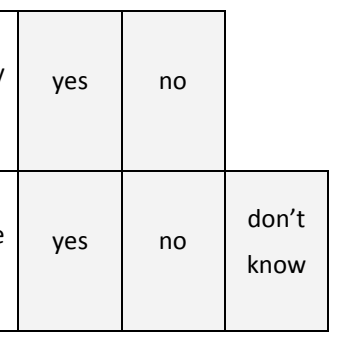


Part 4 Farmer, farm and environment

Can you indicate for the following statements to what extent it applies to your situation?

You can answer by selecting one of the following boxes:

'certainly not agree'- 'not agree' - 'neutral' - 'agree' - 'certainly agree'

Tip: when in doubt do not think too long, select the box of the first thought that came to mind

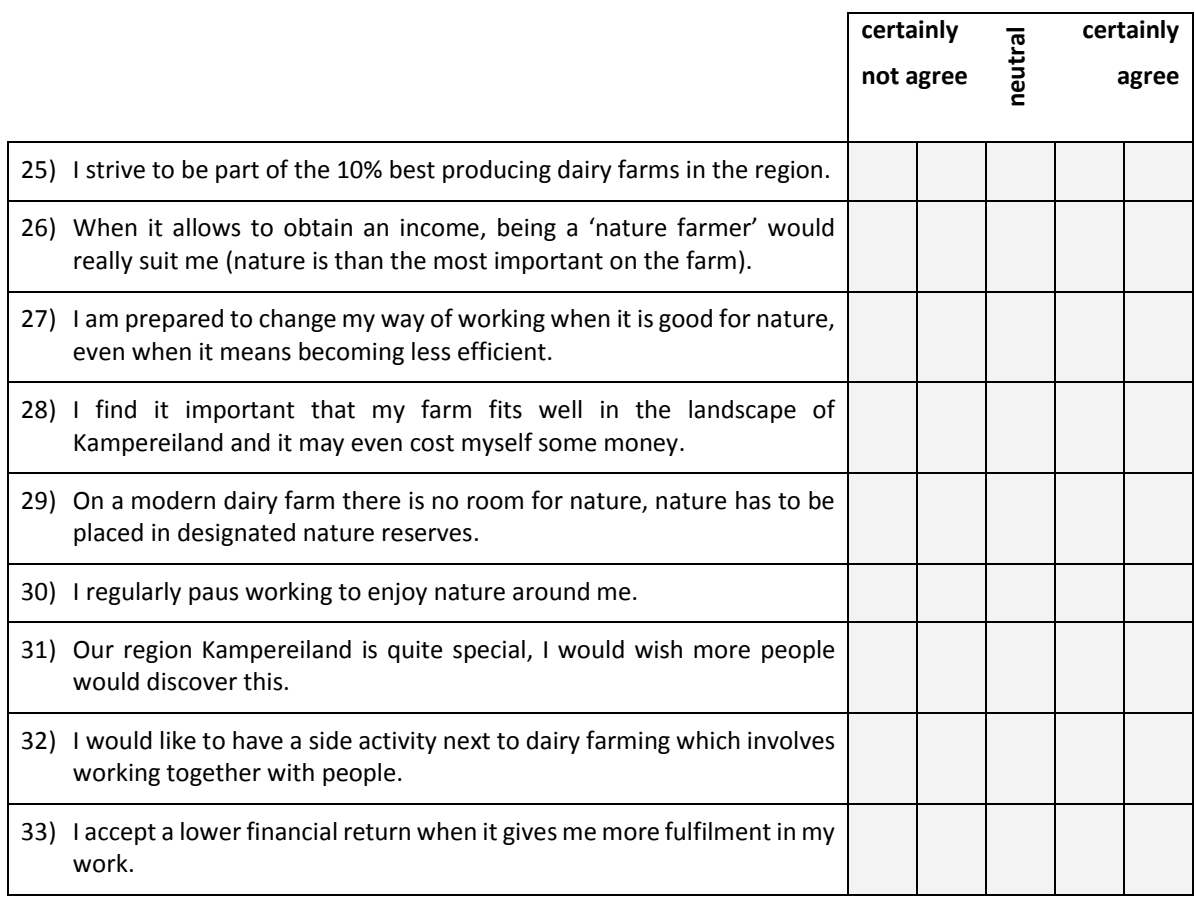


Part 5 Opportunities farm and location

Can you indicate for the following statements to what extent it applies to your situation?

You can answer by selecting one of the following boxes:

'certainly not agree'- 'not agree' - 'neutral' - 'agree' - 'certainly agree'

Tip: when in doubt do not think too long, select the box of the first thought that came to mind

\begin{tabular}{|c|c|c|c|c|}
\hline & & $\begin{array}{l}\text { certainly } \\
\text { not agree }\end{array}$ & 可 & $\begin{array}{r}\text { certainly } \\
\text { agree }\end{array}$ \\
\hline 34) & $\begin{array}{l}\text { I think that my farm will provide for sufficient income for the next } 10 \\
\text { years. }\end{array}$ & & & \\
\hline 35) & On this location I see enough opportunities to enlarge my dairy farm. & & & \\
\hline 36) & $\begin{array}{l}\text { To keep my dairy farm technically 'up to date' in the coming } 10 \text { years, } \\
\text { I need to make big investments. }\end{array}$ & & & \\
\hline 37) & $\begin{array}{l}\text { The maximum amount I can loan is more limiting for the development } \\
\text { of my farm, than the opportunities on this location. }\end{array}$ & & & \\
\hline 38) & $\begin{array}{l}\text { The farm yard and buildings are suitable for the development of } \\
\text { diversified farming, setting aside my personal preference. }\end{array}$ & & & \\
\hline 39) & $\begin{array}{l}\text { Besides dairy farming I want to do other things to increase the pleasure } \\
\text { in my work. }\end{array}$ & & & \\
\hline 40) & $\begin{array}{l}\text { Doing other activities prevents me from working on my own on my } \\
\text { farm the whole week. }\end{array}$ & & & \\
\hline 41) & $\begin{array}{l}\text { I am not so interested where my farm is in the Netherlands, as long as } \\
\text { it is a technically well-functioning dairy farm. }\end{array}$ & & & \\
\hline & $\begin{array}{l}\text { I would not mind moving my farm to a location far away from } \\
\text { Kampereiland }\end{array}$ & & & \\
\hline
\end{tabular}


Part 6 Developments in markets and techniques

Can you indicate for the following statements to what extent it applies to your situation?

You can answer by selecting one of the following boxes:

'certainly not agree' - 'not agree' - 'neutral' - 'agree' - 'certainly agree'

Tip: when in doubt do not think too long, select the box of the first thought that came to mind

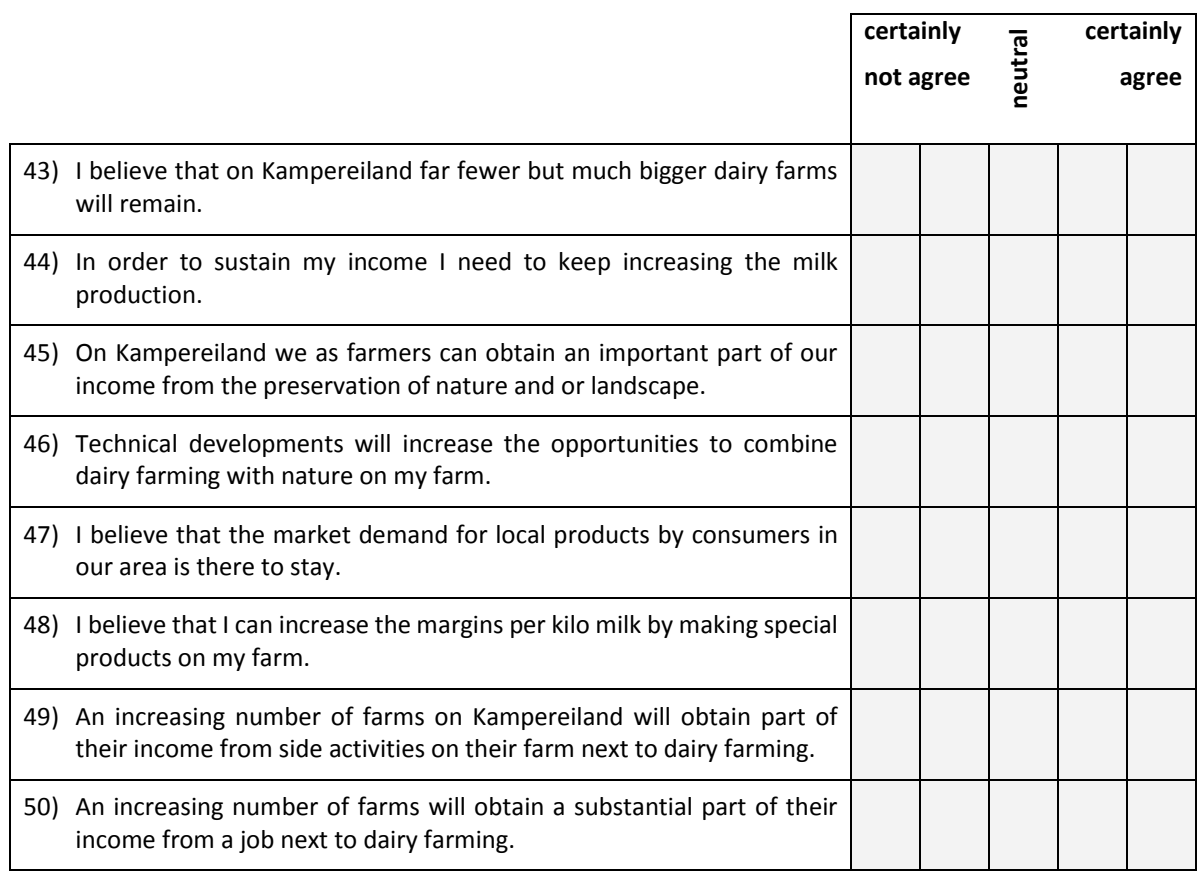


Part 7 Developments in urban-rural

Can you indicate for the following statements to what extent it applies to your situation?

You can answer by selecting one of the following boxes:

'certainly not agree'- 'not agree' - 'neutral' - 'agree' - 'certainly agree'

Tip: when in doubt do not think too long, select the box of the first thought that came to mind

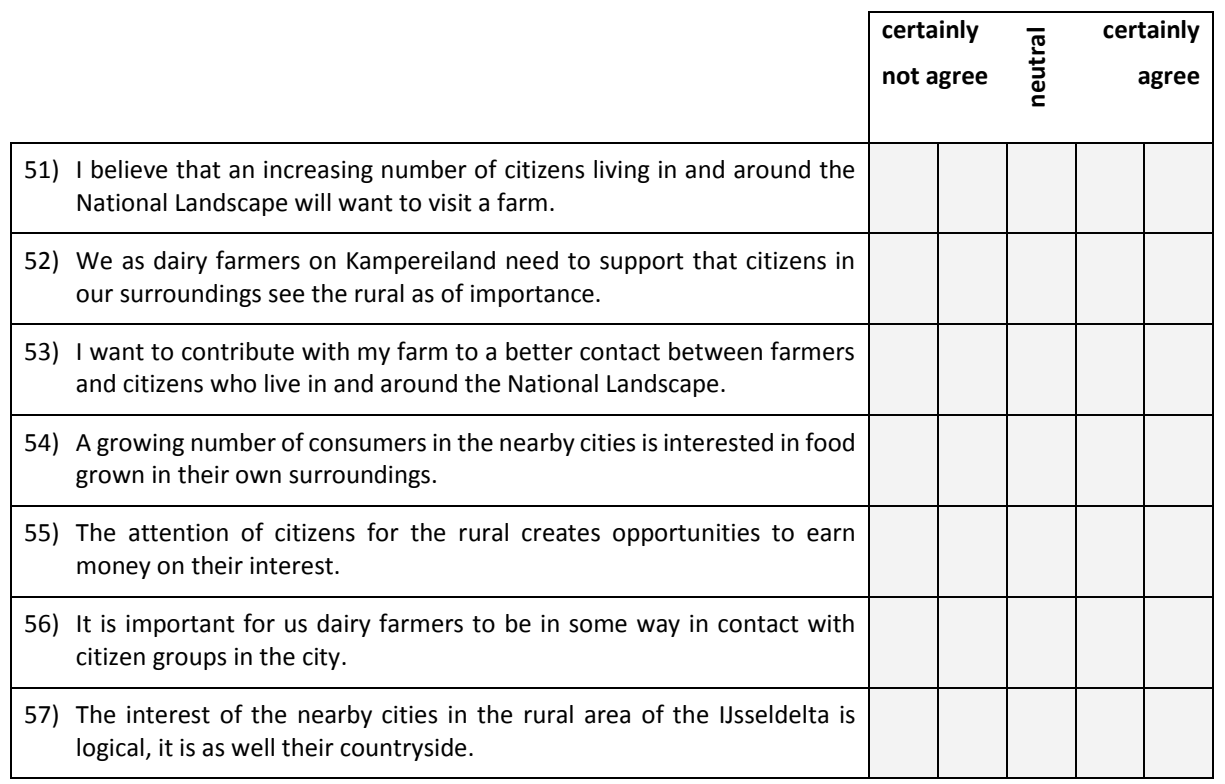


Part 8 You as a person

Can you indicate for the following statements to what extent it applies to your situation?

You can answer by selecting one of the following boxes:

'very low degree'- 'low degree' - 'neutral' - 'high degree' - 'very high degree'

Tip: when in doubt do not think too long, select the box of the first thought that came to mind

There is no right or wrong answer.

\begin{tabular}{|c|c|c|c|}
\hline & & $\begin{array}{l}\text { very } \\
\text { low } \\
\text { degree }\end{array}$ & $\begin{array}{r}\text { very } \\
\text { high } \\
\text { degree }\end{array}$ \\
\hline & I can name my business goals straight away. & & \\
\hline 59) & I have a clear idea of where my enterprise will be in five years. & & \\
\hline 60) & $\begin{array}{l}\text { I consider the funding policy of (international) government to be an } \\
\text { excellent opportunity }\end{array}$ & & \\
\hline 61) & I am not easily diverted from the goals I set myself. & & \\
\hline 62) & $\begin{array}{l}\text { I am involved in activities that contribute to a positive image of my } \\
\text { professional group. }\end{array}$ & & \\
\hline 63) & I evaluate my own actions as much as possible. & & \\
\hline 64) & I look for new information all the time. & & \\
\hline 65) & $\begin{array}{l}\text { have a clear idea about how my enterprise performs in relation to } \\
\text { other enterprises in the sector. }\end{array}$ & & \\
\hline 66) & My goals are laid down in written plans. & & \\
\hline 67) & I am very aware of my own weak and strong points. & & \\
\hline 68) & I am open to criticism from others (colleagues, employees, etc.). & & \\
\hline 69) & I have many networks outside the agricultural sector. & & \\
\hline
\end{tabular}




\begin{tabular}{|c|c|c|}
\hline & $\begin{array}{l}\text { very } \\
\text { low } \\
\text { degree }\end{array}$ & $\begin{array}{r}\text { very } \\
\text { high } \\
\text { degree }\end{array}$ \\
\hline 70) I try to incorporate feedback from the public in my way of farming. & & \\
\hline $\begin{array}{l}\text { 71) I keep an eye on the main issues and can point out the heart of a } \\
\text { problem. }\end{array}$ & & \\
\hline 72) I accept challenges more often than colleagues in my sector. & & \\
\hline 73) I often negotiate with suppliers or buyers regarding our prices. & & \\
\hline 74) I am often the first to try out new things. & & \\
\hline 75) I easily separate facts from opinions. & & \\
\hline 76) I easily identify problems on the work floor. & & \\
\hline 77) I can easily look at things from various points of view. & & \\
\hline 78) I easily identify problems on the work floor. & & \\
\hline 79) I look for new information all the time. & & \\
\hline 80) Cooperation with entrepreneurs in my sector is important for me. & & \\
\hline 81) I can put my ideas across easily to other people. & & \\
\hline
\end{tabular}


Part 9 Farm development, labour and your opinion

Question 82) Can you indicate for each year the ha of land and the number of cows present or you expect to be present? This question is not about the exact numbers but about a good estimate

\begin{tabular}{|l|l|l|l|}
\cline { 2 - 4 } \multicolumn{1}{c|}{} & $\begin{array}{l}\text { Number of dairy } \\
\text { cows }\end{array}$ & $\begin{array}{l}\text { Milk production per } \\
\text { cow (estimate) }\end{array}$ & $\begin{array}{l}\text { Number of ha land (in } \\
\text { total use) }\end{array}$ \\
\hline a) 1965 & & & \\
\hline b) 1985 & & & \\
\hline c) 2005 & & & \\
\hline d) 2012 & & & \\
\hline e) Expected in 2025 & & & \\
\hline
\end{tabular}

83) What are the working hours per week for the following persons on your dairy farm (average on a yearly base)?

Entrepreneur 1 as part of the ownership

Entrepreneur 2 as part of the ownership

Entrepreneur $3+$ hours of other persons which are part of the ownership

Employees (total for all employees)

Family members which are not part of the ownership of the farm (total hours for all family members)

Can you indicate for the following statements to what extent it applies to your situation?

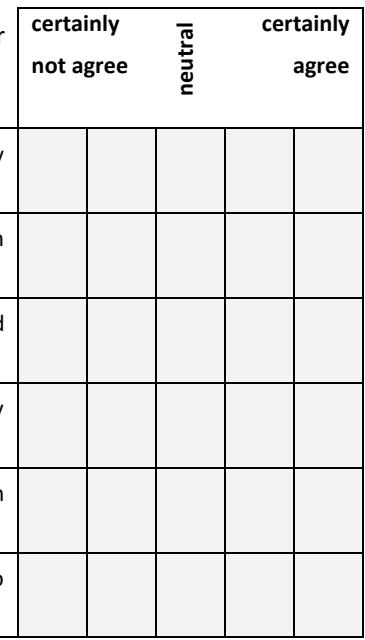

84) Dairy farms on Kampereiland need to be able to increase the number of dairy cows, also when it means less nature.

85) It is necessary to organise plot exchange on Kampereiland to make production on the farms more efficient.

86) My opinion is that we as dairy farmers should contribute actively to nature and landscape of Kampereiland.

87) I think that it is possible to combine a modern dairy farm with a high quality nature and landscape on my farm.

88) Not being able to take a loan due to a lack of pledge is the most import reason that puts plans on hold for our tenant farms.

89) Dairy farms on Kampereiland need to become more intensive in production to be able to continue: more milk per ha is necessary. 
Weidse Waarden and the Stimulation Model started in September 2010

The aim is described as follows:

'to stimulate entrepreneurs and other residents to develop and execute initiatives that will improve the economical perspective of the own farm and the area as a whole and that contribute to the balance of People Planet and Profit'

Can you indicate for the statements below to what extent it suits your opinion.

You can answer by selecting one of the following boxes in the range from:

'certainly not agree' to 'certainly agree'.

\begin{tabular}{|c|c|c|c|c|}
\hline & & $\begin{array}{l}\text { certainly not } \\
\text { agree }\end{array}$ & 焉 & $\begin{array}{r}\text { certainly } \\
\text { agree }\end{array}$ \\
\hline 90) & Kampereiland needs strengthening of economic perspective. & & & \\
\hline 91) & $\begin{array}{l}\text { To have enough ideas and initiatives in the area an extra stimulant } \\
\text { of entrepreneurs and other residents is very important. }\end{array}$ & & & \\
\hline 92) & $\begin{array}{l}\text { The approach as chosen for Weidse Waarden and the Stimulation } \\
\text { Model Kampereiland is a good way to develop and realise } \\
\text { initiatives in our area. }\end{array}$ & & & \\
\hline 93) & $\begin{array}{l}\text { I expect the plans that will be development in the framework of } \\
\text { Weidse Waarden and the Stimulation Model, will clearly } \\
\text { contribute to the economic perspective of Kampereiland }\end{array}$ & & & \\
\hline 94) & $\begin{array}{l}\text { I do make use or I think I will make use of Weidse Waarden / the } \\
\text { Stimulation Model. }\end{array}$ & & & \\
\hline
\end{tabular}


If you wish to do so, you can write additional opinions on the development of Kampereiland and the necessity of supporting the farms:

It is possible to send you an overview of your situation with the average of Kampereiland. Only the researcher can make this overview, it will be given only to you and is strictly confidential. Below you can indicate whether you would like to receive this overview.

95) Would you like to receive this personal overview? 
Thank you very much tor your contribution in this survey. In case you like to make additional comments, you may do so below.

I would like to make the following comments:

Thank you very much for your co-operation.

You can send the completed survey in the envelop that is provided for to:

Ron Methorst

Clemmergulden 6

8253 DG DRONTEN 




\section{Summary}

Family farms operate in a socio-material context that both enables and constrains farm development. In this context farmers develop their farm strategy in order to secure their goals, typically earning a farm income and the continuation of the farm business. The context offers a room for manoeuvre for farm development, in which farmers are knowledgeable and interpretive actors, whose actions are guided by, but not determined by, the context in which they operate. Three developments that highly affect the process of strategic decision-making in farm development are: 1) narrowing product margins (the income squeeze) in farm business; 2 ) shifting societal demands and expectations for farms and the rural areas; and 3) new opportunities enabling a diversification of farm strategies. The perception of opportunities, the perceived room for manoeuvre, for farm development, is based on the farmer's interpretation of the socio-material context. To understand heterogeneity in family farm development, a view on entrepreneurship is required that includes the farmers' perception as a subjective element of opportunity identification. Another field of interest in the relation between the farm and its socio-material context is the embedding of farms in their context. A sociological approach was used to study entrepreneurship in order to understand differences in farmers' perception of opportunities and differences in the embedding of family farms in the socio-material context. A better understanding of these differences is important, as the relation between farms and their context affects the farmers' ability to adapt to changes. Being able to adapt to changes is a necessary condition to maintain economically vital farms and vital rural areas. In this study, the research fields of Opportunity Identification, Strategic Decision-Making and Embedding are combined to support a better understanding of the Sociology of Entrepreneurship in family farms.

The empirical basis for this study is a case study of family dairy farmers operating in a highly comparable socio-material context of the farms in the case study area. All farms are tenant farms from the same landlord and share the same socio-cultural background. The farmers operate in the same market conditions and are affected by a context that brings challenges for farm development: two nearby Natura 2000 nature protection areas and a designated National Landscape. The highly comparable context enables to study the heterogeneity in farm development, with a specific focus on differences between individual farmers. 79 out of 102 dairy farmers participated in the survey. The study was organised around three research questions: 
1. What are the differences in farmers' perception of opportunities for farm development, whilst operating in a highly comparable context?

2. What are the most important drivers for differences in farmers' perception of opportunities for farm development?

3. What are the differences in the embedding of the farm practices that are linked to differences in farmers' perception of opportunities for farm development?

The research was conducted in three phases: an explorative phase in which the analytical framework and the survey were developed; a quantitative phase with a statistical analysis of the data; and a qualitative phase, with interviews to discuss and enrich the statistical results. The analytical framework was based on the research fields of 1) Opportunity Identification; 2) Strategic Decision-Making; and 3) Embedding. Opportunity Identification is an on-going process of interpreting the developments in the socio-material context for opportunities that contribute to the aims of the family farm, and that leads to the farmer's perceived room for manoeuvre for farm development. This process is affected by a range of influences, which were combined in seven different drivers. In the process of strategic decision-making, the farmer assesses the opportunities that are part of the perceived room for manoeuvre to decide whether or not the farm strategy needs adjustments. Strategic decisions lead to farm practices that are embedded in the socio-material context of the farm. This embedding of the farm practices involves three dimensions that are operationalised in the context of family dairy farming as the sets of relations in: 1) socio-cultural context; 2) value chain context; and 3) natural resources context. This three-fold embedding of the family farm affects the spheres of influence in which the farmer operates; this influence in turn affects the opportunity identification. The process of opportunity identification, strategic decision-making and embedding is not to be linked to a specific time frame and is repeated over time.

Opportunity Identification is operationalised in this study as the 'perceived Room for Manoeuvre': 'the opportunities perceived as viable by the farmer in order to obtain a (substantial part of) farm income. To establish a measure for the pRfM of individual farmers, a list of 15 opportunities of farm development was made that represent the routes for farm development in Dutch dairy farming in general, and in the case study area in particular. The farmers were asked to indicate their perception on the viability of the opportunity in their situation for each opportunity on a five-point Likert scale. 
To study three-fold Embedding, the ideal-typical characteristics of the different patterns of farm development were determined based on interviews with farmers and stakeholders. Based on these interviews, an informed judgment was made in positioning the sets or relations on a scale between a more 'Close' and a more 'Stretched' nature of the relations.

The quantitative analysis revealed that farmers differ in the perceived Room for Manoeuvre in three dimensions: 1) opportunities to diversify farm production; 2) opportunities to end farm production; and 3) opportunities to maximise farm production. The cluster analysis assigned the 79 farmers to four clusters that represent different patterns of farm development, the patterns proved to be consistent and coherent and were recognised by relevant stakeholders as meaningful to differentiate farmers. The following four farm development patterns were found in the total of 79 family dairy farmers:

\section{1: $\quad$ Milk Max: Maximising production ( $\mathrm{n}=29)$}

Focus on maximising production per ha using imports of feed next to own feed production. Joint farming is seen as 'maybe possible'. Energy production may add to farm income.

\section{2: $\quad$ Milk Balance: Optimising resources $(n=21)$}

Focus on milk production using on-farm produced feed with limited inputs of (concentrated) feed. The use of the farm as production unit is optimised. Off-farm job and energy production are seen as possible opportunities.

3: $\quad$ Milk Plus: Diversifying production $(n=21)$

Focus on milk production possiblycombined with on-farm diversification. The use of the place where the farm is located is optimised. Dairy farming is based primarily on own produced feed, comparable to Milk Balance.

\section{4: $\quad$ End Milk: Ending production $(n=8)$}

Focus on ending dairy farming in the near future, income from other activities (possibly retirement). Currently optimising on-farm resources: possibly an off-farm job or income from another company. 
The next step was to study the drivers for the differences that were found. The influencing factors on the perceived Room for Manoeuvre were combined in a range of seven drivers. Using a regression analysis the explanatory value of each driver was determined for the three dimensions in which the farmers differ. The following table presents the explanatory value of each driver for the three dimensions resulting from a regression analysis, the values presented in bold and italic are significant at $p<0.05$, the values in bold are significant at $p<0.10$

\begin{tabular}{lccc}
\hline Drivers & Diversifying & Ending & Maximising \\
\hline 1) personal views and preferences & $\mathbf{2 . 6 2}$ & $\underline{\mathbf{4 . 9 1}}$ & $\underline{\mathbf{3 . 7 1}}$ \\
2) personal development & $\mathbf{2 . 0 8}$ & $\underline{\mathbf{2 . 2 3}}$ & 1.58 \\
3) view on entrepreneurial competences & 1.22 & 0.84 & $\underline{\mathbf{2 . 7 0}}$ \\
4) view on continuation / family & 1.97 & $\underline{4.41}$ & 0.55 \\
5) view on current business situation & 0.98 & $\underline{\mathbf{2 . 4 7}}$ & $\mathbf{1 . 8 9}$ \\
6) view on market developments & 0.45 & 0.22 & $\mathbf{2 . 4 8}$ \\
7) view on urban-rural relations & 1.25 & 0.48 & 0.04 \\
\hline
\end{tabular}

Different sets of drivers proved to be significant for the three dimensions. The most influential driver for all three dimensions, and the only driver that showed to be significantforall three dimensions was'personal viewand preferences'. The set of significant drivers was different for the three dimensions. For the dimension 'diversifying', the only other significant driver was 'personal development', which points to the importance of the personal characteristics of the farmer. For the dimension 'maximising', the other significant drivers were: "view on own competences'; 'view on current farm situation'; and 'view on markets'. For the dimension 'ending', the other significant drivers were: 'view on continuation/family'; in combination with 'personal development'; and 'view on current farm situation'. These results have shown that within the combined influence of all the drivers on the pRfM, the personal views and preferences of the farmer are the most influential.

The ideal-typical characteristics of the patterns of farm development have shown differences in the embedding in the context of the value chain, the sociocultural context and the context of natural resources. Milk Max is for all three sets of relations most oriented towards a 'Stretched' nature of the relation, meaning for value chain a more distanced relation between the farm's product and the client, for sociocultural a network that is more distanced from the familiar, agricultural production oriented networks and for resources an active sourcing from all available sources on the market. Milk Balance is more 'Stretched' in the value chain relations but more 'Close' 
in socio-cultural and resources relations. For Milk Plus, the socio-cultural relations are more 'Stretched', whilst value chain and resources are more 'Close' in nature. The combination of three-fold embedding can be viewed as three sliders on a mixing panel; the farmer positions the sliders and the positioning relates to the strategic decisions on farm development. This positioning in the relations can be done in a both explicit and an implicit manner. Milk Max and Milk Plus are more explicit in their reasoning, whilst Milk Balance is only explicit for resources relations. Embedding of farm practices is an on-going process that results in an specific embedding of the farm at a specific moment in the development of the farm.

The combined answer to the research questions was that family farmers' perception of opportunities for farm development is related to the personal views and preferences of the farmer. The views and preferences of the farmer are in turn, related to the spheres of influence of the socio-material context, in which the farmer is embedded. This means that the three-fold embedding of the farm and the perception of opportunities are related. When a farmer changes the positioning of the farm in the sets of relations, it leads to a change in the contacts with actors and developments in the socio-material context. A changing contact may affect the farmers' perception of the context which in turn affects the perceived room for manoeuvre. When taking a step back from these results, it can be stated that strategic decision-making is in fact the process of embedding the farm practices in the socio-material context.

In the contribution to better understand the relation between family farm development and the socio-material context, this thesis supports the view that the family farm can be seen as the materialisation of its implicit and explicit positioning within the socio-material context. The characteristics of the family farm and of the socio-material context are the result of a co-construction in the interaction in the different sets of relations. In these sets of relations, the farmer aims to manage the relations in order to balance the aims and needs of the family farm. The personal views and preferences of the farmer are highly influential for the perception of opportunities for farm development. These findings show the relevance of developing a relational approach on farm development in the research field of Sociology of Entrepreneurship.

The practical relevance of this thesis is that it supports the understanding of the heterogeneity in farms and farm development as the result of a process in which differences in embedding in the context and differences in perception of opportunities are important. A better understanding of the influence of the drivers for farm development that affect the perception of the viability of farm strategies makes it more feasible to connect with the perspective of the individual farmer. For farmers 
and farmer's organisations it is important to acknowledge and address the influence of the personal views and preferences in the perception of opportunities for farm development. This is as well important for education programmes as it emphasises the subjective part of strategic decision-making in farm development and the need to invest in programmes that support the development of personal views and preferences that are well thought through. The awareness of the influence of personal views and preferences and the influence of the embedding in the socio-material context is important to optimise the development and use of the room for manoeuvre for vital farms as part of vital rural areas. 




\section{Samenvatting}

Agrarische familiebedrijven opereren in een socio-materiële context die de ontwikkeling van het bedrijf zowel beperktals in staat stelt. In deze context ontwikkelen de familiebedrijven hun strategie om het doel te behalen: het behalen van een bedrijfsinkomen en de continuering van het agrarisch bedrijf. De context biedt een speelruimte voor de ontwikkeling van het agrarisch bedrijf. De agrarisch ondernemer, dit kan één of meer personen op een bedrijf betreffen, opereert binnen deze context als een geïnformeerde en interpretatieve actor wiens acties worden geleid, maar niet vastgelegd, door de context waarbinnen het bedrijf opereert. Drie ontwikkelingen die de strategische besluitvorming voor de ontwikkeling van het agrarisch bedrijf sterk beïnvloeden zijn: 1) druk op het inkomen door het kleiner worden van de marges op het product; 2) veranderingen in de maatschappelijke eisen en verwachtingen met betrekking tot agrarische bedrijven en het platteland; en 3) nieuwe mogelijkheden om de bedrijfsstrategie te diversificeren. De perceptie van de mogelijkheden voor de ontwikkeling van het bedrijf is gebaseerd op de interpretatie van de socio-materiële context door de agrarisch ondernemer. Om de heterogeniteit in de ontwikkeling van agrarische familiebedrijven te begrijpen is een visie op ondernemerschap nodig die rekening houdt met de perceptie van de ondernemer als subjectief element in het identificeren van mogelijkheden. Een ander belangrijk aspect om de relatie van de agrarische ondernemer met de socio-materiële context te begrijpen, is de inbedding van het bedrijf in die context. Een sociologische benadering van ondernemerschap is gebruikt om de verschillen tussen agrarische familie bedrijven te begrijpen in zowel de perceptie op de mogelijkheden als in de inbedding in de socio-materiële context. Een beter begrip van de achtergronden van deze verschillen is belangrijk omdat de relatie van agrarische bedrijven met de context van invloed is op het vermogen van de ondernemers om zich aan te passen aan veranderingen. Het aan kunnen passen aan veranderingen is een noodzakelijke voorwaarde voor het behoud van economisch gezonde agrarische bedrijven en een vitaal platteland. Deze studie combineert de onderzoeksvelden 'identificeren van mogelijkheden', 'strategische besluitvorming' en 'inbedding' om te komen tot een beter begrip van de sociologie van ondernemerschap op agrarische familiebedrijven.

De empirische basis voor deze studie is een case studie van agrarische familiebedrijven op Kampereiland, een gebied waar de socio-materiële context voor de bedrijven sterk vergelijkbaar is. De bedrijven zijn pachter van dezelfde verpachter en delen dezelfde sociaal-culturele achtergrond. De bedrijven opereren in 
dezelfde marktcondities en de ontwikkeling van de bedrijven wordt beïnvloed door twee nabijgelegen Natura 2000 natuurbeschermingsgebieden en een gebied dat aangewezen is als Nationaal Landschap I]sseldelta. De sterk vergelijkbare context maakt het mogelijk om de heterogeniteit in bedrijfsontwikkeling te bestuderen met een specifieke focus op verschillen tussen de individuele ondernemers. Van de 102 melkveebedrijven hebben 79 bedrijven deelgenomen aan het onderzoek. De studie is opgezet rond drie onderzoeksvragen:

1. Wat zijn de verschillen in de perceptie van agrarisch ondernemers op de mogelijkheden voor bedrijfsontwikkeling terwijl ze opereren in een sterk vergelijkbare context?

2. Wat zijn de belangrijkste aspecten die de verschillen bepalen in de perceptie van agrarisch ondernemers op de mogelijkheden voor bedrijfsontwikkeling?

3. Wat zijn de verschillen in de inbedding van het agrarisch bedrijf die gerelateeerd zijn aan verschillen in de perceptie van agrarisch ondernemers op de mogelijkheden voor bedrijfsontwikkeling?

Het onderzoek is uitgevoerd in drie fasen: een verkennende fase waarin het analytisch raamwerk en de enquête zijn ontwikkeld; een kwantitatieve fase met een statistische analyse van de data; en een kwalitatieve fase met interviews om de statistische resultaten te plaatsen in de praktijk context. Het analytisch raamwerk is gebaseerd op drie onderzoeksvelden:1) identificerenvan mogelijkheden;2) strategische besluitvorming; en 3) inbedding. Het identificeren van mogelijkheden is een voortdurend proces om ontwikkelingen in de socio-materiële context te interpreteren naar mogelijkheden die bijdragen aan het doel van het agrarisch familiebedrijf. Een interpretatie die leidt tot een door de ondernemer beleefde ontwikkelruimte, de speel ruimte voor bedrijfsontwikkeling. Dit proces wordt beïnvloedt door een reeks van invloeden die zijn gecombineerd in zeven verschillende aspecten. In het proces van strategische besluitvorming, beoordeelt de agrarisch ondernemer de mogelijkheden binnen de speelruimte voor bedrijfsontwikkeling teneinde een besluit te nemen over de te voeren bedrijfsstrategie. Strategische besluiten leiden tot een bedrijfspraktijk die is ingebed in de socio-materiële context van het agrarisch familiebedrijf. Deze inbedding van de bedrijfspraktijken omvat drie dimensies, deze worden in de context van het melkveebedrijf geoperationaliseerd als de sets van relaties in: 1) de sociaalculturele context; 2) de waardeketen context; en 3) de context van de hulpbronnen voor 
de bedrijfsvoering. Deze drievoudige inbedding van het melkveebedrijf heeft effect op de invloedsferen waarbinnen het bedrijf opereert; dit heeft vervolgens een effect op het identificeren van mogelijkheden. Het proces van het identificeren van mogelijkheden, de strategische besluitvorming en de inbedding van het bedrijf is niet gekoppeld aan een specifiek moment in de tijd, het is een zich continu herhalend proces.

Het identificeren van mogelijkheden wordt in deze studie geoperationaliseerd als de Perceptie van de Speelruimte voor bedrijfsontwikkeling: 'de set van mogelijkheden die door de ondernemer(s) op het agrarisch familiebedrijf gezien wordt als reële mogelijkheden om een (relevant deel van) bedrijfsinkomen te kunnen behalen'. Om de perceptie van de speelruimte te kunnen meten voor een individueel bedrijf, is een lijst opgesteld van 15 mogelijkheden voor de ontwikkeling van het agrarisch bedrijf. Deze lijst bevat de mogelijkheden voor bedrijfsontwikkeling voor de Nederlandse melkveehouder in het algemeen en specifiek voor het case studie gebied. De agrarisch ondernemers zijn gevraagd om per mogelijkheid aan te geven in welke mate zij die mogelijkheid als haalbare optie zien om voor hun eigen situatie op het eigen bedrijf een (relevant deel van) bedrijfsinkomen mee te behalen. Hiervoor is een schaal met vijf punten gebruikt variërend van 'helemaal niet' tot 'helemaal wel'.

Om de drievoudige inbedding van de bedrijven te bestuderen, zijn de ideaaltypische karakteristieken bepaald voor de gevonden patronen van bedrijfsontwikkeling op basis van interviews met agrarisch ondernemers en andere betrokkenen bij de melkveehouderij op Kampereiland. Met deze interviews als basis is een gefundeerd oordeel gegeven over de positionering in de drie sets van relaties met de context voor de gevonden patronen van bedrijfsontwikkeling. Hierbij is een schaal gebruikt die varieert van een set van relaties die meer 'Nabij' danwel meer 'Uitgestrekt' van aard is.

Uit de kwantitatieve analyse van de data blijkt dat de agrarisch ondernemers verschillen in de perceptie van de speelruimte in drie dimensies: 1) de perceptie van mogelijkheden om het bedrijf te diversificeren; 2) de perceptie van de mogelijkheid om het bedrijf te beëindigen; en 3) de perceptie van mogelijkheden om de productie op het bedrijf te maximaliseren. De daaropvolgende clusteranalyse gaf aan dat er binnen de groep van 79 bedrijven vier clusters gevonden worden die ieder een verschillend patroon van bedrijfsontwikkeling weergeven. Deze patronen werden herkend door relevante betrokkenen als betekenisvol om de verschillen binnen de groep melkveebedrijven te duiden. Daarbij bleken de patronen coherent in de karakteristieken en bleken de verschillen consistent over een langere periode. De volgende vier patronen van bedrijfsontwikkeling zijn gevonden binnen het totaal van 79 melkveebedrijven: 
1: $\quad$ Melk Max: Maximaliseren van de productie $(\mathrm{n}=29)$

Focus op het maximaliseren van de productie per ha, gebruikmakend van aangekochte voeders naast de eigen voerproductie. Een gezamenlijke bedrijfsvoering met andere veehouders wordt als misschien mogelijk gezien. Energie productie kan wellicht bijdragen aan het inkomen.

\section{2: $\quad$ Melk Balans: Optimaliseren van de hulpbronnen $(n=21)$}

Focus op het producerenvan melkmetop heteigen bedrijfgeproduceerde voeders met beperkte aanvoer van aangekocht voeders. Het bedrijf met de daarbij beschikbare hulpbronnen wordt geoptimaliseerd. Inkomen uit een baan buiten het bedrijf en energie productie wordt als misschien mogelijk gezien.

\section{3: $\quad$ Melk Plus: Diversificeren van de productie $(n=21)$}

Focus op melk productie die mogelijk gecombineerd wordt met verbreding van activiteiten op het eigen bedrijf. Het benutten van de locatie van het bedrijf wordt geoptimaliseerd. De melkveehouderij is voornamelijk gebaseerd op voer van eigen productie, vergelijkbaar met Melk Balans.

\section{4: $\quad$ Eind Melk: beëindigen van de melkproductie $(n=8)$}

Focus op het beëindigen van het melkveebedrijf in de nabije toekomst, inkomen uit andere activiteiten (inclusief pensionering). Huidige bedrijfsvoering middels optimaliseren van hulpbronnen op het bedrijf, mogelijk een baan buiten het bedrijf of inkomen uit een ander bedrijf.

In de volgende stap zijn de oorzaken onderzocht die mogelijk van invloed zijn op het ontstaan van de gevonden verschillen. De mogelijk beïnvloedende factoren zijn gecombineerd tot zeven aspecten. Voor de aspecten is middels een regressieanalyse bepaald in welke mate elk aspect verklarend is voor de verschillen tussen de agrarisch ondernemers in hun score voor de drie dimensies van de perceptie van de speelruimte. De volgende tabel geeft de verklarende waarde voor elk van de zeven aspecten voor de drie dimensies. Waarden die zijn weergegeven als onderstreept en italic zijn significant bij $p<0.05$, de waarden weergeven als vet zijn significant bij $p<0.10$. 


\begin{tabular}{lccc}
\hline Aspecten voor beleefde ontwikkelruimte & Diversificeren & Beëindigen & Maximaliseren \\
\hline 1) persoonlijke kijk en voorkeuren & $\mathbf{2 . 6 2}$ & $\underline{\mathbf{4 . 9 1}}$ & $\underline{\mathbf{3 . 7 1}}$ \\
2) persoonlijke ontwikkeling (ervaring, network, scholing) & $\mathbf{2 . 0 8}$ & $\underline{\mathbf{2 . 2 3}}$ & $\mathbf{1 . 5 8}$ \\
3) score op ondernemerschapscompetenties & 1.22 & $\mathbf{0 . 8 4}$ & $\underline{\mathbf{2 . 7 0}}$ \\
4) persoonlijke kijk op bedrijfsovername / familie & 1.97 & $\underline{\mathbf{4 . 4 1}}$ & $\mathbf{0 . 5 5}$ \\
5) persoonlijke kijk op huidige situatie van het bedrijf & 0.98 & $\underline{\mathbf{2 . 4 7}}$ & $\mathbf{1 . 8 9}$ \\
6) persoonlijke kijk op marktontwikkelingen & 0.45 & 0.22 & $\mathbf{2 . 4 8}$ \\
7) persoonlijke kijk op stad-platteland relaties & 1.25 & 0.48 & 0.04 \\
\hline
\end{tabular}

Verschillende sets van aspecten bleken significant voor de drie dimensies. Het aspect met de hoogste verklarende waarde voor elk van de drie dimensies van de perceptie van de speelruimte is 'persoonlijke kijken voorkeuren'. Dit is ook het enige aspect dat significant is voor alle drie de dimensies. Voor elk van de drie dimensies blijkt een andere set van aspecten significant als verklarende waarde voor die dimensie. Voor de dimensie Diversificeren bleek naast 'persoonlijke kijk en voorkeuren' enkel het aspect 'persoonlijke ontwikkeling' significant, dit onderstreept het belang van de persoonlijke karakteristieken van de agrarisch ondernemer voor deze dimensie. Voor de dimensie Maximaliseren bleken naast 'persoonlijke kijk en voorkeuren' de volgende aspecten significant: 'score op ondernemerschapscompetenties', 'persoonlijke kijk op huidige situatie van het bedrijf' en 'persoonlijke kijk op marktontwikkelingen'. Voor de dimensie Beëindigen zijn de andere significante aspecten: 'persoonlijke kijk op bedrijfsovername / familie' in combinatie met 'persoonlijke ontwikkeling' en 'persoonlijke kijk op huidige situatie van het bedrijf. Deze resultaten tonen aan dat binnen de gecombineerde invloed van alle aspecten op de perceptie van de Speelruimte, de persoonlijke kijk en voorkeuren van de agrarisch ondernemer het meest van invloed zijn.

De ideaaltypische karakteristieken van de patronen van bedrijfsontwikkeling laten verschillen zien in de inbedding in de waardeketen context, de socio-culturele context en de context van de hulpbronnen voor de bedrijfsvoering. Melk Max is voor alle drie de contexten het meest georiënteerd op relaties die meer Uitgestrekt' van aard zijn. Dit betekent voor de waardeketen een grotere afstand tussen het bedrijf als producent en de uiteindelijke consument. Voor de socio-culturele context betekent dit een netwerk dat een grotere afstand heeft van het meer traditionele agrarische netwerk. Voor de context van de hulpbronnen betekent dit het actief benutten van alle hulpbronnen die op de markt beschikbaar zijn. Melk Balans is meer 'Uitgestrekt' in de aard van de relaties binnen de waardeketen context, maar meer 'Nabij' in de aard van de relaties in zowel de socio-culturele als de hulpbronnen context. Voor Melk Plus zijn 
de relaties in de socio-culturele context meer 'Uitgestrekt' van aard terwijl de relaties in zowel de context van de waardeketen als van de hulpbronnen meer 'Nabij' van aard zijn. De combinatie van de drievoudige inbedding kan gevisualiseerd worden als drie schuiven op een mengpaneel; de agrarisch ondernemer positioneert de schuiven en die positionering is gerelateerd aan het maken van strategische besluiten over de ontwikkeling van het bedrijf. Deze positionering kan zowel op een expliciete als op een impliciete manier gedaan worden. Melk Max en Melk Plus zijn meer expliciet in de redenatie over de positionering, terwijl Melk Balans alleen expliciet is waar het gaat om de context van de hulpbronnen. Inbedding van de agrarisch bedrijf is een voortdurend, zich herhalend proces dat resulteert in een wijze van inbedding van het bedrijf op een specifiek moment in de ontwikkeling van het bedrijf.

Het samengebrachte antwoord op de onderzoeksvragen is dat de perceptie van een agrarisch ondernemer op de mogelijkheden voor bedrijfsontwikkeling gerelateerd is aan de persoonlijke kijk en voorkeuren van die agrarisch ondernemer. De persoonlijke kijk en voorkeuren zijn vervolgens gerelateerd aan de invloedsferen van de sociomateriële context waarin de agrarisch ondernemer is ingebed. Dit betekent dat de drievoudige inbedding van het agrarisch bedrijf en de perceptie van de speelruimte voor bedrijfsontwikkeling gerelateerd zijn. Als een agrarisch ondernemer de positionering verandert van het agrarisch bedrijf in de sets van relaties met de context, leidt dit tot een veranderend contact met actoren en ontwikkelingen in de socio-materiële context. Een veranderend contact kan de perceptie van de agrarisch ondernemer op de context beïnvloeden wat vervolgens een effect heeft op de perceptie van de speelruimte. Dit geheel betekent dat het nemen van strategische beslissingen in feite een proces is van het inbedden van het agrarisch bedrijf in de socio-materiële context.

In de bijdrage aan het beter begrijpen van relatie van het agrarisch familiebedrijf met de socio-materiële context, onderschrijft dit proefschrift de zienswijze dat het agrarisch familiebedrijf gezien kan worden als de materialisatie van de impliciete en expliciet positionering van het bedrijf in de socio-materiële context. De karakteristieken van het agrarisch familiebedrijf en die van de socio-materiële context zijn het resultaat van een co-constructie in de interactie binnen de verschillende sets van relaties. In deze sets van relaties heeft de agrarisch ondernemer als doel om de relatie zodanig vorm te geven dat er een balans is met de doelen en behoeften van het familiebedrijf. De persoonlijke kijk en voorkeuren van de agrarisch ondernemer zijn sterk van invloed op de perceptievan de mogelijkheden voor bedrijfsontwikkeling. Deze bevindingen tonen de relevantie aan van het ontwikkelen van een relationele benadering van agrarische bedrijfsontwikkeling binnen het onderzoeksveld van sociologie van ondernemerschap. 
De praktische relevantie van dit proefschrift is de onderbouwing dat de heterogeniteit in agrarische bedrijven en bedrijfsontwikkeling begrepen kan worden als het resultaat van een proces waarin verschillen in de inbedding in de context en verschillen in de perceptie van mogelijkheden belangrijk zijn. Een beter begrip van de aspecten die de perceptie van mogelijkheden voor bedrijfsontwikkeling beïnvloeden maakt dat het beter mogelijk is om een verbinding te maken met het perspectief van de individuele agrarisch ondernemer. Voor agrarisch ondernemers en de organisaties van agrariërs is het van belang om te erkennen dat de persoonlijke kijk en voorkeuren van invloed zijn op de perceptie van mogelijkheden van bedrijfsontwikkeling. Dit is ook van belang voor onderwijsprogrammas omdat het de subjectieve kant van strategische besluitvorming benadrukt en daarmee de noodzaak om te investeren in programma's die de ontwikkeling van een weldoordachte persoonlijke kijk en voorkeuren ondersteunt. Het begrip van de invloed van de persoonlijke kijk en voorkeuren en van de wijze van inbedding in de socio-materiële context op het proces van strategische besluitvorming is belangrijk in het optimaliseren van de ontwikkeling van agrarische bedrijven die de speelruimte benutten om te komen tot vitale bedrijven als onderdeel van een vitaal landelijk gebied. 



\section{Acknowledgements / Dankwoord}

Een promotieonderzoek lukt niet zonder de concrete steun van veel mensen. In een periode van vijf jaar zijn er veel mensen op diverse manieren betrokken geweest bij de totstandkoming van dit proefschrift. Dat traject begon met een vraag van Jos Verstegen in het najaar van 2010. Die vraag van Jos opende een voor mij onverwachte richting. In de ruim 13 jaar daarvoor was al mijn werk gericht geweest op de praktijk, op adviseren in bedrijfs- en sectorontwikkeling en doceren. Het werken aan wetenschappelijke analyses was sinds mijn afstuderen in 1996 niet de kern van mijn werk. Sterker, lang heb ik gedacht en gezegd dat ik geen promotieonderzoek zou willen doen. Nu schrijf ik de laatste zinnen van een proefschrift, het kan verkeren..

Dank voor het stellen van die vraag Jos, er is geen dag geweest dat ik spijt had van deze keuze, ik heb er erg van genoten. Naast het denken als adviseur in een praktijk context kon ik nu ook het denken als onderzoeker ontwikkelen. Dat brengt mij direct bij Dirk Roep als de andere co-promotor. Jullie hebben beide de begeleiding van mijn traject het meest van dichtbij begeleid. Jos en Dirk, heel erg bedankt voor jullie erg prettige stijl van werken in het begeleiden van dit proces. In alles was duidelijk dat jullie wijze van begeleiden gericht was op het ondersteunen van mijn proces in het denken, uitvoeren en schrijven. Steeds weer een nieuwe stap zetten in het beter begrijpen van het onderwerp en de diverse aspecten ervan. Vanwege de fysieke afstand was een deel van de contacten via de telefoon, met name Dirk heb ik op menig vrijdagmiddag van zijn werk gehouden met de boodschap dat er 'geen paniek' was. Dirk, dank voor de altijd snelle en inhoudelijke reacties die duidelijk ookje persoonlijke betrokkenheid bij het onderwerp kenmerkt.

Aan Han Wiskerke als promotor mijn dank voor de belangrijke bijdragen op diverse momenten in de gedachtevorming, zowel in de opbouw van het onderzoek als in het schrijven. Het was een goede keuze om het onderzoek onderdeel te laten zijn van de RSO groep. De dagen dat ik op de derde verdieping van de Leeuwenborch werkte waren plezierig door de ontmoetingen en gesprekken. Een mooie mix van onderzoekers en PhD studenten die op diverse onderwerpen bezig zijn om de vraagstukken rondom stad en platteland en voedsel steeds meer te begrijpen. Dank aan allen bij de RSO groep voor die ontmoetingen en gesprekken en zeker ook voor de altijd vlotte reacties vanuit secretariaat en beheer

Thanks to the members of the examination committee Prof. Dr Ruud Huirne, Dr Ika Darnhofer, Dr Lee-Ann Sutherland and Prof. Dr Erik Mathijs. Thanks for your work in examining the thesis and for being opponents at the defence. As well thanks 
to all reviewers and moderators at conferences and scientific journals. Without the work of examination committees, reviewers and moderators, the on-going exchange of ideas would not be possible. A word of thanks is in place for the people behind the very effective digital support system of Wageningen UR Library. A word of thanks as well for Wageningen University and in this university for all places of learning. It is an enormous privilege to have the opportunity to study, a privilege for which I am deeply grateful. Working in science means to increase our understanding of the world we live in, an intriguing journey. For me, being a Christian, another intriguing journey is in discovering evermore aspects of my relation with Cod as my Father. A relation for which I am deeply grateful as well. There are many questions that I encounter in life that I cannot answer. I recognise myself in a quote of Tomas Halik, a Czech theologian, 'For me, to believe is to have the courage to enter the cloud of mystery' (Trouw, March 19, 2016). While striving to understand as much as possible, questions will remain that are wider and deeper than my mind can understand.

Bijzondere dank voor alle mensen in en rond Kampereiland die op enig moment betrokken zijn geweest bij de totstandkoming van dit proefschrift. Dankzij dit onderzoek heb ik dit mooie gebied goed leren kennen. Dit maakt dat ik mij meer thuis voel in de omgeving waar ik nu woon. Dank voor de vele gesprekken en het deelnemen aan de enquête. Het onderzoek is uitgevoerd in afstemming met een ontwikkeltraject opgezet door de verpachter om de kansen te verkennen voor bedrijfsontwikkeling in dit mooie gebied. De samenwerking van mijn onderzoek met dit ontwikkeltraject was wederzijds zinvol zodat er meerdere doelen mee behaald zijn. Dank ook aan de projectgroep van accountants, LEl en de Pachtersbond waarmee ik de twee rapporten over bedrijfseconomie van melkveehouderij op Kampereiland kon maken. Het gebied heeft een bijzonder verhaal en ik hoop dat de melkveehouders in dit gebied hun bedrijf kunnen blijven ontwikkelen met behoud van de bijzondere landschaps- en natuurwaarden

Dank aan Aeres Hogeschool, dit traject was niet mogelijk geweest zonder de gezamenlijke investering in tijd en middelen. Bijzonder dank aan de teamleider, Corné Kocks van team praktijkgericht onderzoek in het ondersteunen van het laatste deel van het proces. Het vrijhouden van tijd om het geheel af te ronden tot een dissertatie was niet mogelijk geweest zonder je actieve meedenken. Dank ook aan de collega's bij Aeres Hogeschool voor het stimulerend meedenken op veel momenten. Mijn hoop en verwachting is dat we samen verder bouwen aan een instelling die bijdraagt aan de uitdagingen voor de doorgaande ontwikkeling van de landbouw. Voor de mede promovendi: veel succes met jullie project! 
Het promotieonderzoek heb ik als erg plezierig ervaren. Het vraagt echter wel om afzondering en dat betekent veel 'nee' zeggen. 'Sorry, ik moet mij richten op het onderzoek.... Mijn dank voor familie en vrienden die hebben geaccepteerd dat ik daardoor veel niet aanwezig was. Of soms wel aanwezig maar dan in gedachten toch niet helemaal... Met het afronden van dit grote project breken er weer nieuwe tijden aan waarin ik weer 'ja' kan zeggen.

Dank aan Hans Schiere and Martin Jans als paranimfen bij de verdediging. Ik voel mij vereerd dat jullie dit moment met mij willen delen.

Lieve Brigitta, dank dat je bent wie je bent. Dank dat ik met jou het leven mag delen. Dank dat ik een behoorlijk groot deel van mijn tijd heb mogen besteden aan dit onderzoek. Veel dagen, avonden, weekenden en vakanties stonden in het teken van mijn werk aan het onderzoek en het schrijven. Er komen nu weer nieuwe tijden, ik hoop nog lang en veel met je te delen in ontmoetingen, activiteiten en reizen. Ik zie er naar uit en voel mij bevoorrecht om dit samen met jou te mogen doen.

Ron Methorst 



\section{About the author}

\section{Curriculum Vitae}

Ron Methorst was born on the 6th of October 1972 in Veenendaal, the Netherlands. After his VWO diploma at Ichthus College in Veenendaal in 1991, he studied Animal Science at Wageningen University. He selected the Free Orientation as specialisation, choosing a study program with a focus on the farm in relation to the context in which it operates. He completed the study (MSc) in 1996 with a thesis in Animal Nutrition, a thesis in Animal Production Systems and a practical training period at Volcani Institute, Bet Dagan, Israel.

After graduating Ron worked on farms to gain hands-on experience including 6 weeks at a large sow farm (Molenaars Fokbedrijf Markelo), one month at a farm for rearing laying hens (Zonne-Ei Farm in Terschuur) and one month at a farm with laying hens in Poland (Zlote Jajko near Płock). In March 1997 he started a job as advisor in environmental issues at a compound feed factory (E.]. Bos B.V. Mengvoeders) in Ederveen. In this newly created position he developed the advisory department for clients with questions related to manure legislation, environmental license and the trade in production rights. Operating in a time with many changes and developments he gained experience in farm development issues on dairy, pig, poultry and veal farms while working for farmers and therefore getting acquainted with the farmers' perspective. This job offered as well valuable insight in the developments in and views of important stakeholder in farm development: agribusinesses, local and national governments.

In May 2001 Ron changed jobs to start as a teacher at CAH in Dronten, the Netherlands, currently integrated in the Aeres University of Applied Sciences. Starting in September 2001 he combined his job as a teacher (40\%) with a job as consultant for Agro Eco (60\%), a consultancy firm in organic agriculture. For Agro Eco he developed a number of projects and study groups for organic egg farming, a fast growing segment of organic farming. He was initiator and secretary of the Organic Poultry Farmers Association (BPV). For Agro Eco and Grolink (a Swedish consultancy firm in organic agriculture) and the local partner ECON (Sarajevo) he organised in 2004-2005 a number of training sessions in advisory for organic farmers in Bosnia-Hercegovina. For $\mathrm{CAH}$ Ron was project leader of a project that developed a course called 'Learning to Innovate'.

From May 2006 to May 2007 Ron and his wife Brigitta lived in BosniaHercegovina and jointly managed a Dutch-Bosnian company in plant production in 
Srebrenik, Tuzla Canton. The company, called Plantarium doo, reproduced ornamental plants in tissue culture for export to Dutch growers, produced seeds for garden plants for Kieft Seeds, the Netherlands, and sold ornamental plants that were produced in the own nursery or were imported. The company was in its first years and experienced technical and management problems. For this reason Ron and Brigitta were asked to take on management. The technical problems in the tissue culture proved to be too big and costly, leading to the end of the company.

Starting in June 2007 Ron renewed his contact with CAH in Dronten as teacher. Besides organising courses in advisory, environmental issues of agriculture and a minor in strategic entrepreneurship he was project leader of a number of projects. In one of the projects he developed the concept Slow Advice. This concept aims to facilitate a good co-operation between companies and university in student projects. From September 2009 to September 2013 Ron was programme coordinator for the GKC (Green Knowledge Cooperative) on the topic Multifunctional Agriculture. A number of educational products was developed and the general level of awareness on the importance of multifunctional agriculture was raised in education institutes.

In 2011 Ron started the research project for his PhD as part of his work for Aeres University of Applied Sciences. In this research project Ron was able to integrate his interest in the relation of the farm with its physical and societal surroundings and his interest in the farmers' perspective on farm development.

Ron Methorst

E-mail: r.methorst@aeres.nl

Twitter: @ronmethorst

Blog: ronmethorst.blogspot.com

Phone: $\quad+31(0) 636226637$ 
Completed Training and Supervising Plan

Reinold Gerrit Methorst

Wageningen School of Social Sciences (WASS)

Completed Training and Supervision Plan

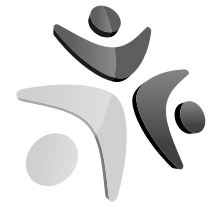

Wageningen School of Social Sciences

\begin{tabular}{|c|c|c|c|}
\hline Name of the learning activity & Department/Institute & Year & $\begin{array}{c}\text { ECTS } \\
(1=28 \mathrm{hrs})\end{array}$ \\
\hline
\end{tabular}

\section{A) Project related competences}

Masterclass Future Games

From Topic to Proposal

Proposal Writing

B) Ceneral research related competences

Introduction course
Information Literacy
Scientific Writing
Efficient Writing Strategies
System Thinking and Practice in PhD Research
Papers presented at conferences:
'Opportunity identification of farmers in a
challenging environment: the case of Kampereiland'
'Perceived room for manoeuvre of farmers in a
situation of limiting growth possibilities: The case of
Kampereiland'

'Autonomy of agricultural entrepreneurs:

between opportunities and room for manoeuvre'

'Farmers' perception on options for farm development in a situation of limiting nearby surroundings'

What drives opportunity identification for farm income strategies in a region rich in nature and landscape values'

'Differences in perception of income strategies by dairy farmers in areas with high natural and cultural heritage value'

'Embeddedness of the farm in relation to farm development strategies' Best $\mathrm{PhD}$ paper award

'Three-fold embeddedness of farm development'
Expertisenetwerk Regiowaarde - LEI - Future IQ Partners and Interactive 2011 Consult

WASS

WASS

2011

2012

4

WASS

2012

WUR

2011

1

WUR

WUR

2014

2015

1.8

IFSA-Humboldt University

2014

Agriculture in an Urbanizing Society, Wageningen

REC, Rural Entrepreneurship,

Dumfries, Scotland

ESRS, European Society of Rural Sociology, Florence, Italy

IFSA, International Farming Systems Association, Berlin, Germany

REC, Rural Entrepreneurship, Islay, Scotland

ESRS European Society of Rural Sociology, Aberdeen, Scotland

2015

REC, Rural Entrepreneurship, Lincoln, England

IFSA, International Farming Systems Association, Newport, England

\section{2}

2013

2013

2014

2015

2016

2016

1
C) Career related competences/personal development

Oxford Online English test

$\mathrm{C}_{1}$

Brain Training

Wageningen Graduate Schools

2016

0.3

various
Various 
1) Accredited Prior Learning is based on the following work experience:

- experience as farm advisor in farm development (1997-2001)

- experience as consultant in organic agriculture (2001-2006)

- experience as director of a Dutch-Bosnian company in Bosnia Herzegovina (2006-2007)

- experience as teacher at Dronten University of Applied Sciences (2001-2005, 2007-present)

- supervisor Bachelor and Professional Master theses

- programme co-ordinator CKC-Multifunctional Agriculture (2009-2013) 
The research described in this thesis was possible due to a joint investment by Aeres University of Applied Sciences and the author.

Financial support from Wageningen University for printing this thesis is gratefully acknowledged.

This thesis is printed on recycled paper.

\section{Colophon}

Cover photo: De Stadserven NV

Cover design: $\quad$ Ron Methorst and Ineke Jansen (CVO drukkers \& vormgevers B.V.)

Lay out design: Ferdinand van Nispen tot Pannerden, Citroenvlinder-DTP.nl, my-thesis.nl

Printed by: $\quad$ CVO drukkers \& vormgevers B.V., Ede, NL 




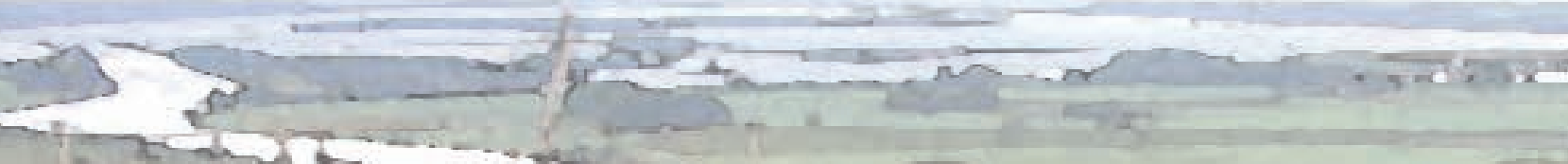

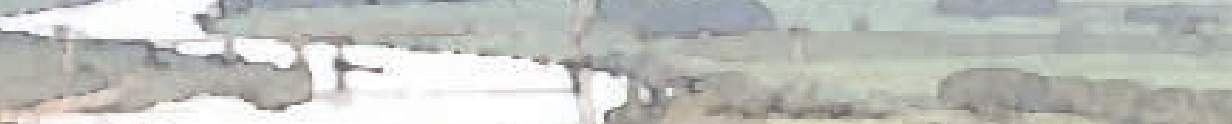
5

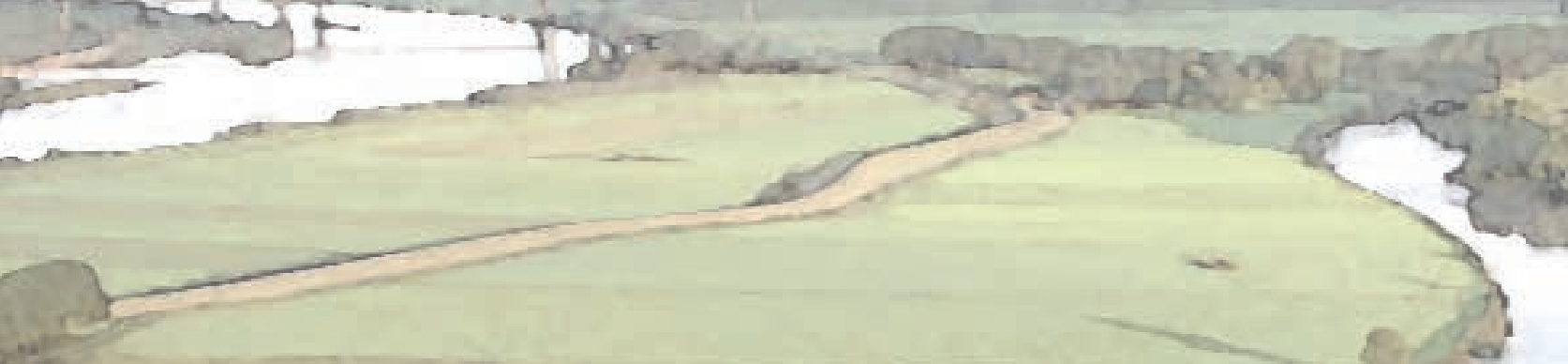
al

aibixyos

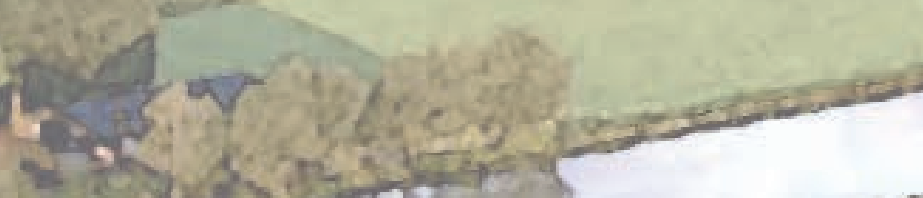

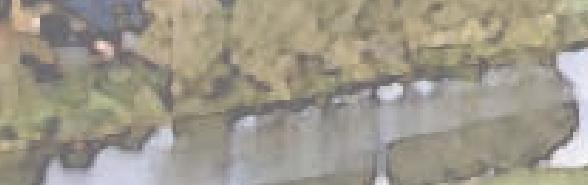

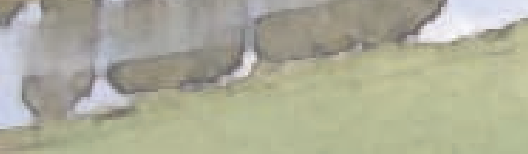
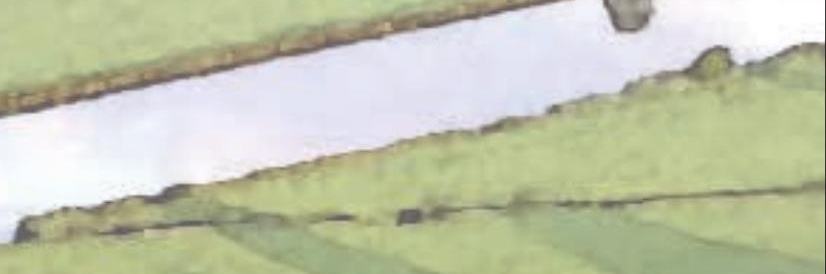